\title{
INSTRUMENTAL MUSIC TEACHER PERCEPTIONS REGARDING STUDENT SELF-REGULATION OF MUSIC LEARNING
}

A Dissertation Presented to
The Faculty of the Graduate School
at the University of Missouri-Columbia
In Partial Fulfillment
of the Requirements for the Degree
Doctor of Philosophy
Dr. Antonio. J. Castro, Dissertation Supervisor
Philip T. Horsley
by

July, 2019 
(C) Copyright 2019 by Philip T. Horsley

All Rights Reserved 
The undersigned, appointed by the dean of the Graduate School, have examined the dissertation entitled

\title{
INSTRUMENTAL MUSIC TEACHER PERCEPTIONS REGARDING STUDENT SELF-REGULATION OF MUSIC LEARNING
}

\author{
presented by Philip T. Horsley,
} a candidate for the degree of doctor of philosophy, and hereby certify that, in their opinion, it is worthy of acceptance.

Professor Antonio J. Castro

Professor Wendy L. Sims

Professor Carol Gilles

Professor Samuel Griffith 


\section{DEDICATION}

To every musician who endeavors to solve their own learning problems. 


\section{ACKNOWLDGEMENTS}

This dissertation would not have been possible without a lot of support from my family. When I first began the daunting task of pursuing my doctoral degree, it was those who mean the most to me who gave me the encouragement and confidence I needed to see the process through to completion three and a half years later. Thank you.

I would also like to thank Dr. Ariel Robinson for her editorial support and guidance. I'll never write another anthropomorphism in my life. To my dissertation committee: Dr. Griffith, thank you for sharing your insightfulness in music learning, the jazz idiom, and your knowledge of American popular music. To Dr. Gillis, thank you for sharing your experience and knowledge with me and especially for your wonderful comments. Every aspect of my research is better for it. To Dr. Sims, thank you for letting me express myself and for letting me pursue this research into self-regulation in instrumental music. Finally, I would most of all like to thank Dr. Castro. For the past three years we have gotten to know each other through classes and this research study. In no way, shape, or form, could this dissertation have turned out like it did without your extraordinary input, guidance, perseverance, and dedication. Thank you most of all. 


\section{TABLE OF CONTENTS}

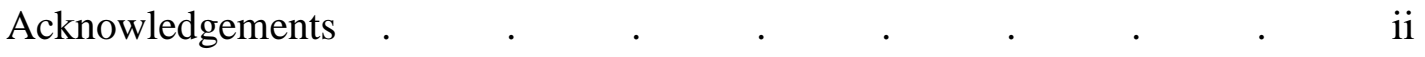

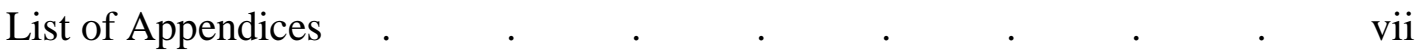

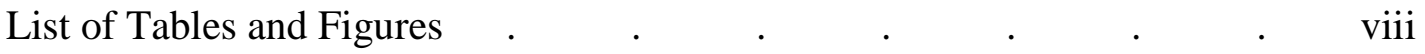

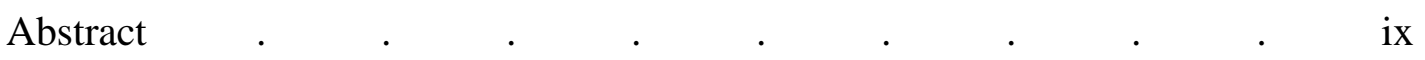

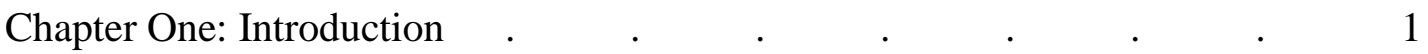

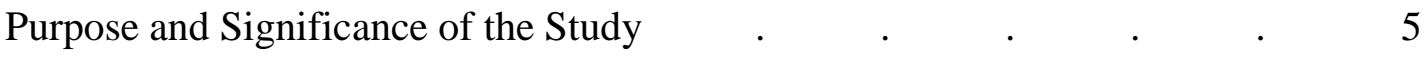

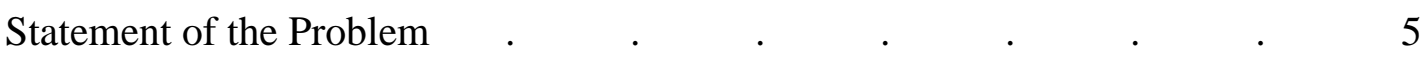

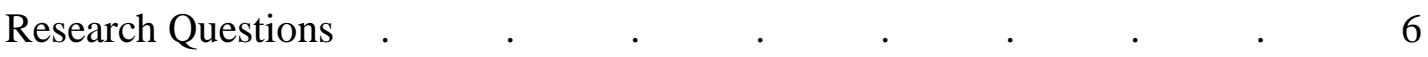

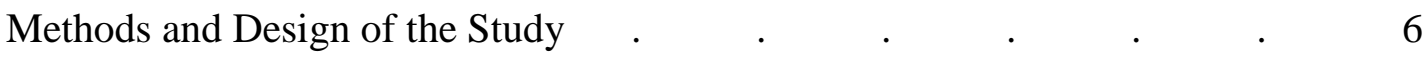

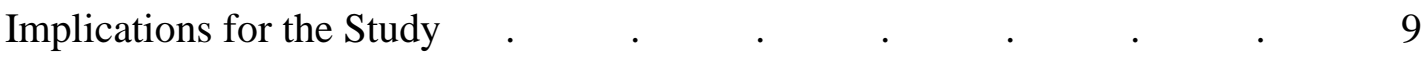

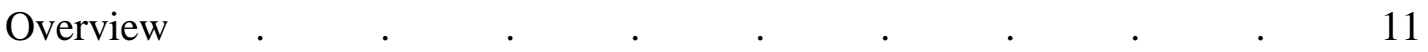

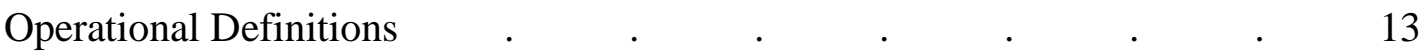

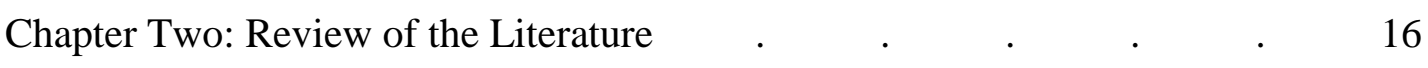

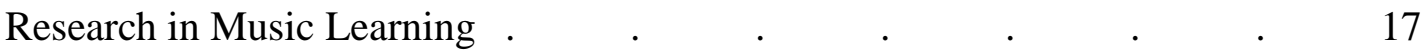

Factors That Facilitate Learning Instrumental Music. $\quad$. 19

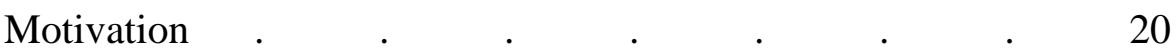

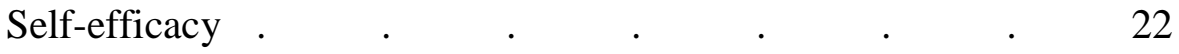

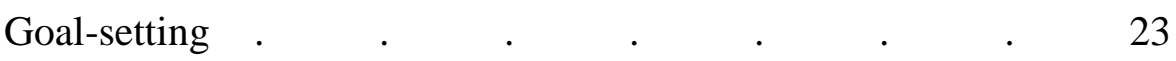

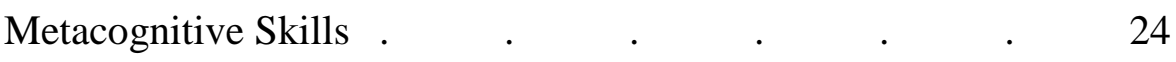

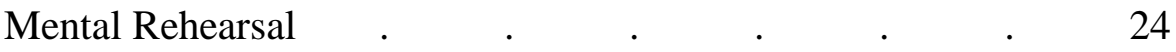

Self-regulated Learning Strategies . $\quad$ • $\quad$. $\quad 25$

Other Factors That Facilitate Music Learning _ . $\quad$. $\quad$. 27

Leveled Practice Strategies for Students _ . . . $\quad$. 27

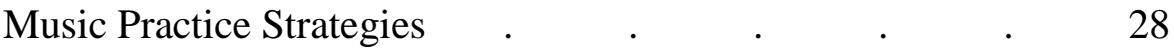

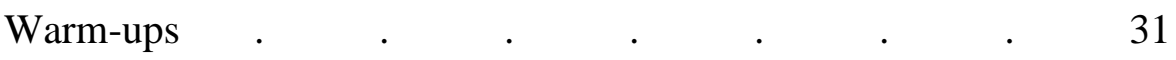

Inculcation During Practice $\quad . \quad$. $\quad$. $\quad$. $\quad$. 32

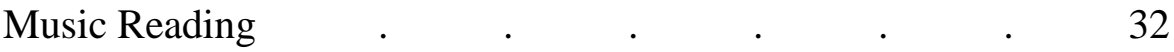




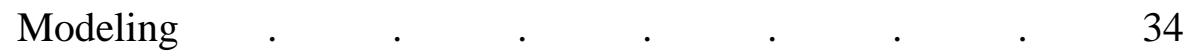

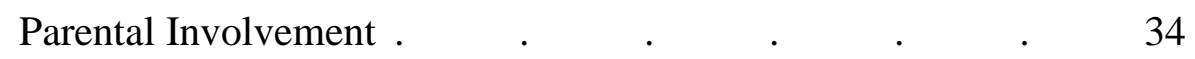

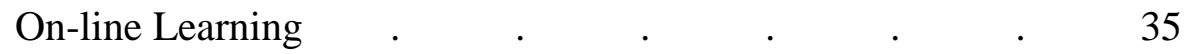

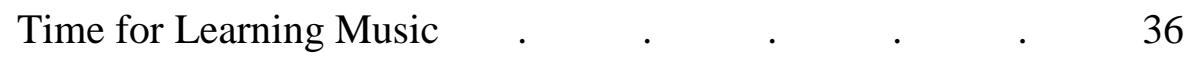

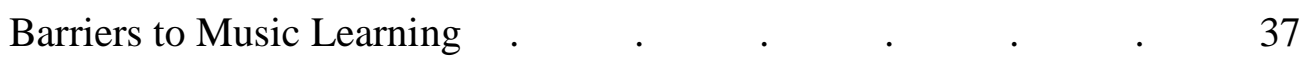

Learning Outside of the Classroom . $\quad . \quad$. $\quad . \quad$. 38

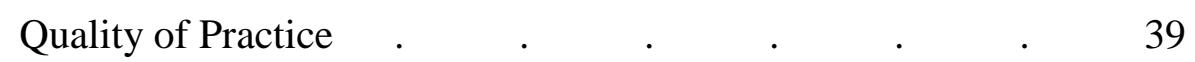

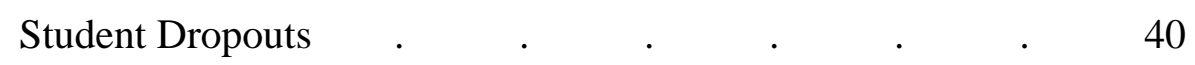

Implications of the Research for the Present Study . $\quad$. $\quad$. $\quad$. 41

Self-regulation of Musical Learning: A Framework for the Current Study . $\quad 43$

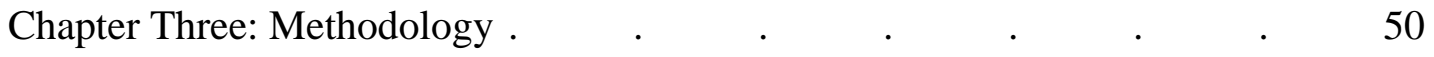

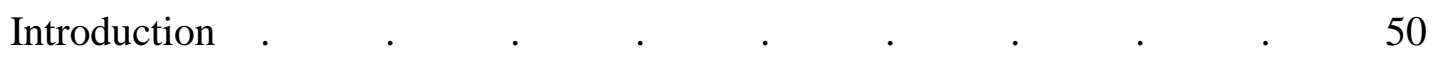

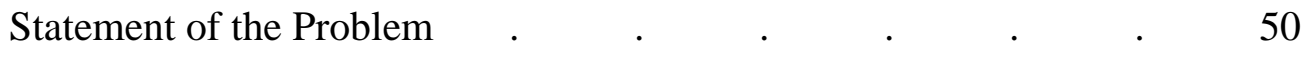

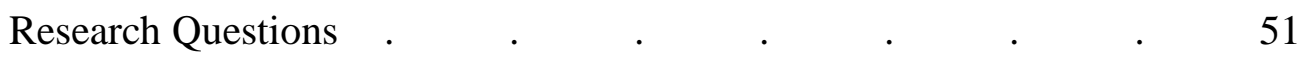

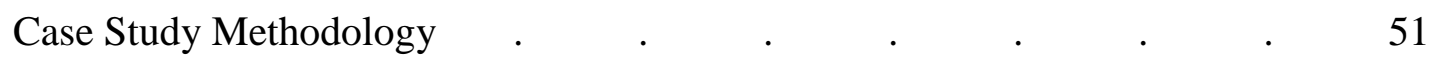

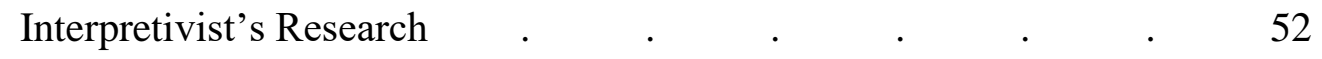

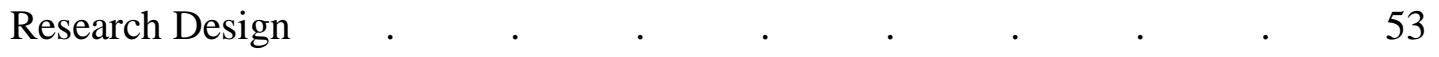

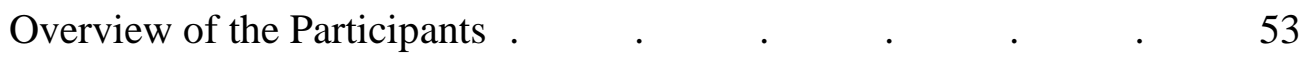

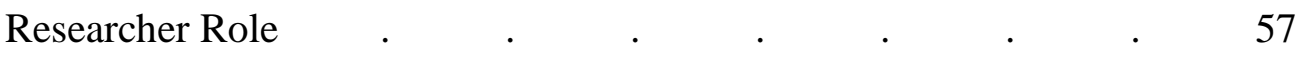

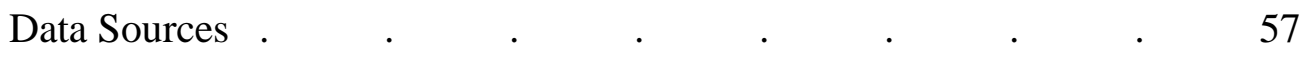

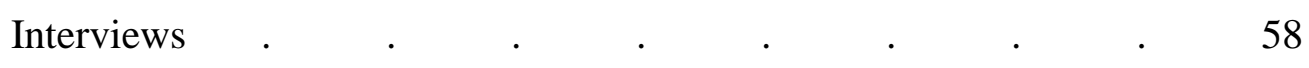

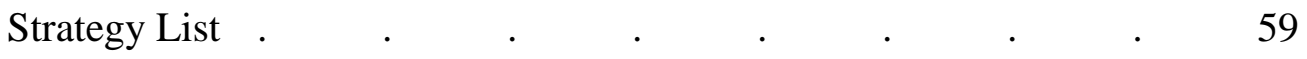

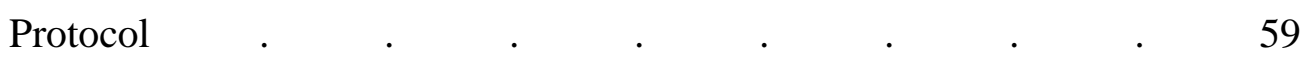

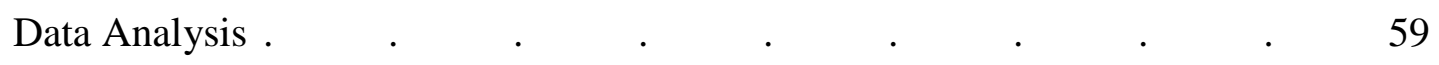

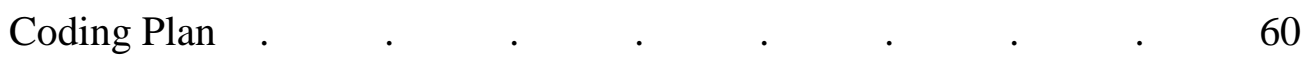

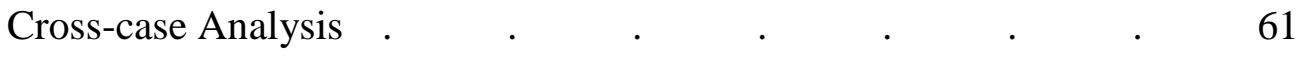

Ethics, Researcher Positionality, and Reflexivity $\quad 62$

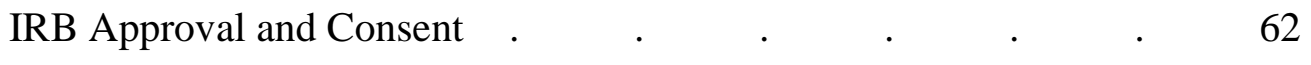




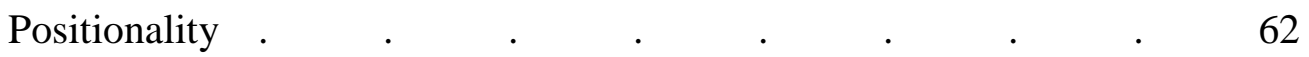

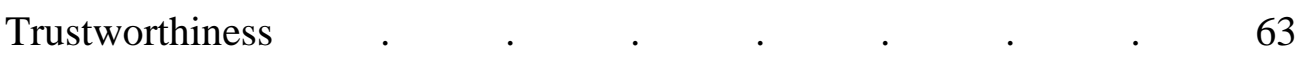

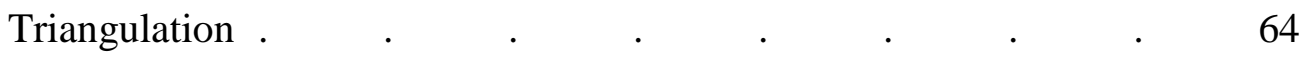

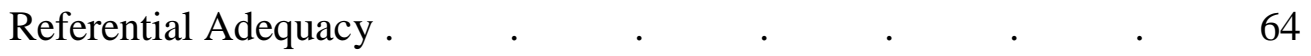

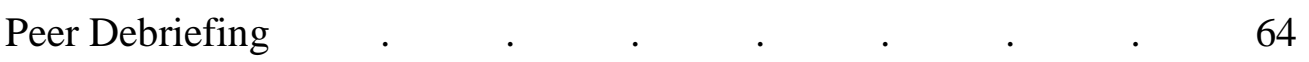

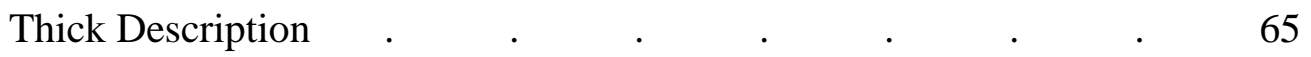

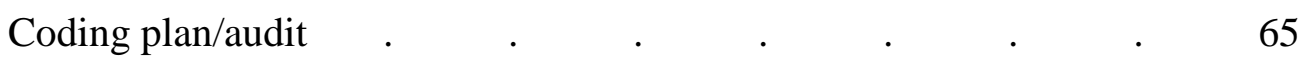

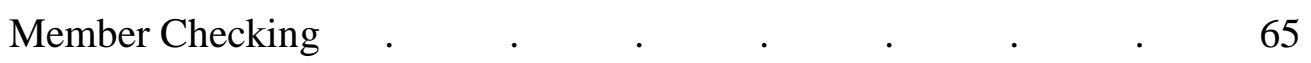

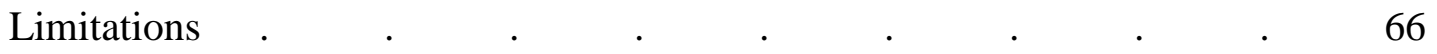

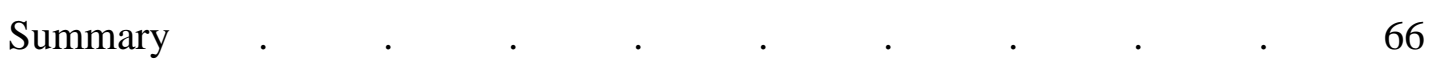

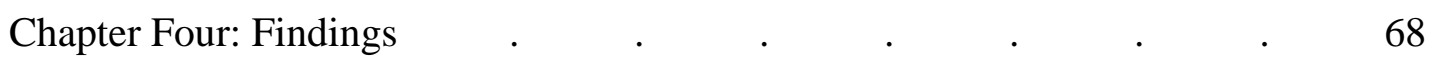

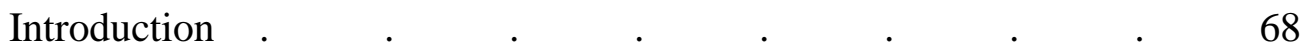

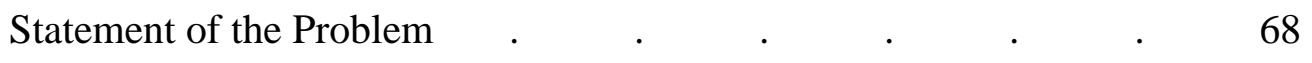

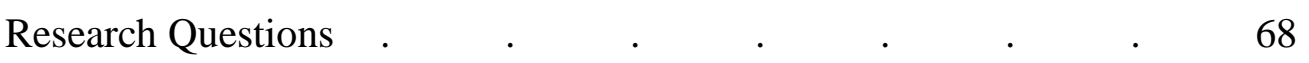

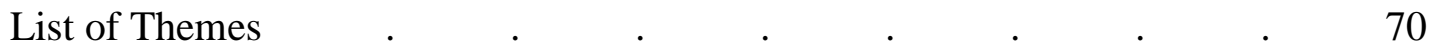

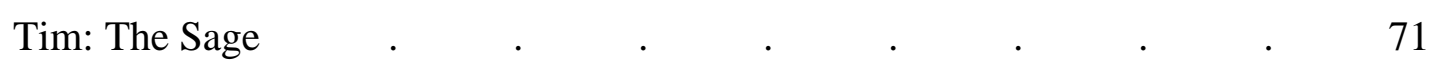

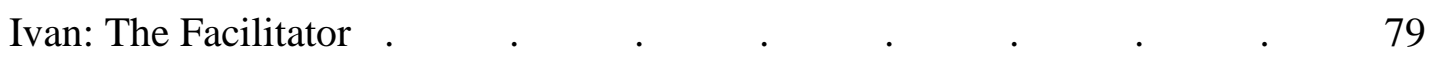

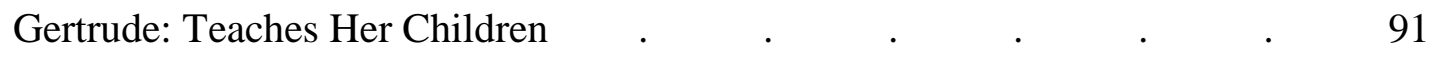

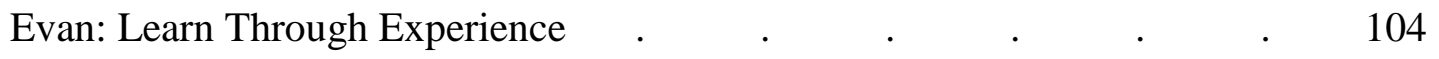

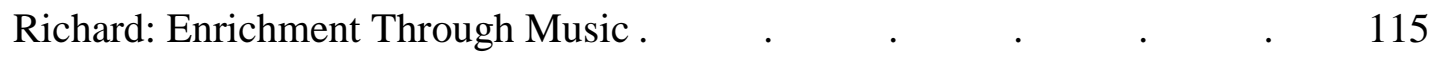

Samuel: The Student Already Knows How It Goes · 126

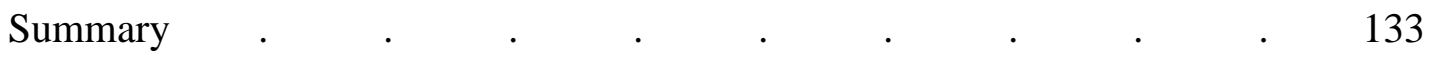

Chapter Five: Conclusions, Limitations, Recommendations, Implications 135

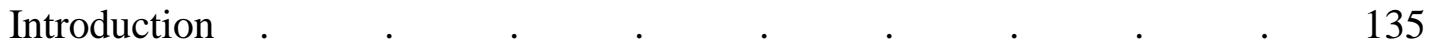

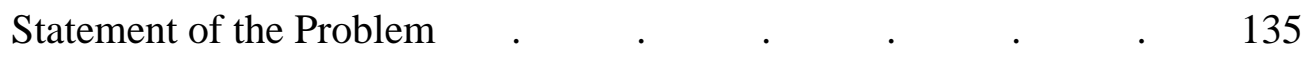

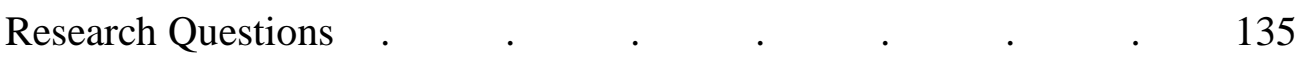

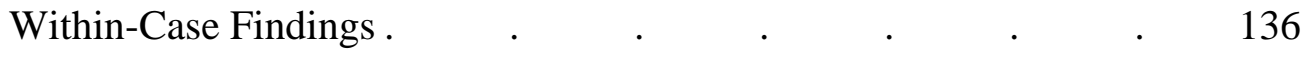

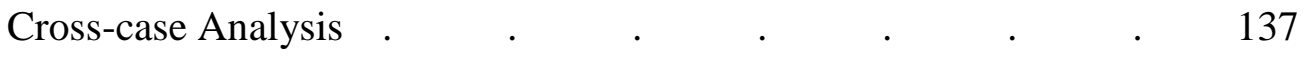


Instructional Strategies for Self-Regulated Learning . $\quad$ $\quad$ $\quad 137$

Instructional Strategies for Self-Regulated Learning . $\quad 139$

Preparing Students for Home Practice $\quad$ . $\quad$. $\quad$. 142

How Teachers Assess for Self-Regulation . $\quad$. $\quad$. 145

Perceptions about Most Important Self-Regulation Strategies 148

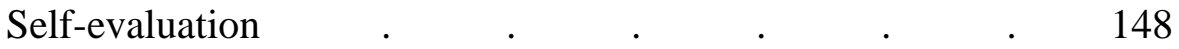

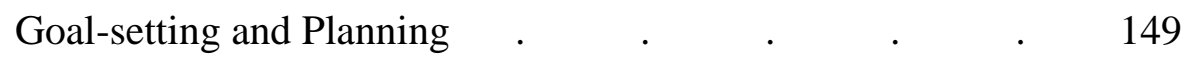

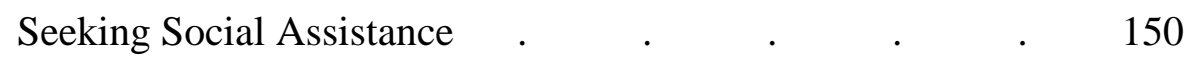

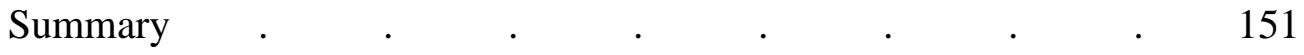

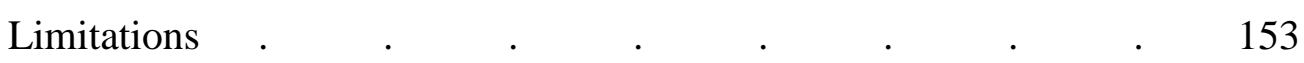

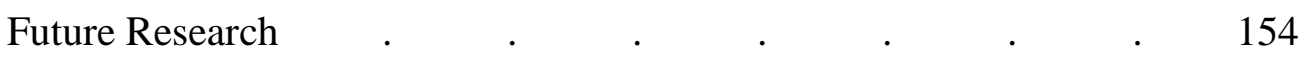

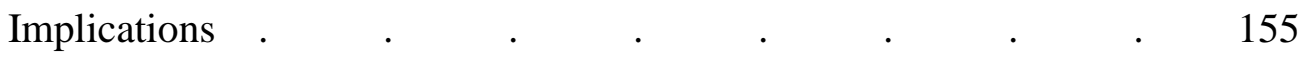

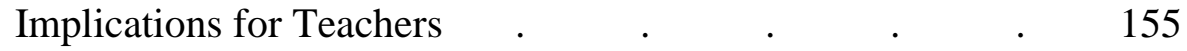

Implications for Music Teacher Education Programs $\quad$. 158

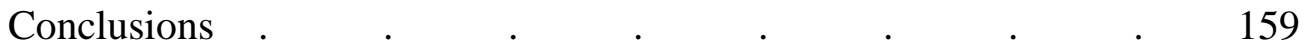

References . .

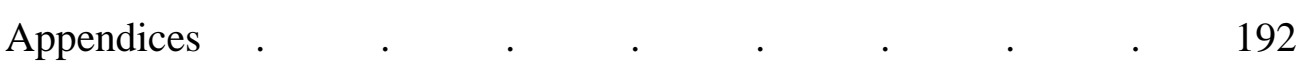

Vita . . . . . . . . . . . . . 200 


\section{LIST OF APPENDICES}

Appendix A - McPherson and Zimmerman (2011) Music Learning Theory . 192

Appendix B - Zimmerman (1989) Self-Regulating Learning Strategies 193

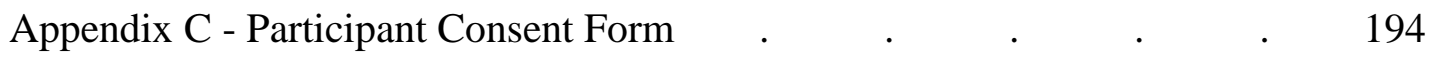

Appendix D- Interview Protocols $\quad$. $\quad$. $\quad$. $\quad$. $\quad$. $\quad$. 197 


\section{LIST OF TABLES AND FIGURES}

Tables

1.0 Music Learning Facilitators and Barriers $\quad$. $\quad . \quad$. $\quad . \quad 18$

2.0 Psychological Dimensions of Self-Regulation $\quad$. $\quad$. $\quad$. 46

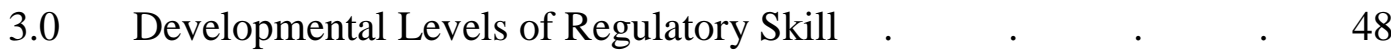

4.0 Participant's Demographics and Teaching Background . $\quad . \quad 56$

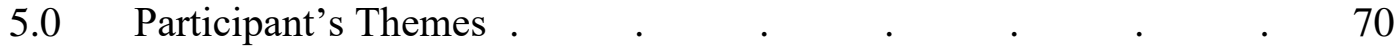

6.0 Instructional Strategies for Self-Regulated Learning . . . . 140

7.0 Common Practice to Prepare Students for Home Practice . 143

Figures

$1.0 \quad$ Theory of Self-regulation in Music Learning . $\quad$. $\quad$. $\quad$. 44 


\title{
INSTRUMENTAL MUSIC TEACHER PERCEPTIONS REGARDING \\ STUDENT SELF-REGULATION OF MUSIC LEARNING
}

Philip T. Horsley

Dr. Antonio J. Castro, Dissertation Supervisor

\begin{abstract}
In this study I examined instrumental music teacher's perceptions regarding student selfregulation of music learning. Relying on an interpretivist approach to an instrumental collective case study, data were collected from six instrumental music teachers who gave two in-depth interviews each. The McPherson and Zimmerman (2011) music learning theory served as the theoretical framework for this study and the Zimmerman (1989) selfregulated learning strategies were used to interpret the participant's perceptions. Data were analyzed using both with-in case and cross-case analyses. Findings from this study revealed that most of the participants used instructional strategies oriented towards the forethought phase of the theory. They also used instructional strategies that were oriented with the performance phase of the theory when they focused on student home practice. The participants believed that the most important self-regulation strategies their students could adopt were self-evaluation, goal-setting and planning, and social-seeking assistance. Future research could focus on how students develop into self-regulating learners, the effect guided instruction in the self-regulated problem-solving process could have on instrumental music student's academic achievements, and providing preservice music teachers with instruction in teaching self-regulation.

Keywords: Instrumental music, Metacognition, Music practice, Self-efficacy, Selfregulation
\end{abstract}




\section{CHAPTER ONE: INTRODUCTION}

\section{Children should begin their education with an understanding of their own nature - Johann Heinrich Pestalozzi}

Learning instrumental music is a unique challenge for many middle school and high school beginners. As McPherson and Zimmerman (2011) discuss from the findings of their research, every school year millions of children and adolescents across the country begin their first instrumental music classes, only to discover that music skill building is a long arduous process. It requires complex motor-skill sets and, as Craik and Lockhart (1972) found, the deepest orders of semantic level processing. Moreover, most of the skills are largely expected to be developed alone during home practice where there is an absence of immediate instructional feedback from a teacher (Pitts, Davidson, \& McPherson, 2000).

Consequently, many students fail to adequately learn on their own, get frustrated, embarrassed, disillusioned, ultimately drop out of their programs, and miss opportunities to engage in artistic expressions with others (Jørgensen \& Lehmann, 1997; Lehmann \& Ericsson, 1997). To compound the matter, stakeholders maintain the view that "the ultimate goal of the education system is to shift to the individual the burden of pursuing his own education," (Gardner, 1987). This implies that schools will continue to push the responsibility of academic achievement, including music learning, over to the student.

In school music programs then, it would help if music educators would consider the possibility that it is equally important for students to become self-regulated learners as it is to learn music performance skills. Thus, as a strategy for improving learning outcomes, teachers should consider providing students with instruction in self-regulation. 
Self-regulation is an open-ended cyclical process that occurs in three phases: forethought, performance control, and self-reflection (Zimmerman (1998b). As Orange (1999) indicated, becoming better at self-regulation is likely to help students better understand themselves as learners and better handle the burden of responsibility for their own education.

There is strong research-based support for encouraging student participation in self-regulation activities to fortify study habits and assure higher levels of academic achievement in school (Bembenutty, 2011; Dembo \& Eaton, 2000; Edossa, Schroeders, Weinert, \& Artelt, 2018; Gestsdottir, Brown-Urban, Bowers, Lerner, \& Lerner, 2011; Steffens, 2006). Self-regulated learners also tend to become more metacognitively, motivationally, and behaviorally active participants in their own learning (Zimmerman, 1989). Research findings also indicate that when self-regulatory factors, such as goalsetting and strategy use have been taught to students, they experience more favorable learning outcomes (Pressley \& McCormick, 1995;1997). Consequently, researchers have conceived new paradigms and theories about independent learning and of late, calibrated test instruments that measure the effects of self-regulation in school so well that they claim they can now predict a student's academic success by examining the self-regulation processes they employ (Boekaerts, Pintrich, \& Zeidner, 1999; Pintrich, Smith, Garcia, \& Mckeachie, 1993).

The impact that learning about self-regulation behaviors can have on academic achievement in school should not go unnoticed by music educators. Nevertheless, as Pape, Zimmerman, and Pajares (2002) propound, most music teachers do not help their students understand or improve upon their self-regulatory processes. The extant literature 
about teaching self-regulation to music students is scarce; only a small number of music education researchers have addressed the issue of teaching academic self-regulation to music learners. Zimmerman (2002) identified the six psychological dimensions students can self-regulate using a number of specific processes. McPherson and McCormick (1999) identified the motivational and self-regulated learning components of music practice and Miksza (2011) developed and tested a measure of self-regulated practice behavior for beginning and intermediate instrumental music students.

Austin and Haefner-Berg (2006) explored music practice among sixth-grade band and orchestra students and identified motivation and self-regulation as two unique dimensions experienced by music learners. Bartolome (2009) examined the selfregulating practice behaviors of successful beginning recorder students. The study illuminates for practitioners the naturally emerging self-regulated practice behaviors young instrumentalists display when first learning to make music. Another study by Araujo (2016) explored the self-regulating practice behaviors in more advanced musicians.

Consequently, in music programs where students' abilities to develop performance and technical skills are major determinants of success, students who fail to adequately self-regulate their learning, as Miech, Essex, and Goldsmith (2001) note, either fail to develop to their full potential by not adjusting well, or, as Huh and Reigeluth (2017) indicate from the findings of their study, quit trying altogether. Zimmerman, Bonner, and Kovach (1996) propose that instruction in self-regulation could act as an intervention to mitigate the drop-out rate among struggling children and adolescents. Zimmerman (2002) shows that instruction in self-regulation improves the quality of 
academic lives overall. Bembenutty (2011) suggests that self-regulation improves selfconcepts. Instruction in self-regulation can also help students address other life challenges and improve their socialization skills (Edossa, Schroeders, Weinert, \& Artelt, 2018; Fine, Baglivio, Cauffman, Wolff, \& Piquero, 2017; Geldhof, Little, \& Hawley, 2012).

To fully understand this issue, I explored the theoretical processes of selfregulation as they relate to music learning. I then studied academic self-regulation strategies and the ancillary factors that go into music skill building. Finally, I researched how self-regulation ties into instrumental music practice strategies. I was led to this particular study by research and practitioner articles that provided insight into the educational challenges children and adolescents experience as they learn to play musical instruments in school music programs. Many of them indicated in their findings that there are extenuating factors that can help students learn as well as barriers that can inhibit development. Others stressed the importance of how students approach the learning process from a metacognitive perspective. What I drew from my collection of articles was the importance researchers place on student decisions and their ability to successfully mitigate extenuating factors such as environmental distractions, while retaining ancillary factors such as parental support, and learning about what, when, where, why, how, and with whom to practice. 


\section{Purpose and Significance of the Study}

The purpose of this study was to determine instrumental music teacher perceptions regarding the importance of student self-regulation in music learning. I sought to identify problem solving processes and instructional strategies that could help music students become independent, self-regulated learners. I also wanted to determine which self-regulation strategies identified by Zimmerman (1989) were relevant to the participants. Understanding what other practitioners think about them would give insight into new teaching approaches. Finally, I investigated how teachers measure their students' perception and performance outcomes. I accomplished this by interviewing six instrumental music teachers who teach in six different school districts in a midwestern state.

\section{Statement of the Problem}

The ability to self-regulate learning becomes especially important as children and adolescents, who upon entering a school music program, are frequently required to spend large amounts of time in solitary practice periods learning a musical instrument where there is an absence of immediate instructional feedback from a teacher. As a consequence, students who enter school music programs, but lack the knowledge, skills, and strategies necessary to solve their own learning problems, fall behind, fail, or ultimately drop out (Boyle, De Carbo, \& Jordan, 1995; McPherson \& Zimmerman, 2011; Miksza, 2012; Sandene, B. A., 1994). 


\section{Research Questions}

This study addressed the following research questions:

1. What instructional strategies do instrumental music teachers report using to help their students become self-regulated learners on their musical instruments?

2. How do instrumental music teachers assess their students' levels of selfregulatory development with respect to their instrumental music performance skills?

3. What self-regulation strategies do instrumental music teachers perceive as most significant for students learning to play musical instruments?

This research addressed gaps in the literature and helped illustrate the effectiveness of teacher instruction in self-regulation. I also ascertained which strategies the participants believed to be most important in helping their students develop their selfregulatory skills.

\section{Methods and Design of the Study}

The structure of the study includes an introduction to the problem, an identification of the research questions, a description of the specific case within its own context, and data collection procedures. It also includes an analysis of the data, conclusions, recommendations, and an opportunity to address issues that arise from the study. Also, based on the findings, I will offer suggestions for further research. I believe that a case study is an appropriate instrument to use for this study because of the 
differences in experiences between participants, even when teaching the same topics (Creswell, 2007).

Philosophical assumptions have also played an important role in determining the design of this study. As an interpretivist, my position on the nature of reality, as well as my beliefs concerning my personal knowledge and the role my personal values have in my research have each impacted my choices. Based on the merits of my assumptions, the language I use in the research process, as well as my research questions, I have decided that the research method for this investigation will be an instrumental collective case study because it is the best design for answering my research questions (Creswell \& Poth, 2018). An instrumental collective case study helps to provide insight into an issue, refine working theories, and helps investigators compare and contrast differences both within and between cases (participants) (Creswell, 2007).

Additionally, as a comprehensive research strategy, case study research takes a qualitative approach where the investigator explores a single case or multiple cases over time. While illuminating a phenomenon, a case study can also improve our understanding of the entities and individuals associated with it. Some researchers make the argument that a case study is more of a choice of what is to be studied than it is a methodology. The focus of this research is to complete an in-depth description and analysis of the case, which is a bounded system, (i.e., in a particular setting where contextual conditions that are important to the study can be exposed) (Creswell, 2007). The boundaries as currently identified include each participant as a case, time, place, activities, and definitions. Emerging boundaries that appear to affect the case will also be identified. 
Case study research design will be an effective method for eliciting important data from participants in my study because there are plainly identifiable and distinct cases within the established boundaries. It also fits the three qualitatively based how and what research questions asked in this study. A case study design gave me the opportunity to record and archive evidence directly linked to the McPherson and Zimmerman (2011) music learning framework that I used as a theoretical lens. An important benefit of case study research is that it makes it possible to illuminate for the reader specific human experiences that may be of interest to them (Creswell, 2007; Denzin \& Lincoln, 2008; Merriam, 1998; Stake, 2006; Yin, 2014).

This study included six participants residing in a large midwestern state. They were recruited from a list of music teachers who are currently practicing or have practiced instrumental music instruction with middle school and high school age students. They were male $(N=5)$ and female $(N=1)$ instructors; their number of years teaching varied from five to thirty years to include beginner, intermediate, and advanced educators. There were two additional criteria for the participants: They had to be state licensed K-12 instrumental music teachers and hold at least a bachelor's degree. Finally, I was able to investigate participants widely dispersed across the state.

My approach to research comes with the view of an interpretivist (Denzig \& Lincoln, 2008). I believe that people experience and understand the same object reality in different ways and will express unique and individual responses to it. Reflexively, this has led me to systematically attend to social knowledge construction in a highly personal way as I observe students and other practitioners in the field of music education. In retrospect, I find myself holding to a paradigm that appears to favor a qualitative 
approach to research as qualitative research examines the nuances of individuals' lived experiences. I also find myself closely sharing many of the same concerns my participants have and feeling a high degree of empathy for struggling learners who are much too young to be so disillusioned about themselves, their teachers, and their schools.

Ethical consideration was also been given to this research study. I obtained IRB approval from the University of Missouri and provided the participants with an informed consent form that helped them understand the inherent risks to themselves if they were to participate in the study and what would be asked of them in terms of questioning and time commitments. I must also address my research limitations. As the research instrument, I was subject to bias while I engaged in purposive sampling with a small number of participants where I conducted interviews. I share the opinion that students need more instruction in practicing and learning about problem-solving on their own. This made it impossible to generalize to a larger population.

\section{Implications for the Study}

For this study, there are three specific implications that may arise from the findings. First, they may help identify specific and tangible instructional strategies practitioners can use to teach self-regulation concepts to their students as participants will be asked about the instructional strategies they use to teach their students how to cope with their learning challenges. Second, findings could illuminate how instrumental music teachers assess their students' self-regulatory development with respect to their instrumental music performance skills in response to specific questions about how their students are practicing on their own. Third, findings might add to the literature regarding 
self-regulation strategies instrumental music teachers perceive as most significant as participants.

My research study sought to offer music practitioners an understanding of how important music teachers believe self-regulation processes are to music learning, how self-regulation skills can be learned and taught, and how knowing about self-regulation concepts can help their students answers the why, how, what, when, where, and with whom questions independent learning issues raise. Also, since the interview questions in the protocol address other research study conclusions that reveal large gaps in achievement between students who can successfully self-regulate their learning and those who cannot, this study might also offer practitioners a better understanding of the degree to which self-regulation influences academic achievement.

For students, this study could provide insight into the nature of learning and how they can take better control of the process foe their own benefit. They might learn about the importance of personal motivation, goal-setting, and how to monitor their learning processes. In the end, this study has the potential to help both practitioners and students better predict the likelihood of their academic success in relation to the curriculum. 


\section{Overview}

This is a five chaptered dissertation. In Chapter One, I provide an introduction to the study, state the problem in a manner that clearly indicates the need for it, and place the problem in the appropriate educational context. I also include an overview of the methods to be used, implications, describe the topic in detail, and ask the following three research questions:

1. What instructional strategies do instrumental music teachers report using to help their students become self-regulated learners on their musical instruments?

2. How do instrumental music teachers assess their students' levels of selfregulatory development with respect to their instrumental music performance skills?

3. What self-regulation strategies do instrumental music teachers perceive as most significant for students learning to play musical instruments?

In Chapter Two, I include a review of literature related to the topic of selfregulation and establish an empirical rational for this study based on the gap in the literature. I then include a theoretical rational and introduce the McPherson and Zimmerman (2011) self-regulation of music learning theoretical framework. The reason for using this theory is that it takes a triadic view of self-regulation in music learning by suggesting that there is a three-phase process involving forethought, performance, and self-reflection that self-regulating students engage in. The utilization of this process is what makes it possible for students to become independent learners. The self-regulation of music learning theory is complimented with a list of six psychological dimensions that 
ask the scientific questions of why, what, how, when, where, and with whom. These questions are linked to specific self-regulation strategies that can, in turn, be linked to the three-phases of the self-regulation process. I also provide a conceptual framework for my research and give in-depth explanations of exactly how the self-regulation of music learning theory works, an in-depth explanation of the six psychological dimensions, the related scientific questions, the related social processes, and the interconnected selfregulation processes that go with it.

In Chapter Three, I introduce my specific methodology for this study. After creating a database from my collection of research findings, I concluded that a case study would be the appropriate choice. The purpose was to illuminate the participant's motives and methods and the consequences of their actions. To address trustworthiness in chapter three, I will record all interviews and make detailed field notes. I will also employ a peer debriefer to audit my research process. Finally, I identify biases and assumptions and write thick descriptions (Geertz, 1973) in my findings.

In Chapter Four, I organize and report my study’s main findings from all qualitative data. The report includes a complete and valid representation of the data that emerged as a result of the transcription coding process. Visual representations also represent the data. Findings are presented with attention to core ideas emerging from the data.

In Chapter Five, I present a cross-case analysis of the cases and then offer a set of conclusions and recommendations. The conclusions are in the form of assertions warranted by the findings. They are based on an integration of the research study findings, analysis, interpretation, and synthesis. The recommendations table implications 
for education policy and practice and provide logical steps for future action planning. They also recommend further research study as well as new research questions.

The appendices include a copy of the participant consent form and copies of the interview protocols. It also includes a list of learning strategies commonly used by selfregulating students. Finally, I include a list of the references used in this research study.

\section{Operational Definitions}

Assessment - the comparison of a relative quality to an end-state quality (Carver \& Scheier, 1998).

Behavior - the way in which one acts or conducts oneself, especially toward others (Bandura, 1986).

Deliberate practice - the structured, goal-oriented activities of a practice period that are created specifically to improve performance in a domain (Ericsson, Krampe, \& TeschRomer 1993).

Forethought - the thought processes and personal beliefs that precede efforts to engage in a task and therefore influence subsequent learning (Zimmerman, 2000a).

Learning strategies - the actions and processes directed at acquiring information or skill that involve agency, purpose, and instrumentality perceptions by learners. They include such methods as organizing and transforming information, self-consequencing, seeking information, and rehearsing or using memory aids (Zimmerman \& Martinez-Pons, 1986). Locomotion - a commitment to initiate and maintain goal-oriented progress (Carver \& Scheier, 1998).

Mental rehearsal - the ability to cognitively engage in vivid mental images (Barry, 1990). 
Metacognition - the active monitoring, regulating, and controlling of thoughts while learning; an understanding of one's own thought processes (Bandura, 1986).

Modeling - Behavioral, cognitive, and affective changes deriving from observing one or more models (Schunk, 2012).

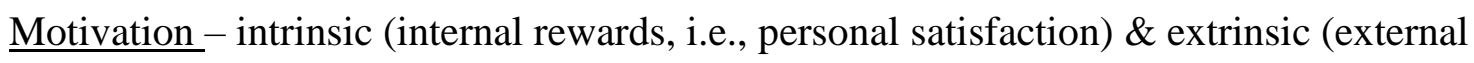
rewards, i.e., money). The motivational state of mind is composed of thoughts and emotions and is sustained by maintaining self-perceptions of efficacy (Zimmerman, 2000a).

$\underline{\text { Music }}$ - an ordering of tones or sounds in succession, in combination, and in temporal relationships to produce a composition having unity and continuity (Merriam-Webster, 2018).

Negative feedback loop - a response by one factor to a stimulus from another (McPherson \& Zimmerman, 2011).

Performance / volitional control - involves processes that occur during learning which affect concentration and performance (Zimmerman, 2000a).

Practice - repeated performances of the same or similar tasks that improve accuracy and speed of performance in cognitive, perceptual, and performance tasks (Ericsson, Krampe, $\&$ Tesch-Romer, 1993).

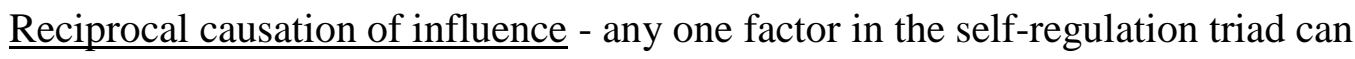
influence or be influenced by the others (McPherson \& Zimmerman, 2011).

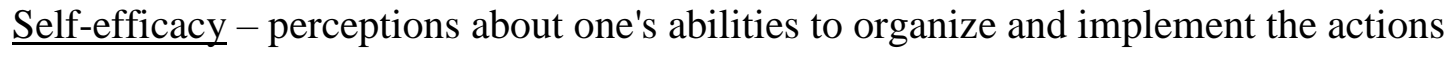
necessary to attain specific learning goals or performance skills. It is the best predictor of performance achievement (Bandura, 1986). 


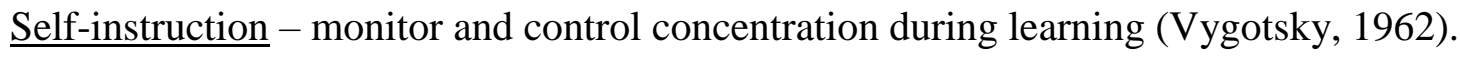

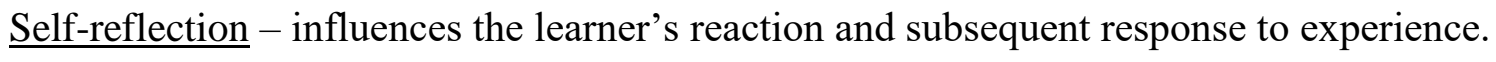
Self-reflection feeds back into forethought to influence future learning (Zimmerman, 2000a).

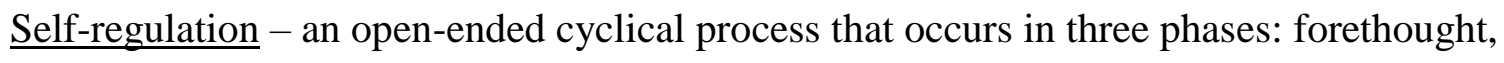
performance control, and self-reflection (Zimmerman (1998b).

Self-regulated learning - a context-specific set of processes that students draw on as they promote their own learning. Students can be described as self-regulated to the degree that they are metacognitively, motivationally, and behaviorally active participants in their own learning process (Zimmerman, 1986, 1989,1998a, 1998b).

Self-regulation of music learning theoretical framework - meets the Bandura criteria for self-regulation in that it uses a reciprocal causation of influence along a negative feedback loop and identifies self-regulation as a three-phase problem solving process when students work at educational objectives. The three phases are (1) planning and forethought, (2) performance and volition, and (3) self-evaluation. The theory asserts that self-regulating music students employ learning strategies, include six psychological questions, and be metacognitively, motivationally, and behaviorally active participants in their own learning (McPherson \& Zimmerman, 2011). 


\section{CHAPTER TWO: REVIEW OF THE LITERATURE}

Administrators, music educators, students, and parents have at their disposal an abundance of research journals related to music education. Many provide generous amounts of articles that address a variety of interesting topics that focus on primary and secondary grade children and adolescents, college students, and professional musicians. Comparatively little literature has focused on instrumental music practitioners who teach at the middle school and secondary school levels and what their thoughts are on how their students learn.

In recent years there has been growing interest among researchers about how music students learn and more specifically about the topic of self-regulation in music learning. Researchers posit that the topic of self-regulation can be used as an educational tool in instrumental music classes to help maximize academic achievement (Miksza, 2006; Prichard, 2017). Although there are a number of definitions in use, self-regulation can best be defined as the metacognitive, motivational, and behavioral activities students engage in while learning (McPherson \& Zimmerman, 2011). It entails psychological processes working together that activate and sustain, in a cyclical manner, the thoughts, behaviors, and emotions necessary to achieve a goal (Ludovico \& Mangione, 2014; Zimmerman \& Kitsantas, 2005).

Researchers have also found that that self-regulating students tend to take a more proactive stance toward learning, possess greater self-efficacy, better coping skills, and realize higher levels of academic achievement (Schunk \& Zimmerman, 1994). These are essential and pervasive qualities found among successful individuals (Zimmerman, 2002; Zimmerman \& Schunk, 1989). Other researchers propound that along with the 
development of self-regulation skills in students comes improved cognitive engagement and the confidence in their ability to identify, isolate, and solve their own educational problems (Cahn, 2008; McPherson \& McCormick, 1999). McPherson and McCormick (2006) also posit that there is no greater predictor of student achievement than when they believe they can solve their own educational learning problems.

In this chapter I reviewed the research literature that focused on instrumental music learning as it relates to self-regulation in school instrumental music programs and discussed key findings. Then, I discussed the McPherson and Zimmerman (2011) SelfRegulation of Music Learning theory that serves as the lens through which I conceived my research questions.

\section{Research in Music Learning}

In this chapter I conducted a comprehensive search and synthesized the research findings on music education germane to self-regulation since 1970. The findings were selected because they focus on what researchers consider the learning thoughts and skills instrumental music students should develop in order to be successful performers. See

table 1. Two broad themes emerged from the analysis: factors that facilitate children and adolescents learning instrumental music, and barriers to music learning (McPherson \& Zimmerman, 2011; Ramdass, \& Zimmerman, 2011; Sloboda, Davidson, Howe, \& Moore, 1996).

There are barriers and facilitators to instrumental music learning. Self-regulation factors that facilitate children and adolescents learning instrumental music include motivation, self-efficacy, goal-setting, metacognition, mental rehearsal, and learning 
strategies. Other factors include specific practice strategies, warm-up exercises, parental involvement, and modeling. Barriers include isolated practice periods outside the school music room, and quality of practice.

Table 1. Music learning facilitators and barriers

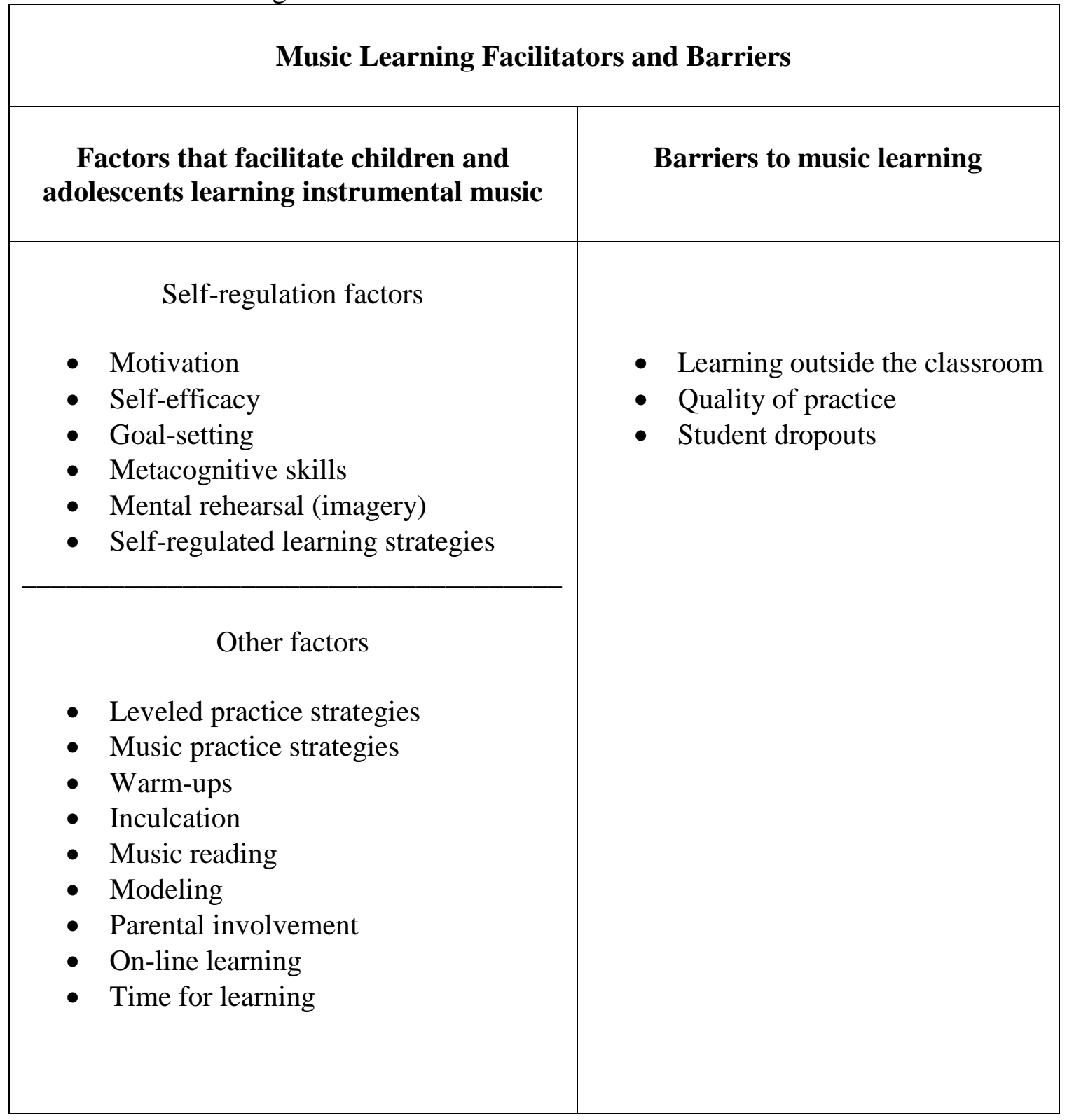


Table 1 identifies the barriers and facilitators associated with instrumental music learning. Although there appear to be fewer barriers to learning than facilitators, they tend to be difficult for young learners to overcome.

\section{Factors That Facilitate Children and Adolescents Learning Instrumental Music}

Whereas much of the research in the field focuses on the experiences of high school and college level music students, some studies also provide insight into students' instrumental music learning at the middle school level (Miksza, 2011). Instrumental music students use both self-regulating strategies and music practice strategies as they engage in musical instrument learning (Miksza, 2013). Self-regulation is a goal-oriented, adaptive, cyclical, and context-specific problem-solving process (McPherson \& Zimmerman, 2011). Learners who take responsibility for their own education, are motivated, have self-generated thoughts and feelings about their goals, and actively monitor and regulate their behaviors based on performance feedback, are characterized as self-regulating (Araujo, 2016; Ersozlu \& Miksza, 2015; Hallam et al., 2012; Pintrich, 2004; Zimmerman \& Bandura, 1994). Music practice strategies are used during fixed time periods when musicians, who have structured their activities to improve their abilities in a learning domain, use purposeful effort to achieve goals (Macnamara, Hambrick, \& Oswald, 2014). Practice strategies systematically reinforce learning received through instruction or self-discovery, nurture habits of mind, and improve fluency, accuracy, and speed of performance (Austin, \& Haefner Berg, 2006). They are empirical in nature and are oriented towards musical literacy and the improvement of both technical and performance skills (Chaffin \& Imreh, 2002; Platz, Kopiez, Lehmann, \& Wolf, 2014). However, as Ericsson (2008) points out, practice strategies alone are not 
enough to ensure expertise. What is also needed, as Lehman (1997b) stipulate, are the integrated systems of representations of musical performances within the learner's mind that can only come through experience. Other extant research literature on practice strategies focus on student attitudes as well as the theoretical and philosophical influences on student thinking. Tan (2016) illustrates how conceptual knowledge, experience, reflection, and even imagination can be guided by strategies envisioned in various Eastern and Western philosophies. Additionally, based on survey results of teachers and students, Kostka (2002) note that college students are likely to engage in a combination of both mental and physical strategies when they practice. In a broader sense, Hallam (1997b) posits that effective practice is whatever works in the short term without interfering with long term goals. Factors that facilitate children and adolescents' instrumental music learning include motivation, self-efficacy, goal-setting, metacognitive skills, mental rehearsal, and self-regulated learning strategies. Other factors include music practice strategies such as warm-ups, inculcation, fluency in music reading, leveling of skills, modeling, parental involvement, on-line learning, and time for learning (Miksza, 2006).

Motivation. A number of researchers have indicated that motivation is a fundamental factor to success in musical instrument learning (Asmus \& Harrison, 1990; Fortney, 1992; McPherson \& McCormick, 2000). Schmidt (2005) reports that instrumental music students relate their success to intrinsic motivations such as goal setting and personal accomplishment rather than to extrinsic motivations such as competitive events. Similarly, in an examination of motivation orientations which included mastery, cooperative, individual, competition, and ego, Schmidt, Zdzinski, and 
Ballard (2006) found that differences in motivation and musical self-concept were nonsignificant. In addition, there is extant research that examines the motivations of students to study music as compared to other subjects. McPherson and O'Neill (2010) note from their findings, where the musical arts were compared to five other subjects including the arts, language arts, physical education, mathematics, and science across eight countries and three grade levels, that once students were able to successfully play a musical instrument, they become more motivated toward other school subjects.

Identifying intrinsic rewards by music students as a prime motivator for participation in school music programs predicts a long-term investment by students. Success in a school music program may have a positive effect on student achievement in other academic subjects as well (Austin \& Vispoel, 1998). Motivation has a positive influence on selfregulation (Miksza, 2006). McPherson and McCormick (1999) advance the idea that motivations change as music students grow and learn, and that their self-regulating strategies become better developed as a consequence. Furthermore, there is evidence to suggest that motivated students can improve motor skills when they practice selfregulation strategies. In their study of undergraduate college students, Keetch and Lee (2007) found that after allowing motivated participants to self-regulate their learning, the performance accuracy of their motor skills improved. Miksza (2006) also purports that self-regulation strategies create conditions that facilitate successful practice periods. This scholar promotes the idea that, prior to practice, students should receive instruction on how to complete an analysis of their music and how to devise and assess their goals. Students who lack the intrinsic interest or willpower to implement self-regulation strategies are more likely to need remediation (Bandura \& Schunk, 1981). Maturation, 
cognitive engagement, and motivation are the key differences between music students who practice self-regulation strategies and those who do not (Pintrich, 2004).

Practitioners should take note of these findings as motor skill development is one of the pillars of instrumental music success and implementing strategies that foster it should be encouraged (Barry, 1990).

Self-efficacy. Researchers have illustrated how important it is for practitioners to help their students develop the thinking skills that will improve their cognitive engagement in instrumental music classes (McPherson \& McCormick, 2006). As Chong (2007) indicates, metacognitive skills help students manage competing activities, overcome difficulties, and master the process they use to establish long-term goals.

Furthermore, Zimmerman and Kitsantas (2005) report that self-efficacy plays a mediating role between school work and student's perceived educational responsibilities. The findings show that homework practices could predict self-efficacy beliefs concerning learning abilities and responsibilities. Rojas and Springer (2014) found that in adverse or trying conditions such as a rigorous academic music program, the number of days practiced per week, and hours of practice per day significantly predicted musicians' selfefficacy. They note that self-efficacy is what compels musicians prevail in the face of adversity. Bandura, Barbaranelli, Caprara, and Pastorelli (1996) posit that students with a refined sense of self-efficacy have heightened motivations, think strategically, and believe that they can be masters of their own learning. Additionally, Zimmerman, Bandura, and Martinez-Pons (1992) found that a reciprocating by-product of self-efficacy is that it can encourage students to engage in beneficial learning behaviors such as goal setting, self-monitoring, devising learning strategies, and self-evaluation. In instrumental 
music practice is the hallmark of achievement, but practice environments, learning goals, and expectations are often challenging to young learners in school music programs (McPherson \& Zimmerman, 2011). Self-efficacy beliefs can help them develop a sense of personal agency in their goal setting, self-monitoring, self-evaluation, and in learning strategy selection and assessment.

Not only are these skills useful in music classrooms, but as adaptive behaviors they help students address other challenges in life (Schunk \& Pajares, 2001; Schunk \& Pajares, 2002). It is the student's self-efficacy that affects their ability to effectively engage in the self-regulating behaviors that help them realize their goals (Schunk \& Miller, 2002).

Goal setting. Students who are able to establish goals in music learning achieve higher levels of performance (McCombs, 2001). Zimmerman and Bandura (1994) found that goal setting strategies can mediate low self-standards and help improve the academic performance of learners. Ericsson, Krampe, and Tesch-Romer (1993) concluded that goal-setting strategies, which can change with experience and the passing of time, are related to student training and diminish as formal education with music teachers dissolve.

Nevertheless, practice remains an integral mechanism for music learning throughout life. There is also a difference in goals between age and ability groups (Miksza, 2011). Beginning instrumentalists tend to focus on skill building, while more advanced musicians tend to focus on performance issues such as interpretation, expressiveness, and musical structure (Chaffin, Lisboa, Logan, Begosh, 2009). For either group, goal setting involves careful consideration of the factors that go into music making such as correct fingering and overcoming technical difficulties (Chaffin \& Logan, 2006). 
Metacognitive skills. Extant research in the field of music education focuses on the effects of certain metacognitive beliefs on children and adolescents who participate in school music programs (Hallam, 2002; Kemp, 1996; Papageorgi, Hallam, \& Welch, 2007; McCormick \& McPherson, 2003; McPherson \& McCormick, 1999; McPherson \& McCormick, 2006). The three metacognitive factors that most influence children and adolescents' learning instrumental music are goal setting, self-efficacy, and selfinstruction (McPherson \& McCormick, 2006). Metacognition as a cognitive process is the active monitoring, regulating, and controlling of higher order thinking skills and thoughts in academic learning (McCombs, 2011).

In instrumental music, where proficiency can take years to attain, the students who use self-efficacy as a metacognitive process tend to persist (McPherson \& McCormick, 2006). When metacognition involves students' self-efficacy, that is, the belief in their abilities to carry out plans to achieve goals, it is viewed as a motivational process (O’Neill \& McPherson, 2002).

Mental rehearsal. Mental rehearsal, which is the ability to cognitively engage in vivid mental images, can have a significant effect on the quality of a musical performance (Brooks, 1995). Clark and Williamon (2011) posit that proficiency in mental rehearsal comes after effortful practice on the part of the learner. The process of practicing music by mentally visualizing oneself either performing a piece of music on their instrument or mentally visualizing oneself reading a piece of music is done without physically playing an instrument (Lowe \& Belcher, 2012).

Mielke and Comeau (2017) note a taxonomy in which there are four forms of mental rehearsal accessible to the learner: visual imagery, kinesthetic imagery, motor 
imagery, and auditory imagery. In a related study, Cahn (2008) found that students who first had opportunities to mentally rehearse chord progressions before improvising with them significantly outperformed those who did not. The goal of mental rehearsal is to increase the capacity to declare when and where every note is located both on the sheet music and on the instrument (Fine, Goldemberg, Wise, \& Bravo, 2015). Mental rehearsal can lead to deeper semantic level learning and thus improved performance by enhancing the performer's recall of the music (Chaffin \& Imreh, 2002).

The mental rehearsal strategy has shown to be helpful (Chaffin, Lisboa, Logan, \& Begosh, 2009). However, it is also a time-consuming process that might interfere with other skill-building activities (Ericsson, 2008). Nevertheless, instrumental music students are more likely to advance as musicians if they are able to mentally link the sound of a note to the fingerings on their instruments (Kostka, 2002).

Self-regulated learning strategies. Researchers have found that using selfregulating learning strategies to solve problems can benefit music students (McPherson \& Renwick, 2001; McPherson \& Zimmerman, 2011; Zimmerman, 1989). Nevertheless, Zimmerman and Risemberg (1997) posit that few teachers systematically help their students develop self-regulatory skills, even though they are teachable. Based on the findings from their questionnaire, Hatfield, Halvari, and Lemyre (2017) emphasized the functional effectiveness of self-regulating learning strategies when students try to solve problems. Students who successfully implement self-regulation strategies to solve their learning problems may realize performance and technical gains in music as well as higher grade point averages across their academics. They may even realize better emotional 
states (Kreutz, Ginsborg, \& Williamon, 2009; Miksza, 2013; Shields, Moons, \& Slavich, 2017).

Additional research indicates that practitioners who help their students implement strategies that promote problem solving skills usually encourage them to ask questions along the line of what, how, and why. Questions of this sort, as Mieder and Bugos (2017) propose from the findings of their research study, prompt the selection of specific learning goals and a working plan to achieve them. In an earlier study, Miksza and Tan (2015) noted that one of the most important factors that facilitates learning instrumental music is the teacher's learning strategy instruction. They advocate that teachers should encourage their students to implement self-regulation strategies, to be persistent in their efforts, and to work diligently to achieve their goals.

The psychological organization of the steps involved in learning is fundamental to academic success, but mastery of the process can take numerous attempts on the part of children and adolescents (Schunk, 1990; Schunk \& Zimmerman, 1998). In addition, one of the aims of educators is for their students to become adept at learning on their own (Schunk, 1991). Therefore, as Mieder and Bugos (2017) argue from the findings of their study, practitioners should provide their students with opportunities to experience a selfregulating process that encourages both learning independence and a sense of personal responsibility for their academic success.

Impulsivity and poor academic discipline can have an adverse effect on selfregulation strategies. In an investigation of relationships between achievement goal motivation, impulsivity, and music practice, Miksza (2011) findings propound that individuals who exhibited low impulsivity were more likely to use their time more 
efficiently. That is, when compared to highly impulsive people, they were more likely to successfully implement self-regulation strategies into their practice. In her study of music practice instruction, Prichard (2017) notes that students' purposeful efforts are necessary for employing self-regulation strategies and that facing challenges to learning such as maintaining self-control is fundamental to success. Impulsivity can be addressed on the part of the student through help-seeking behaviors (Miksza, 2011) and teachers can establish clear learning goals and stress the value of achieving them to help improve practice room behavior (Mieder \& Bugos, 2017).

Motivation, self-efficacy, goal-setting, metacognitive skills, mental rehearsal, and self-regulated learning strategies are cognitive factors that facilitate children and adolescents learning instrumental music. Teaching materials and learning experiences can facilitate exposure to these factors. Other factors facilitate music learning as well.

\section{Other Factors That Facilitate Music Learning}

The research literature also points to other factors that impact learning music (McPherson, 2005). These factors include leveled practice strategies, music practice strategies, warm-ups, inculcation, music reading, modeling, parental involvement, on-line learning, and time for learning (Cash, Allen, Simmons, \& Duke, 2014; Fortney, 1992; Hewitt, 2001).

Leveled practice strategies for students. There are four developmental stages in the music practice behaviors of children and adolescents. A self-report study by Harnischmacher (1997) identifies them as "activity," "adoption," "assimilation," and "identification." The activity phase can be seen in children Eight to 10 years of age and their practice is usually limited to self-created play. Eleven to 12 -year-old children 
usually participate in the adoption stage in which they "adopt" a work ethic and consider a goal-oriented practice period for the first time. Thirteen and 14-year-old students experience the assimilation stage in which practice evolves into a scheduled daily habit and intentionally practice to maintain formerly acquired skills, learn new skills, as well as perform formally and for entertainment. Lastly, in the identification stage, fifteen to 18year-old students learn to reflect on the quality of their practice. Jørgensen and Lehmann (1997) also posit that young learners may lack the maturation necessary to engage in some types of practice strategies. Children learn differently than adolescents and adults both because of personal differences such as emotional maturation, and because of developmental differences such as physical maturation. Therefore, practice periods should be tailored to the individual student and organized around levels of difficulty ranging from easy to complex. For the teacher then, understanding the maturation process is requisite to knowing what specific skill building activities they should encourage for students' learning periods.

Music practice strategies. Despite the differences between scholars about the various structural types of music practice, Barry (1990) for example posits three forms, "deliberate," "informal," and "unstructured," Oare (2012) advances the idea that instrumental music students whose motivations are goal oriented, and employ practice strategies to achieve them, learn better regardless of the structure. Similarly, Ericsson, Krampe and Tesch-Romer (1993) found that practice strategies are essential to the development of musical expertise. They purport that learning happens best after students define their personal goals and then successfully implement specific strategies to achieve them. Sloboda, Davidson, Howe, and Moore (1996) also posit that, despite the individual 
differences in some of the practice habits observed in their research participants, the formal and effortful behaviors associated with practice strategies have a positive correlation with music achievement.

Additionally, results offered by Duke, Simmons, and Cash (2009) propound that practice strategies were more determinative of the quality of a musical performance than was the actual length of a practice period. Lehman and Ericsson (1997) also indicated that among the most important factors to influence a practice period is the student's perceptions of the skills to be acquired and the strategies they use to achieve them. Hallam, Rinta, Varvarigou, Creech, Papageorgi, Gomes, and Lanipekun (2012) found that music students targeting specific skill goals with practice strategies appropriate for their age, environment, and experience would limit their behaviors to those that would most likely help achieve them.

In a Barry (1992) study using an ANCOVA test, results confirmed that the structured procedures found in practice strategies were more conducive to learning. Additionally, Uygun and Kilincer (2017) posit that instrumentalists process information better and ultimately gain greater performance improvements when they can identify strategies that address their attentional, organizational, rehearsal, elaboration, or articulation needs. There is also extant research on practice behaviors among different age groups.

Rohwer \& Polk (2006) found among eighth grade instrumentalists that performances were generally better when students could verbalize their practice techniques. They also showed from their findings that there were greater gains among students who practiced analytically than among students who practiced holistically. 
Other research has focused on practice strategies used by professional instrumentalists. After observing how concert soloists prepare for their performances, Chaffin and Logan (2006) postulate that when practicing for a performance, instrumentalists identify particular features of the music and use them as performance cues to aid in the recall of their automatic movements. They also propose the use of basic cues for matters relating to technique and interpretive cues that address issues such as phrasing, dynamics, and tempo. In a later study, Chaffin, Lisboa, Logan, and Begosh (2009) identified strategies that affect performance cues their participant attended to when memorizing music.

To determine the extent applied studio teachers were teaching practice strategies to their students, Barry and McArthur (1994) used a MPII in their research study. The findings indicate that most teachers almost always discuss the importance practice strategies with their students. The findings also indicated that teachers who worked with students at the college level were suggesting different learning strategies than teachers who worked with younger or less experienced students.

Specific learning strategies have been identified in other research studies. Després, Burnard, Dubé, and Stévance (2017) used a retrospective verbal protocol to elicit their participant's use of strategies and then coded the data. The results of the coding identified forty-six separate strategies organized into five categories: preplanning, conceptual, structural, atmospheric and stylistic, and real time.

Pike (2017) notes specific practice strategies such as (1) playing through the entire piece of music without stopping, (2) using a metronome, (3) counting out loud, (4) making notes on the manuscript with a pencil, (5) rhythmically sight-reading the music, (6) playing the music at slow tempos, and (7) isolating hands. Other practice strategies 
include reading, writing, listening, singing melodies, tapping rhythms, analyzing, identifying fingerings, repeating both small and large chunks of musical passages, slowing down through difficult passages, targeting and solving technical problems through repetition, psychomotor skill building, recording performances, conducting maintenance rehearsals of repertoire, memorizing new literature, and performing for an audience (Meinz \& Hambrick, 2010; Miksza, 2011; Nielsen, 1999). Additionally, there are two practice strategies that researchers have taken a greater interest in: warm-ups and inculcation.

Warm-ups. Current literature also points out that many advanced musicians begin their practice sessions with warm-ups strategies (Chaffin \& Logan, 2006). Consistent with prior research, practicing scales, arpeggios, and chord voicings are commonly rehearsed technical activities (Hallam et al., 2012; Pitts, Davidson, \& McPherson, 2000). Playing etudes is another warm-up strategy students can use (McPherson \& Renwick, 2001). After warm-ups, as Duke, Simmons and Cash, (2009) report, musicians are also likely to turn their attention to learning new literature and correcting errors. Practice strategies such as warm-ups are needed because of the innate interferences humans experience when learning. Since all learning is a process which follows logical steps, both learning objectives - which guide the process - and practice warm-up strategies should be implemented before practice begins. Successful outcomes are affected by the competency of the use of the strategies during practice. If students do not meet the objectives, their strategies should be examined or the objectives should be readdressed. The result of effectively employing strategies are improvements in both the 
technical and expressive components of instrumental music making (Chaffin \& Imreh, 2001).

Inculcation during practice. Repetition of motion for the acquisition of complex motor skills is an important learning strategy (Chaffin \& Imreh, 2002). Chaffin and Logan (2006) state that repetition of specific movements improves students' coordination, accuracy, fluency, velocity, and consistency on their instruments. Sloboda, Davidson, Howe, and Moore (1996) found that the principal determinant of success in music is effortful practice. However, if not handled properly, repetitive exercises become mere rote memory learning activities that are of little musical benefit to beginners (Meinz \& Hambrick, 2010). Additionally, young learners' musical interests are likely to be short-term in nature, which purports they may become unmotivated if asked to repeatedly perform complex motor skills over an extended period (Stambaugh, 2011). Teachers can also provide thorough explanations of how the skills transfer to more advanced techniques and interesting performance skills that align with longer term music goals.

Music reading. There is evidence from the current literature on music learning to indicate that the ability to sight-read music notation is a fundamental precept of music literacy (Lehmann \& Ericsson, 1996). Zhukov (2016) found that the number of hours students engage in sight-reading practice are predictive of their music reading accuracy. However, s Mishra (2014 indicates, there are certain factors that affect sightreading fluency including the students' abilities to concentrate, their ability to simultaneously chunk groups of notes, and their capacities to process both pitch and rhythm as they decode. Other research findings indicate that both a student's musical experience and their ability to create a scheme of the music help them anticipate what 
notes are likely to come next as they read (Hayward \& Gromko, 2009; Meinz \& Hambrick, 2010).

Moreover, findings from Henry (2011) note that the ability to sight-read can be predicted through a combination of aural pattern discrimination and the student's technical proficiency. Nevertheless, some learners struggle to read music but as Mishra (2014) posits, interventions can help struggling learners improve reading accuracy. Treatment types with potentially effective supports include instruction in aural skills, controlled eye movement reading, and having students engage in music notation writing (Penttinen \& Huovinen, 2011). The intervention derives from the belief that music reading is a cognitive process based on perceptual relationships and relies, in part, on the knowledge of the performer (Furneaux \& Land, 1999). Kostka (2000) found that perceptual relationships associated with instrumental musicianship improve after increased exercise of the spatial-temporal regions of the brain.

Fluent sight-reading is a time-consuming process that involves multiple learning factors which develop years, rather than in days or weeks Additionally, musicians whose reading fluency is sufficiently developed are capable of decoding written notation at high speeds and recognizing both horizontal harmonic patterns and vertical melodic patterns with minimal errors (Gromko, 2009). This has implications for music students who are intent on becoming good instrumentalists as there is a prevailing notion in the field of music education that better musicians tend to be better sight-readers (Betts \& Cassidy, 2000; Rosemann, Altenmüller, \& Fahle, 2016; Zhukov, 2016; Zhukov, Viney, Riddle, Teniswood-Harvey, \& Fujimura, 2016). 
Modeling. Modeling is a proven and attractive learning strategy for many students. Research shows that music students eagerly attempt to emulate the "what-topractice" and "how-to practice" behaviors their teachers present to them (Hewitt, 2001). This is especially true after teachers model the expressive elements of the music in a performance (Cash, Allen, Simmons, \& Duke, 2014; Duke \& Simmons, 2006). Modeling draws on the social learning processes of attention, retention, motor reproduction, and motivation (Bandura, 1971; Fortney, 1992). However, Hewitt (2001) indicates that although overall student performance is likely to increase as a result of teacher modeling, student intonation and melodic accuracy will not necessarily improve after an instructor modeled performance. Practice strategies teachers can model include (a) completing a theoretical analysis of the music, (b) mapping: identifying and isolating difficult passages, (c) chunking, (d) engaging in part-whole playing, (e) identifying patterns, (f) playing along with a metronome at different tempos, and (g) listening to recorded and live performances of the music (Austin \& Haefner, 2006; Barry and Hallam, 2002; Bartolome, 2009; McPherson, 2005; Miksza, 2011).

Parental involvement. Besides the classroom, the home environment should be the best place for a child to learn because parents have an influence over learning (Sloboda \& Howe (1992). Nevertheless, homelife can be distracting and stressful for students when trying to learn how to play a musical instrument (McPherson \& Davidson, 2002; McPherson, 2005). Parents should try to provide their children with an adequate learning space in the home and model problem-solving skills such help seeking and time management practices to help young learners realize potential ways to negotiate the challenges they face. Parents can also teach their children to learn to work both 
independently or cooperatively in groups. What they teach them affects their ability to make meaningful choices in education and life (Bandura, 2006).

However, as Davidson, Howe, Moore, and Sloboda (1996) report, many parents do not know how to help their children cope with the plethora of frustrating problems, like which instrument to even learn to play, that arise in the early stages of instrumental music learning. Similarly, McPherson (2009) reported that parents are integral to children's musical development and though necessary, often cannot help them with the practical matters of music skill building. Nevertheless, they can also nurture the metacognitive skills their children need to effectively monitor their own independent learning (Schunk \& Meece, 2006). Cheung and Pomerantz (2011) found that parent instructional behaviors toward their children generally convey their feelings toward their children's learning behaviors. This suggests that what is important in the parent-child teaching relationship is that the parent provide some structure and guidance and, rather than being controlling, should encourage and support their child's autonomy.

Online learning. Online learning is becoming an important aspect of instrumental music learning (Bond, 2003). As Brook and Upitis (2015) discuss, some students can mitigate their poor self-regulatory skills through the use of online learning tools and computer software. Online tools include checklists that provide instruction on help-seeking, study strategies, self-evaluation, managing distractions, and self-motivation (Upitis, Abrami, \& Brook, 2010). Purves (2012) states that improvements in selfregulated learning assessments are good predictors of future standardized achievement test scores and corroborate the notion that reflection is a beneficial self-regulation strategy. 
Research from Huh and Reigeluth (2017) focused on online teacher perceptions and practices that support learning centered-instruction and learning strategies. Their findings indicate that learners become more interested in taking control of their learning when using online tools, and can realize successful outcomes. Professional development could help teachers identify which software programs and online websites will help instrumental music learners define their goals, communicate more effectively, reflect more thoughtfully, and respond to feedback (Partti, \& Karlsen, 2010; Partti, 2014). These tools enable students to manage distractions and focus their attention, which are essential to music learning (Waldron, 2013a).

Time for learning music. A wealth of research indicates that many hours, years, and even decades of effortful practice activities are required for students to become accomplished musicians (Ericsson \& Smith, 1991a; Ericsson, Tesch-Romer, \& Krampe, 1990; Williamon \& Valentine, 2000). Ericsson (2008) purport that superior musical performance skills are the result of internally developed mental representations that enhance domain specific performances tasks such as motor control. In a related study, Ericsson and Ward (2007) documented that musical expertise is only attained after 10 years of deliberate practice trials in which the automatization of performance skills was a priority. Additionally, as Macnamara, Hambrick, and Oswald (2014) note, music students who aspire to become expert violinists can accumulate more than 10,000 hours of practice time. Those who strive to accel as violinists will likely acquire almost 8,000 hours of practice time. The least accomplished will still practice over 4,000 hours.

Music teachers and their students know that learning music is time consuming (Krampe \& Ericsson (1995). Some ways the time factor can be mitigated are through the 
analysis of music practice and the establishment of goals to achieve certain performance objectives that have the correct level of difficulty for the students (Chaffin \& Imreh, 1997). These mental representations only appear after repeated practice trials spaced over time and depending on the quality of instruction and students' abilities to maintain concentration during practice, some of these representations can take years to acquire (Duke, Flowers, \& Wolfe, 1997). The factors involved in the acquisition of expert skills are time-consuming and complex processes that are not always enjoyable (Duke, Simmons, \& Cash, 2009).

Practice strategies such as warm-ups and inculcation, music reading, observing and emulating proficient models, parental involvement, on-line learning, and taking the time to learn, are important factors in the music learning process. Taken together, they can help students develop the technical and performance skills necessary to participate in school music programs. Nevertheless, there are also barriers to music learning that can jeopardize academic success for some students.

\section{Barriers to Music Learning}

Over the past several years researchers have taken an interest in understanding the barriers that block student academic success (Schunk, Pintrich, \& Meece, 2008; Schunk \& Zimmerman, 1997; Zimmerman, 2000). Barriers in instrumental music programs often lead to frustrating set-backs or present insurmountable difficulties that inevitably force musicians to quit (McPherson \& Zimmerman, 2011). Barriers may appear in the form of personal factors such as poor goal setting skills (McCormick \& McPherson, 2007; Oare, 2012), or poor organizational skills (McPherson \& Zimmerman, 2002). Barriers may also appear as a consequence of environmental factors such as inadequate practice space 
(Davidson, Howe, \& Sloboda, 1997), lack of parental support (Davidson, Sloboda, \& Howe, 1995), or negligible instruction on the part of a teacher (Costa-Giomi, Flowers, \& Sasaki, 2005). Mantalvo, Mansfield, \& Miller, 2007; McPherson, 2005; McPherson, 2009; McPherson \& Davidson, 2002).

Thwarting many of the barriers instrumental music students are likely to face are self-regulation strategies that can (a) improve personal functioning such as with a selfconsequencing strategy, (b) improve academic learning skills such as keeping and reviewing notes and records, and (c) reshaping an environment to make it more conducive to learning (Zimmerman, 1989). Barriers may also be defeated with an improved understanding of the benefits of time management, self-efficacy, and selfreflection (Stoeger, \& Ziegler, 2008). Music students can also improve their chances of success by adhering to a greater sense of personal responsibility with their own success (Kitsantas \& Zimmerman, 2009).

Learning outside of the classroom. Students do not automatically employ many learning strategies outside of school (Miksza \& Tan, 2015). As the research findings from other studies have shown, learning strategies do not naturally appear on their own at an early age, and as a result, children tend to not learn as well at home as they do in school (Bartolome, 2009; Pitts, Davidson, \& McPherson, 2000). Bergin (1996) posit the remedy is for teachers to encourage a transfer of learning from school to home by helping students find topics of interest in school and then indicate learning strategies that they can use to learn independently outside of school. Furthermore, Austin and Haefner (2006) found that sixth-grade band and orchestra students' motivation to practice and abilities to self-regulate through an entire practice period at home were dependent upon the quality 
of their home environment that provided a quiet, well-lit place to work and supportive parents.

There is also evidence that social modeling can have a positive effect on learning. In a related study, Orange (1999) found that in a social learning situation, distractions can have an adverse effect on fragile learning behaviors. Nevertheless, motivational intervention and peer modeling can be effective means for educators who teach learning strategies (Hewitt, 2001). Therefore, in addition to taking a supervisory role while their children are practicing, parents should also actively look for ways to ensure that the home environment facilitates instrumental music practice (McPherson, 2009).

Quality of practice. Practice is necessary for developing music performance skills. According to Williamon and Valentine (2000), the quality of individuals' private practice period is subject to a number of variables including their abilities to create goals, focus attention, and sustain concentration over relatively long periods of time, as well as identify and correct errors independently. Yet, many beginning music students may not consider these factors or lack the capacity to effectively engage in them without receiving prior instruction (Lehmann \& Ericsson, 1997). Nevertheless, as Stambaugh (2011) noted, teachers expect that their students will frequently engage in effortful practice periods to maintain adequate progress in their programs of study.

Additionally, Duke, Simmons, and Cash (2009) note three important factors that differentiate between successful and unsuccessful student practice periods. Students who immediately addressed their mistakes, targeted difficult passages for additional study, and thoughtfully considered musical interpretations showed better performance results than those who failed to address errors, note their location on the music, or failed to 
conceptualize the music at different tempos. Explicit instruction in the factors that influence successful practice, such as the habit of defining practice goals, should be part of every lesson (Vaughan, 1980). This has implications for practitioners who are tasked with the job of guiding their students' musical growth and suggests, as the findings from Cremaschi (2012) reveal, that in addition to music instruction, educators should inform their students of the benefits of good practice habits such as the use of a checklist.

Student dropouts. A number of researchers have reported that students drop out of school programs because of the perception that they either lack ability or possess the attitude that learning music is difficult and unpleasant (Hallam, 1998; Hartley, 1991b; Hartley, 1996; Kruth, 1964; Lehmann, 2002). Hyllegard and Bories (2009) reported that student misperceptions about the complexities and difficulties associated with music practice contribute to the high attrition rate in school music programs. They also report from their research findings that music students often prefer to engage in less effortful rehearsals than work in more taxing private practice sessions.

Similarly, McPherson and Renwick (2001) found in their three-year study that beginning instrumentalists often fail to employ the very learning strategies that facilitate advancement, and instead perpetuate the errors that prohibit it. Nielsen (2011) found educators should encourage adaptive epistemic beliefs. Such instruction might help mitigate the high dropout rates in school music programs. Nevertheless, private effortful practice that includes the use of problem-solving process and learning strategies can improve student outcomes (Zimmerman \& Schunk, 2001).

Barriers to music learning affect academic achievement, the quality of music practice, and the dropout rate in school music programs. There are possible consequences 
for students that extend beyond their ability to participate in music programs.

Researchers suggest that students who fail to overcome music learning barriers and do not participate in musical activities, may experience weaker memory skills, weaker organizational skills, and less emotional control during the course of their lives. They may also be more prone to anxiety issues and have greater attention deficits (Grape, Sandgren, Hansson, Ericson \& Theorell, 2003; Hudziak, Albaugh, et al., 2014;).

\section{Implications of the Research for the Present Study}

The findings from my synthesis of the research advance three major conclusions about music learning. First, music learning is highly individualistic; its mastery essentially occurs in isolated practice sessions involving personal motivation that addresses both the metacognitive and music performance skills necessary to succeed. Second, music learning takes thousands of hours of practice and years of study to develop expertise and thus, music practice requires both a strong personal commitment and longterm goal planning. Finally, educators should address the self-regulatory processes that emphasize self-set goals and self-reinforcing affirmations that enable learners to persevere through the time-related issues that lead to the development of music performance skills.

These conclusions inform the development and design of this study in several ways. Most importantly, I seek to determine music teacher perceptions on the importance of providing instruction in self-regulation to their students and to identify the instructional strategies music teachers use to help students become independent, selfregulated learners. These purposes arose out of the realizations that learning is highly 
individualistic and mostly occurs in isolated practice sessions away from the immediate instructional feedback of a teacher. Understanding music teacher perceptions is needed because they hold expectations that students will invest substantial time practicing alone. Therefore, it becomes paramount that students be able to effectively function as independent learners.

Little is known about instrumental music teachers' understanding of students' self-regulation processes and the extent to which they teach self-regulation learning strategies to students. In numerous studies, researchers have examined self-regulation in music practice among secondary and college-age students, but few have focused on elementary instrumental music students (e.g., see Renwick \& McPherson, 2002 and McPherson, 2005)

I aim to discover what instructional strategies music teachers use to help their students become self-regulating learners. I do this by asking what aspects of selfregulation they perceive as most important. I also focus on how music teachers promote student's perceptions of themselves as musicians and how they measure their student's performance outcomes.

Finally, this study draws on the self-regulation of music learning theoretical framework. My review of the related literature and the conclusions I drew from the articles led me to this theoretical lens as it identifies and focuses on the principal factors that influence the development of independent learning skills, and the behavioral, personal, and environmental factors that influence learning. It also identifies the processes individuals go through as they respond to academic learning challenges, and the psychological dimensions that are involved with music learning. 


\section{Self-Regulation of Musical Learning: A Framework for the Current Study}

McPherson and Zimmerman's (2011) self-regulation of music learning theory is the theoretical lens for this case study. It asserts that self-regulated music students are metacognitively, motivationally, and behaviorally active participants in their own learning while they plan, execute, and evaluate their learning activities. This theory addresses the needs stakeholders have for understanding the problem-solving processes that arise in music students as they learn along cognitive, affective, and psycho-motor lines (Committee of College and University Examiners, 1956; Dave, 1970; Harrow, 1972; Krathwohl, Bloom, \& Masia, 1964; Simpson, 1972).

The three factors McPherson and Zimmerman (2011) identify in their framework are the three phases through which learners progress when attempting to achieve educational objectives: (a) planning and forethought, (b) performance and volition, and (c) self-evaluation. During the forethought phase, students engage in task analysis activities such as strategic planning, identifying goals, identifying learning challenges, and identifying learning strategies. Students will also address self-motivational beliefs as they affirm their self-efficacy, outcome expectations, task interests, and task values. 
Figure 1. Theory of self-regulation in music learning (McPherson \& Zimmerman, 2011)

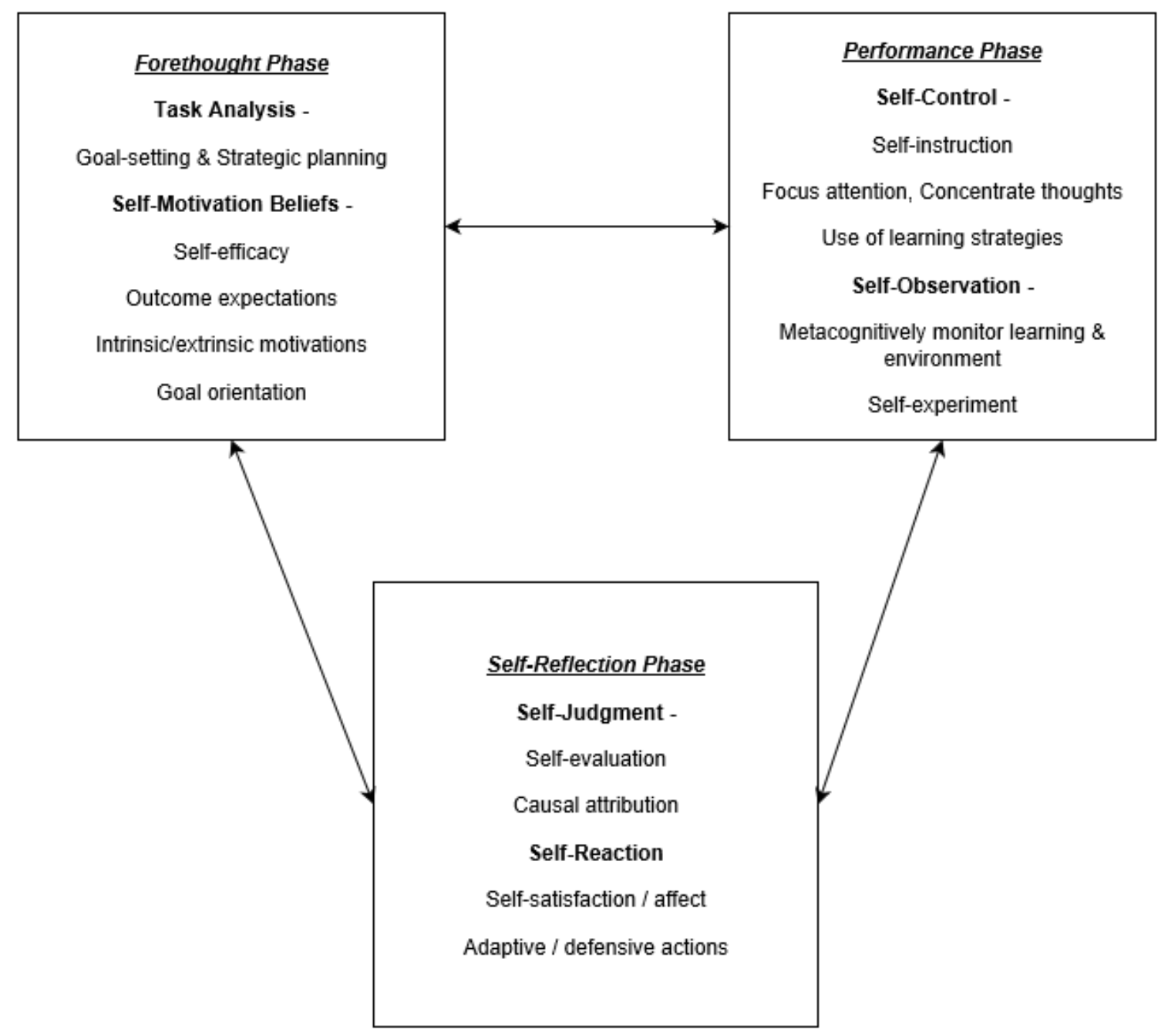

Figure 1 shows the three phases of the McPherson and Zimmerman (2011) selfregulation theory. The theory posits that when students are given a learning goal they first engage in forethought, then attempt to achieve the goal in the performance phase and finally self-judge and self-react in the self-reflection phase.

In the performance phase, students work to achieve goals. They engage in selfcontrol behaviors as they focus their attention on the subject and concentrate thoughts on the comprehension of the information, employ and modify learning strategies and goals, set sub-goals, and metacognitively monitor their progress while maintaining a motivated 
disposition. In the self-evaluation phase, students engage in self-reflection and selfjudgment as they evaluate their achievements and assign causal attributions to their progress. They will experience self-satisfaction (homeostasis) or consider defensive behaviors such as laying blame on others and adaptive actions such as making new goals and plans.

When students take responsibility for learning and assess differences between their current abilities in reference to their new learning goals, they engage in a cyclical, context-specific process that includes self-generated thoughts and feelings, as well as modifiable sets of personal skills. They also think along metacognitive lines, actively monitor, regulate, evaluate their progress, and modify their learning behaviors based on self-assessment feedback.

This theoretical framework meets Bandura's (1971) social cognitive criteria for defining self-regulation as a triadic structure in that it relies upon a reciprocal causation of influence along a negative feedback loop between three discrete factors that exist in a homeostatic relationship: (a) personal behavior, (b) personal domain-specific learning abilities, and (c) environment. In this model there is a reciprocal causation of influence between the factors and each can influence or be influenced by the other via the negative feedback loop. A reciprocal causation of influence, as defined by McPherson and Zimmerman (2011) states that any one factor in the triad can influence or be influenced by the others. A negative feedback loop occurs as a response by one factor to a stimulus from another (McPherson \& Zimmerman, 2011).

The response causes a decrease in the function of a behavior, thus leading to a restoration of homeostasis between factors. For example, when an individual observes a 
discrepancy between their current skill level and a desired skill level, they engage in actions to reduce the discrepancy. Thus, when individuals monitor the current status of their action with a reference value (stimulus) self-regulation is composed of two basic processes: They make a comparison through an assessment and engage in the action necessary to progress by locomoting. Together, the assessment and locomotion represent the two basic components of self-regulation (Carver \& Scheier, 1998).

McPherson and Zimmerman's (2011) music learning theory also posits six psychological dimensions: motive, method, time, behavior, environment, and social factors. They relate either social processes of learning where help is provided or to internal processes where students are self-regulating their learning.

Table 2. Psychological Dimensions of Self-Regulation

\begin{tabular}{llll}
\hline Dimension & Scientific & Social & Self-Regulation \\
& Question & Process & Processes
\end{tabular}

$\begin{array}{llll}\text { Motive } & \text { Why? } & \begin{array}{l}\text { Intrinsic and extrinsic } \\ \text { motivations }\end{array} & \begin{array}{l}\text { Self-set goals, } \\ \text { Self-efficacy, } \\ \text { Self-reinforcement }\end{array} \\ \text { Method } & \text { How? } & \begin{array}{l}\text { Guided instruction, } \\ \text { modeling }\end{array} & \begin{array}{l}\text { Self-initiated learning } \\ \text { strategies }\end{array} \\ \text { Time } & \text { When? } & \begin{array}{l}\text { Socially planned and } \\ \text { managed time use }\end{array} & \begin{array}{l}\text { Self-planned and } \\ \text { managed time use }\end{array} \\ & \text { What? } & \begin{array}{l}\text { Performance is } \\ \text { socially monitored } \\ \text { and evaluated }\end{array} & \begin{array}{l}\text { Performance is self- } \\ \text { monitored and evaluated }\end{array} \\ & & \text { Environment is } & \text { Environment is structured } \\ & & \text { Structured by others } & \text { by self } \\ \text { Environment } & \text { Where? } & \text { Help is provided } & \text { Help is sought personally } \\ & & & \end{array}$


In table 2 the dimensions relate to the three phases of the self-regulation problemsolving process and levels of self-regulatory development found in students. The questions provide a basis for understanding where the key dimensions occur and what self-regulation processes can be used.

Another feature of McPherson and Zimmerman's (2011) music learning theory is a hierarchical learning table that identifies four skills levels of self-regulating learning (table 2). They are observational, emulative, self-controlled, and self-regulated. Research findings purport basic level self-regulation occurs in children by the age of three and the ability to fully self-regulate learning can be realized by the age of thirteen. In this hierarchical model, McPherson and Zimmerman (2011) assert that self-regulation begins as a social activity but becomes a self-directed initiative on the part of the student as teachers model, define goals (task structuring), and support motivation (Schunk \& Zimmerman, 2003).

McPherson and Zimmerman's (2011) theory of self-regulation in music learning will assist in the development and analysis of this research study by providing a framework from which to observe the participants and assess the extent to which they discuss with their students the benefits of self-regulating their learning. McPherson and Zimmerman (2001) also identifies four developmental levels of self-regulatory skills. They are observational, emulative, self-controlled, and self-regulatory. 
Table 3. Developmental Levels of Self-Regulatory Skill (McPherson \& Zimmerman, 2011)

\begin{tabular}{l}
\hline Level of Development $\quad$ Description \\
Influences
\end{tabular}

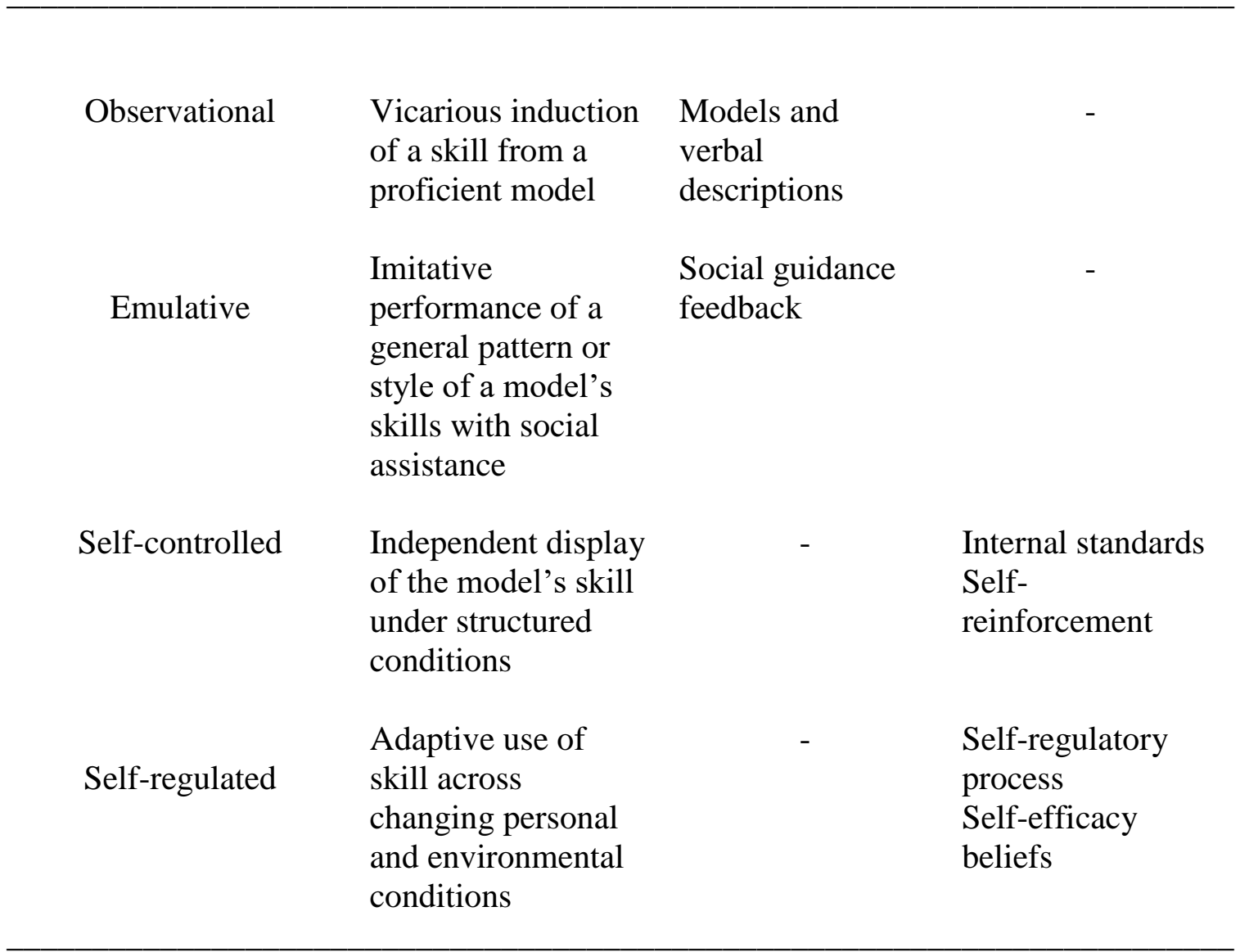

Table 3 shows how as students develop independent self-regulatory skills as they progress through the developmental stages. Self-regulating students move away from social influences who act as models that provide them with verbal feedback and descriptions to realizing internal standards of their own, acquiring a sense of selfefficacy, and using their skills in different learning situations.

Each psychological question can be associated with the three phases of the problem-solving process and were incorporated into the interview protocols. In the analysis of the interview questions, the theory helped identify the strategies the 
participants used to instruct their students in self-regulation and identify the importance they gave to the level of regulatory skill their students were achieving. I believe that this study uncovered insights that could add to the current scholarship on music teaching and learning among children and adolescents.

McPherson and Zimmerman's (2011) theory of self-regulation in music learning will assist in the development and analysis of this research study by providing a framework from which to observe the participants and assess the extent to which they discuss with their students the benefits of self-regulating their learning. Each psychological question can be associated with the three phases of the problem-solving process and were incorporated into the interview protocols. In the analysis of the interview questions, the theory helped identify the strategies the participants used to instruct their students in self-regulation and identify the importance they gave to the level of regulatory skill their students were achieving. I believe that this study uncovered insights that could add to the current scholarship on music teaching and learning among children and adolescents. 


\section{CHAPTER THREE: METHODOLGY}

\section{Introduction}

The purpose of this research study was to gather meaningful information that would contribute to the field of music education research and improve the quality of instruction in music rooms across the country. After considering the nature of the research questions and devising an ontological database from an amalgamation of the research findings I read, I selected an instrumental collective case study methodology for this study (Stake, 1995; Yin, 2014). An instrumental collective case study is a detailed empirical inquiry that investigates a contemporary phenomenon but lacks much preliminary research. The six participants used for this study were each treated as a "case" in a bounded system that could be examined in a real-life context. (Stake, 2006; Yin, 2003).

\section{Statement of the Problem}

The ability to self-regulate learning becomes especially important as children and adolescents, who upon entering a school music program, are frequently required to spend large amounts of time in solitary practice periods learning a musical instrument where there is an absence of immediate instructional feedback from a teacher. As a consequence, students who enter school music programs, but lack the knowledge, skills, and strategies necessary to solve their own learning problems, fall behind, fail, or ultimately drop out (Boyle, De Carbo, \& Jordan, 1995; McPherson \& Zimmerman, 2011; Miksza, 2012; Sandene, B. A., 1994). 


\section{Research Questions}

1. What instructional strategies do instrumental music teachers report using to help their students become self-regulated learners on their musical instruments?

2. How do instrumental music teachers assess their students' levels of selfregulatory development with respect to their instrumental music performance skills?

3. What self-regulation strategies do instrumental music teachers perceive as most significant for students learning to play musical instruments?

\section{Case Study Methodology}

A case study is an empirical enquiry that "investigates a contemporary phenomenon within its real-life context, especially when the boundaries between phenomenon and context are not clearly evident" (Yin, 2005, p. 13). It is used in the social sciences to illuminate the motives and methods of study participants and the results that occur from their actions. Case studies generally focus on contemporary events and are a good choice when control over behavioral events are not needed. The strategy behind using a case study methodology also rests on the need to answer questions related to how and why. (Yin, 2014). Nevertheless, Stake (2006) takes a slightly different approach from Yin (2014) as he suggests that case study reporting should follow one of three paths: chronological or biological development of the case, researchers view of coming to know the case, or a description of major components of the case. 
Case studies follow basic procedures and protocols including the maintenance of a collection of transcripts that house an unbroken chain of evidence. They also help establish boundaries for the researcher. Indeed, a distinction cannot be drawn between the phenomenon under investigation and the context in which it is found. Lastly, case studies also make it possible to consider alternative points of view with the examination of the evidence.

\section{Interpretivist's Research}

My approach to case study draws from my interpretivist view of research. Interpretivism is a naturalistic approach to data collection and is based on the observations of the investigator. It can also include interviews, which I find personally and appealing. There is, however, an axiological disadvantage to the interpretivist approach in that the investigator may inadvertently inject personal values into the research. As a consequence, the investigator may also inject bias. This can have the effect of creating more than one interpretation of the results. I intend to address the issue of bias by asking interview questions in such a way that each of the participants is able to clearly state his/her honest beliefs. Moreover, given that the investigator collects detailed data, it is impossible to form generalizations from the data if it is highly personal in nature. Nevertheless, methodologically, the research topic in this case can be studied using inductive logic, studied within its context, and an analysis of the participant's perceptions of the importance of teaching their students about self-regulation can be made. The factors that impact teacher perceptions and the outcomes music students realize as a consequence of their ability to engage in self-regulation can also be studied in great detail. 
Ontologically, the interpretivist approach holds that the nature of reality is socially constructed, that there are indeed multiple realities. This is in opposition to the positivist approach which argues that reality is objective and singular (Stake, 1995). When watching two middle-school music students leave the same rehearsal, one happy about the outcomes of his efforts and the other dejected, it is easy to appreciate the suggestion of multiple realities. Their words and expressions provide ample evidence that each holds different views of a situation.

Interpretivism also holds that the goal of the research is to develop an understanding of a phenomenon and draw conclusions and offer implications. The interpretivist approach also helps the investigator identify and focus on what is unique and integral to the research topic, to create meanings, to determine the kinds of problems people are faced with, and how they deal with them in a participatory manner. In a rhetorical sense, I also prefer to use qualitative terminology and a formal voice. Lastly, while using an interpretivist approach, I intend to write an engaging narrative using language appropriate for qualitative research.

\section{Research Design}

\section{Overview of Participants}

Due to the nature of my research design, and after obtaining IRB approval, I invited six music teachers, drawn from a list of practicing instrumental music teachers working in schools throughout a midwestern state, to participate in my research study after a process of purposeful sampling (Creswell, 2007). The reason for using purposeful sampling was to target primary data sources with experience teaching children and 
adolescents, identifying students who struggle to learn, supporting students who are at risk for dropping out of a music program, and who could best answer my research questions.

Additionally, each participant was required to be a licensed practitioner holding at least a bachelor's degree and have current or past experience working with middle school or high school bands or orchestras composed of students aged eleven to eighteen. They were five male instructors and one female instructor and varied from six to over thirty in the number of years they have been teaching. I gave them pseudonyms to conceal their true identity and protect their privacy (see Table 4).

Tim, a man in his early sixties, was a retired band director with thirty years of teaching experience at the middle school and high school level and projects his views of music teaching and learning as a middle school and high school band director. He found that music educators have a responsibility to teach their students good personal behaviors as well as good musicianship. He also believes that parents should be active participants in the learning process.

Ivan is a middle school and high school band director in his late twenties and has been an instrumental music practitioner for six years. As a result, he has developed his own views on teaching. He believes that modeling is important in music learning and that students begin to recognize and value the importance of goal-setting and memorization as they advance through his program.

Gertrude, was a middle school and high school orchestra teacher in her early thirties. She has been teaching for eight years and as a result, has formed certain opinions about how her students learn and how teaching should be conducted in the music room. 
It is important that her students form good habits that get practiced in the context of skill building and music performance. She also believes that students should learn to be accountable for their own behaviors and experience the consequences of them for better or worse.

Evan was a middle school and high school director in his late thirties and has been teaching for fourteen years. In addition to concert band, he also teaches jazz band and is a Boy Scout Lions troop leader. He believes that formative assessments are integral to understanding student progress and that students, during the course of their education, should be exposed to a variety of real-life learning experiences.

Richard, who was in his late fifties, has been working in the field of education for twenty-two years. Much of that time was spent in middle school and high school music rooms serving as a band director. For the past twelve years, he has been a district superintendent. He holds advanced degrees in education and additional certification in administration. He insists that instruction in music is sequential in nature and that practitioners should build on student's prior knowledge before teaching new skills. Richard also believes that student progress is evidenced through periodic performance assessments, and that the rewards music students realize from participating in school music programs enrich their lives.

Samuel was a forty-five-year-old orchestra conductor and has been teaching for twenty-six years. He has multiple advanced degrees and a wide range of teaching experiences to draw from. As an educator, he values modeling as an instructional strategy and argues that the students who are learning best are those who are involved in a down right love affair with their instruments. 
Overall, the demographics of the participants demonstrate that they have each acquired specialized degrees that prepared them for careers in teaching instrumental music. They have experience teaching band and orchestra in grades six through 12 .

Table 4. Participant's Demographics and Teaching Background

\begin{tabular}{|c|c|c|c|}
\hline Participant & Education & Subject \& Grades & Years of Experience \\
\hline Tim & $\begin{array}{l}\text { Master's degree } \\
\text { Bachelor's degree }\end{array}$ & $\begin{array}{l}\text { Band: grades 7-12 } \\
\text { and adults }\end{array}$ & Thirty-five years \\
\hline Ivan & Bachelor's degree & Band: grades 6-12 & Six years \\
\hline Gertrude & $\begin{array}{l}\text { Master's (in progress) } \\
\text { Bachelor's degree }\end{array}$ & $\begin{array}{l}\text { Orchestra: } \\
\text { Grades 6-12 }\end{array}$ & Eight years \\
\hline Evan & $\begin{array}{l}\text { Master's degree } \\
\text { Bachelor's degree }\end{array}$ & Band: grades 7-12 & Fourteen years \\
\hline Richard & $\begin{array}{l}\text { Education Specialist } \\
\text { Master's Degree } \\
\text { Bachelor's Degree }\end{array}$ & $\begin{array}{l}\text { Band: grades 7-12 } \\
\text { District } \\
\text { Superintendent }\end{array}$ & Twenty-two years \\
\hline Samuel & $\begin{array}{l}\text { Doctor of Musical Arts } \\
\text { Master's degree } \\
\text { Master's degree } \\
\text { Master's degree } \\
\text { Bachelor's degree }\end{array}$ & $\begin{array}{l}\text { Orchestra: } \\
\text { grades } 7-12 \\
\text { and adults }\end{array}$ & Twenty-five years \\
\hline
\end{tabular}

All of the participants have a minimum of a bachelor's degree. Five participants have master's degrees. One participant has a bachelor's degree, three master's degrees, 
and a Doctor of Musical Arts degree. Together, the participants have a combined 110 years of teaching experience.

\section{Researcher Role}

My role as researcher was to collect data through interviews with participants and code the data. As the interviewer, I used both predetermined questions, which were asked in the same order for each participant, as well as probing questions as necessary. The questions focused on situations, actions, time, and results and I kept them moving towards the topic of interest.

\section{Data Sources}

I intended to find out more background information from each of the participants once the interviews began. I asked them what led them to become music teachers, which instruments they play, where they received their training and education, how long they have been teaching, and what grade levels they have taught. I also determined how long they have been working at their current teaching assignment and what other responsibilities they held.

In addition, I determined their personal views on music learning: how they, in fact, learned to play an instrument as students and as teachers how they believe their students learn best. I also wanted them to elaborate on their early musical experiences. Other background questions related to their views on learning influences in and out of school. Did they change instructional strategies based on age and experience, or does the same strategy work on everyone?

Of particular interest was their understanding of how their students are practicing at home. Did practice behaviors differ by age group? Did they differ by experience? 
What factors most influenced student practice at home? Investigating these questions using participants who experienced these issues on a daily basis provided a rich source of primary data. The results may pioneer new ways of thinking about teaching music students what to think about when they go home and practice.

\section{Interviews}

For the purposes of this research study, each of the six participants were questioned during two separate semi-structured interviews. Semi-structured interviews use both open and closed questions and incorporate follow-up questions such as how and why (Adams, 2015). I used semi-structured interviews as I had minimal opportunities to interview the participants due to their work schedules. I prepared my questions ahead of time and let them express their responses in their own way and on their own terms. This gave them the opportunity to discuss issues that were important to them. Each interview took approximately ninety minutes to complete. In total, the interviews took about fifteen hours total. They illuminated their pedagogical practices and their thoughts on student self-regulated learning. This produced a total of twelve data points.

In interview one, I gathered information on the participant's backgrounds, their current teaching assignments, their views on teaching students to play instrumental music, the instructional strategies they use for teaching students to become independent learners, and any other views they have on instruction strategies and students' musical instrument learning. When trying to understand their perspectives on their own practices as educators, I find it helpful to know how long teachers have been working and where they got their educations. A handout with the definition of learning strategies used by self-regulating students will be provided to the participants (Appendix B). 
In interview two, I gathered information on how teachers support independent learning with their students as well as how they support home practice. I also questioned them about how they assess the degree to which their students are learning independently at home.

\section{Strategy List}

Also, during the course of the interviews, I presented the list of Zimmerman (1989) self-regulation strategies to each participant and asked them to tell me which strategy they thought was most important. The participants took the time to consider the meaning of each strategy and then offered their opinions.

\section{Protocol}

A protocol template was developed to guide the interviews to completion (Appendix D). To gather the participant's thoughts on the topics under investigation fully, flexibility was designed into it. Opportunities to follow-up on ideas and thoughts that might have arisen during the interviews were essential to the process and taken into consideration.

\section{Data Analysis}

I conducted a with-in case analysis to arrive at an understanding of each individual participant's account of their experiences in the context of their music rooms. The key elements of data emerged as themes. I conducted a cross-case analysis of the themes to deepen my understanding of the participant's perceptions and determine their relevance and applicability as they relate to the McPherson and Zimmerman (2011) selfregulation in music learning theory (Miles \& Huberman, 1994). 


\section{Coding Plan}

In accordance with a case study research approach, the transcriptions from all interviews were coded for with-in case themes relating to teacher perceptions of selfregulated learning and home practice as identified in the McPherson and Zimmerman (2011) theoretical framework. Triangulation was achieved through a cross-referencing of data. I also looked for similarities and patterns in the follow-up questions and statements that arose from the interviews (Creswell \& Poth, 2018).

The purpose of the coding plan was to arrive at a better analysis of the data. Step one of my plan was the use of the music learning theory and my three research questions as a basis for my research study. With that, I collected data from participant interviews. After creating a repository for the data, I created transcripts from the interviews. All interviews were recorded on a portable digital recorder and transferred as audio files to a laptop computer. Transcriptions were made when the audio files were played back on computer software called Transcribe! After completing the transcripts, I moved forward to step two.

Next, I created initial codes from the interview transcripts that derived from the constructs in the research questions. I studied fragments of data such as words, phrases, thoughts, and coded them by assigning a word or short phrase as a summative attribution to them. Then, I engaged in focused coding to determine what seemed to be the most useful initial codes. This allowed me to select, separate, sort, categorize, summarize, synthesize, and account for the data in a more incisive way. I also studied fragments of data in the search for emerging open codes. 
In step three, I tagged and labeled the data. Each label was categorized and assigned a different color during the process. This helped distinguish shared characteristics and lead to step four in which the categories were organized and sorted. From the organization of the categories, I created themes and subtheme generalizations as the last step to my plan. The themes generated from the categories were abstract and mutually exclusive and identified central problems and did not resemble codes. Rather, they had more depth and were more specific. I used phrases when creating themes to give them direction.

\section{Cross-case Analysis}

Cross-case analysis examines themes, similarities, and differences across the cases. After completing a with-in case analysis, I compared and contrasted the units of analysis from each participant and constructing meaningful relationships to arrive at new themes. At the end of the data analysis process I addressed each specific research question and drew conclusion I discuss the implications of the findings as they relate to instrumental music education (Creswell, 2007; Creswell \& Poth, 2018; Stake, 2006; Yin, 2014). 


\section{Ethics, Researcher Positionality, and Reflexivity}

\section{IRB Approval and Consent}

Approval from the Institutional Review Board was received November 8, 2018. Approval from the review board was needed as the research involved interaction with live human subjects and access to their private, identifiable information. Prior to the beginning of each interview, I discussed informed consent (Appendix C) with the participants, their right to withdraw from the study at any time, the purpose and procedures of the study, confidentiality, known risks, and the expected benefits I had about the findings from the research. I also answered the questions they had about the study. Each participant was given a pseudonym to protect their identity. All data are being stored digitally using passcode protected computer software in a locked and secure location.

\section{Positionality}

I am an instrumental music teacher from New York State working toward my doctoral degree in music education at the University of Missouri. I shared many of the working experiences and teaching challenges as the participants of this study. Over the years, I have had the benefit of numerous opportunities to witness primary and secondary grade instrumental music students both fail and succeed in school music programs. Consequently, when it comes to disillusioned children and adolescents, I have become rather interested in finding out why. With few exceptions, it comes down to the students' ability to learn to adequately practice on their own.

It has always been a pleasure to watch an instrumentalist relish the personal satisfaction that comes from successfully performing music and always heart-breaking to 
see one drop out of a music program because they cannot keep up. Most disappointing of all is to think that the cause of such failure was likely preventable had they developed the skills necessary to mitigate their learning problems. When faced with the task of learning in relative isolation away from their teacher's feedback, students must learn to solve their own problems. They must determine what it is they have to learn, come up with a learning strategy, and find a time and place to study. As I began to pursue my doctorate, I chose to study how teachers could nurture self-regulated learning in students and support their independent, self-directed learning in instrumental music.

\section{Trustworthiness}

I used several strategies to ensure trustworthiness within this study which I will discuss here. Trustworthiness has been defined in terms of credibility, authenticity, transferability, and dependability (Lincoln \& Guba, 1985). Authenticity was realized through the accurate interpretations of the participant's meaning. The dependability of the results of the study, though subject to change, were established through an auditing of the research process and the use of multiple coders who held a consensus of the code names and themes. I also identified the cultural context of the environment my participants worked in to identify and minimize inaccuracies and inconsistencies (Creswell, 2007).

As Merriam (1988) suggests, I identified the biases and assumptions I hold as the researcher, I provided comments on my previous educational experiences relating to the research topic and I addressed potential prejudices that may have shape my views relating to this research. The interviews were transcribed with the aid of a computer software program that was capable of processing the audio files from the portable digital audio 
recorder. Playback of the audio files were heard through high-quality audio monitors renowned for their life-like realism. Transcriptions were made on a computer software program. Trustworthiness was further ensured with triangulation, referential adequacy, peer debriefing, thick descriptions, a coding plan/audit, and member checking.

\section{Triangulation}

Triangulation promotes data validation through cross verification of multiple sources and aids in helping develop an understanding of a particular phenomenon. Of the four types of triangulation available to researchers, this research study will rely on data source triangulation (Denzin \& Lincoln, 2008). My data source triangulation helped me to understand teacher perceptions from different perspectives.

\section{Referential Adequacy}

Referential adequacy requires the researcher to identify and archive some of the collected data but not analyze it. Only the remaining data is then analyzed and used for preliminary findings (Lincoln \& Guba, 1985). In addition to data that were analyzed, my data collection also includes data that were not analyzed because it did not address the research questions.

\section{Peer Debriefing}

Peer debriefing is "a process of exposing oneself to a disinterested peer in a manner paralleling an analytical session and for the purpose of exploring aspects of the inquiry that might otherwise remain only implicit within the inquirer's mind" (Lincoln \& Guba, 1985, p. 308). A peer debriefer can keep written records of meetings and act as a secondary outside check on the research process. A peer debriefer can help uncover 
researcher bias and provide the researcher with an opportunity to defend emerging hypotheses to see if they are reasonable (Lincoln \& Guba, 1985).

\section{Thick Description}

Thick descriptions, as indicated in Geertz (1973), give readers the opportunity to decide if the results are transferable. Thick descriptions make it possible to not only write in detail about the participants in the study but also to write about their behaviors in the context of the settings in which they occur (Creswell, 2007; Rolfe, 2006). Thick descriptions in this research include themes, subthemes, data claims, and data analysis.

\section{Coding Plan/Audit}

The coding plan involves focusing on the theoretical framework and research questions as I code data. From the codes, categories will emerge. From the categories, themes will emerge. A chain of evidence, as described in Yin (2003), acts as a case study tactic and provides construct validity during the data collection phase. I established a chain of evidence during the coding process.

\section{Member Checking}

Member checking is a process whereby the researcher takes the data, categories, themes, interpretations, and conclusions back to the participants in order to establish the validity of his account. Drawbacks to member checking include the fact that different members may have different views of the same data (Lincoln \& Guba, 1985). Nevertheless, the goal was to illuminate and underscore the themes and perspectives relative to the research questions and to give participants an opportunity to correct errors or challenge interpretations (Silverman, 2005). I sent each participant an overview of the 
themes that were generated from the coding process and asked them to comment on them.

\section{Limitations}

An appealing characteristic of qualitative research is that a researcher can collect, analyze, and interpret data that would otherwise not be easily quantified. As a result, various forms of qualitative research can be seen permeating research journals in the social sciences. Nevertheless, qualitative research has limitations.

This study was limited because I used myself as the data collection instrument. My research skills were likely not as good as other, more experienced researchers would be, and any idiosyncrasies I may possess could have affected the research process at different steps - including the participants' responses to my interview questions. Furthermore, as a researcher and practitioner, I am also prone to bias in that I feel that educators have a responsibility to teach their students about the inherent problems they are likely to face as they begin to study instrumental music. Another limitation is that of the small purposive sampling size I used for this study. Finally, the fact that I only used interviews as sources of data significantly limits this study. I can't really know that what the participants are telling me they do is what they really do.

\section{Summary}

In this chapter I explained my research methodology. My intention for this study was to determine the importance instrumental music teachers gave to providing instruction in self-regulation to their students. My hope was that the research would contribute meaningful knowledge to the field of music education research and improve 
the quality of instruction in music rooms across the country. In that spirit I chose to use an exploratory collective case study methodology.

This case study methodology relied upon a bounded system that included multiple interviews with six different participants. Each participant was treated as a separate case. The purpose was to draw themes across the cases. The participants, who varied in age, gender, geographic location, and experience, were asked to describe why the different dimensions of self-regulation were important, how they assess their students' level of self-regulatory development, and the self-regulation strategies they perceive as most important.

I discussed ethics, my positionality, and the trustworthiness of the research. I also discussed the limitations to my research, explained how I obtained IRB approval, and when I conducted interviews to collect data. Finally, I explained where the data were to be securely stored and the coding process. 


\section{CHAPTER FOUR: FINDINGS}

\section{Introduction}

The purpose of this instrumental collective case study was to explore instrumental music teacher perceptions on the importance of providing instruction in self-regulation to their students. The McPherson and Zimmerman (2011) music learning theoretical framework (Appendix A) and the Zimmerman (1989) list of self-regulating learning strategies (Appendix B) were used to interpret instrumental music teachers' perceptions and research questions.

\section{Statement of the Problem}

The ability to self-regulate learning becomes especially important when children and adolescents, upon entering a school music program, are frequently required to spend large amounts of time in solitary practice periods learning a musical instrument where there is an absence of immediate instructional feedback from a teacher. As a consequence, students who enter school music programs, but lack the knowledge, skills, and strategies necessary to solve their own learning problems, fall behind, fail, or

ultimately drop out (Boyle, De Carbo, \& Jordan, 1995; McPherson \& Zimmerman, 2011; Miksza, 2012; Sandene, B. A., 1994).

\section{Research Questions}

The following research questions guided this research:

1. What instructional strategies do instrumental music teachers report using to help their students become self-regulated learners on their musical instruments? 
2. How do instrumental music teachers assess their students' levels of selfregulatory development with respect to their instrumental music performance skills?

3. What self-regulation strategies do instrumental music teachers perceive as most significant for students learning to play musical instruments?

This chapter is organized around the thematic categories that emerged from the coding process (Creswell, 2007). Initial coding began with the assignment of labels that summarized analysis of the data segments gleaned from the interview transcripts. The labels were then categorized (Charmaz, 2006). They include: help students learn, support and develop self-regulation in students, student accountability, barriers to learning, and relationships. Themes, guided by the McPherson and Zimmerman (2011) music learning theory and the self-regulation strategies identified in Zimmerman (1989), emerged from the categories. These themes are illustrated in the following table, and will be described in the sections that follow (see Table 5). 


\section{Table 5. Participant's Themes}

Tim

Theme I: Teachers should model personal skills as well as musical instrument skills

Theme II: Practice is the best of all instructors

Ivan

Theme I: Remember the past if you want to understand the future

Theme II: Imitation in practice is half the battle

Theme III: Personal efforts affect music learning

Gertrude

Theme I: Instrumental music teaching happens in a prescribed order

Theme II: Meeting social standards encourages students to self-regulate their learning

Theme III: Teachers do not have all the answers

$\overline{\text { Evan }}$

Theme I: Knowledge is gained by watching others

Theme II: Assessments help students take personal responsibility for their own education

Theme III: Learning comes from experiences

Richard

Theme I: Structure music programs to build on fundamental precepts

Theme II: Be mindful of student learning needs

Theme III: Instruction should begin based on what the student already knows

Samuel

Theme I: Teaching and learning happen through relationships

Theme II: Mastery of music starts and ends with honesty

None of the participants mentioned that they had ever received instruction in the problem-solving process of self-regulation, the different ways to assess self-regulation in their students, or the significance of self-regulation strategy use prior to the interviews. I present the findings of this study in seven sections. The first six sections provide a

detailed analysis of each case including Tim, Ivan, Gertrude, Evan, Richard, and Samuel. 


\section{Tim: The Sage}

Tim has been a musician since the age of five and his principal instruments are piano and trumpet. He is a graduate of a midwestern music conservatory and became an educator after realizing the strength of his teaching abilities. He has been teaching brass, woodwind, and percussion instruments to students in grades six through 12, as well as to adults, for over thirty years.

Overall, Tim's teaching practice relies on a cyclical process of instruction and formative assessments that inform and complement each other. In his music room he draws on a Wood, Bruner, and Ross (1976) scaffolding precept as he conveys a sense that one day his voice will become his student's voice. Consequently, he teaches to the whole person and while doing that, makes an effort to build a positive relationship with them. Analysis of Tim's data revealed two themes: Teachers should model both personal behavior skills and musical skills, and practice is the best of all instructors.

\section{Theme I: Teachers Should Model Personal Skills as Well as Musical Instrument}

\section{Skills}

Tim's teaching experiences have helped him forge a pedagogy that emphasizes "firm control" (Interview 1) of the learning process and a belief that "modeling" (Interview 1) performance skills, domain specific learning strategies, and certain personal behaviors gives his students the "right ideas" (Interview 1) about the art and science of instrumental music performance. As a result, he teaches technical skills on and demonstrates how to be successful musicians who need to maintain working relationships with their peers and other musicians. 
Modeling is a form of social learning whereby students first observe their teacher demonstrate a specific skill and then attempt to imitate it on their own through repeated practice trials (Schunk, 2012). Because learning coordinated motor movements usually requires substantial time during a music lesson, modeling is a natural choice for music teachers to employ. It is direct and efficient and helps the student vicariously learn skills that they can refine in enactive practice.

Tim emphasized his view that modeling not only helps his students learn to play their instruments but also helps with "self-discipline things" (Interview 1) and personal character because in fact "you're not just training musicians" (Interview 1). He reiterated his belief that addressing personal character issues during instruction periods underscores "the difference between somebody who knows how to teach and somebody who doesn't" (Interview 1). His belief is that good personal behavior complements musical artistry. "You're teaching them to be nice too!" (Interview 1). He indicated that, as a teacher of students who would soon be leading their own lives, "you want to train them to be good consumers of music and good parents of children" (Interview 1). Tim submits that his students are essentially going to grow up and become parents and citizens and not necessarily professional musicians.

Nevertheless, he argued that with too much modeling at once students get overwhelmed. "You have to start simple" (Interview 1). He recommends modeling only small parts of complicated skills at a time and then providing students with the opportunity to master the individual parts before trying to execute the whole skill. "If you do it all at once, it's too confusing" (Interview 1). He lets his students practice their 
skills until "it was second nature to them" (Interview 2.) Enactive drill and practice habits help develop performance skills in instrumental music students.

Tim also takes measures to make sure that his students grasp musical concepts.

He does this through expository teaching methods where he explains musical meanings in terms of relationships. Accordingly, cognitive comprehension strategies involve "creating visuals" written "on the board" (Interview 1). This is especially true when students are learning to decode music notation or evaluate the differences between musical elements. "I wrote the lyrics to the notes on the board and their eyes went wide, so they got the notes" (Interview 1). He also teaches by integrating multi-media, audiovisual, and computer networks in the classroom. "I like to take advantage of technology when I can" (Interview 1). Technology, and especially the internet, help students learn faster and realize more success from their efforts.

Tim likes to model behaviors for his students as well because "they learn by watching" (Interview 1) and they have to be able to behave in ways that facilitate their learning in social situations. "You have to have a few friends who will tell you the truth" (Interview 2). Teaching appropriate behaviors through modeling also lets the students know that "you care more about them and you care about them as a human being and as a student than as a musician" (Interview 1). Caring on the part of the teacher fosters learning and promotes healthy relationships.

Relationships are supported by developing a sense of trust between the teacher and student. "As a teacher, coming up with a good relationship with the student is really important" (Interview 1). It facilitates learning and helps the student learn to "listen to other people." In part, this is done by "keeping them involved and letting them know 
they are relevant." Tim also noted that once they see that you are investing in them and they understand that they indeed have a relationship with their teacher, "they cut out the craziness and stuff."

There are other relationships that are important as well. Tim also posits that, "it is important to have a healthy relationship with the parents or caregiver" (Interview 2). One central reason for that is because some students "will try to pit the teachers against the parents and the students need to realize the adults are on the same team" (Interview 2).

When building relationships, Tim emphatically stated that "there's nothing wrong with being nice to them" (Interview 1). He likes to "stay away from too much of a negative thing" (Interview 1). He always "refuses to speak in terms of winning and losing" (Interview 1), and emphatically states that "I would never ask them to do anything that I would never do" (Interview 1). Instead, he "guides" them and doesn't "force them" (Interview 2) to do anything they are not prepared to do as musicians or as individuals. Modeling facilitates a transfer of knowledge and can persuade students to believe that they can learn competently (Rosenthal \& Zimmerman, 1978). During the modeling phase of instruction teachers should remember that the student needs to attend to learning, process the demonstration, and practice the skill for themselves. Teacher's should be consistent in their instruction or students may discount the value of the instruction.

\section{Theme II: Practice Is the Best of All Instructors}

The point of music practice is to maintain skills and knowledge and synthesize new skills and knowledge received in a lesson. Practice is essential for the mastery of skills such as sight-reading or the automatization of complex procedures that are only 
acquired through a process of inculcation. As far as practicing in instrumental music, Tim advises students with high aspirations that home practicing periods should last 6-8 hours per day. "No phone, no tv" (Interview 2).

Tim recounts having one such student who needed no encouragement to go home and practice after school. He was very enthused about becoming a professional musician. "You don't get it," he stated. "I am going to be a professional trombone player" (Interview 2). Other students need to be motivated to practice. To accomplish that Tim uses a strategy whereby he first compliments the students on a certain aspect of their playing like their breathing and then offers a critique to improve their performance. "You know what, that kid is going to go home and he is going to practice" (Interview 1). When he returns, he's better. "They will see the value in the time they are spending and they will want to do it more" (Interview 1). The idea being that a student's enthusiasm to practice will increase if they like the rewards their efforts bring. Other students don't always respond so positively to instructional input. "So how do I get them to practice? I grade them on it" (Interview 2). I have them "play in front of everyone. That helps them develop the guts to play in front of people" (Interview 2). Tim motivates his students to practice with extrinsic reasons.

Tim claims that the most impactful strategy on student learning is when they "record themselves" (Interview 2) and then listen back to it. He maintains that students who record their performances at home during a practice period, regardless of their aspirations, are better able to assess where they are with respect to the results they would like to achieve. "Kids have to record themselves so they can hear what they're doing" (Interview 2). He tells them, "they can just video tape themselves. Just do it" (Interview 
2). This is a strategy he models for them in the music room. He indicated that recording performances and then taking the time to listen back and analyze the quality at different points helps his students assess their artistry. The question he wants them to ask themselves during playback is, "what happened?" (Interview 2). This gives the students the opportunity to identify both the good and bad points of their performances and then come up with a plan to make the corrections they need to realize the performance level they want for themselves.

Another important home practice issue is a home practice space. Tim advises his students to find a place where 'there's no distractions or where you won't bother anyone else" (Interview 2). Once that is done, "practice like I'm there with you so you can make judgments about what you're doing wrong" (Interview 2). The idea being that they will stay on track better and think about what he would say to them if they were with him in the music room. He also helps them "set the correct type of artistic goals" (Interview 1) during class for their home practice periods. Goal setting has the added benefit of helping his students "monitor themselves in both their practice time and their musical results" (Interview 1).

For other students, Tim posits that they may be assessing the wrong issues when it comes to their personal progress. Musical skills take a long time to master and he believes that some students become disillusioned with music because they don't see immediate results. One particular student "was using the wrong yard stick on himself." To address that he gave him "little bench marks" spread out over time so he didn't have to worry so much about being good enough. He just had to meet those bench marks and the learning issue vanished. 
One thing he noted was that he does not use "practice cards" to assess student's practice behaviors. When doing that, "the card becomes the thing, not the music" (Interview 2). So instead, he sets standards and rather than monitor actual student practice time, assesses how well the students are meeting the standards. "You just have to hold them accountable" (Interview 2). It's easy to see if students have been practicing, because "you can observe the differences in their playing from week to week" (Interview 2). Tim motivates his students to be accountable with grades.

Students can also demonstrate how well they are learning on their own by how they behave when they enter the music room. According to Tim, a motivated, selfregulating student who believes in himself will enter a class and get themselves "all set up and ready to go and they've got their book open and they're ready, they're enthusiastically ready to play and they don't wait for me to tell them where to start. They know where they want to start and what they want to do.” Tim claims that organized students who are constantly prepared are motivated and in control of their own learning to a high degree.

Regardless of the student's aspirations or motivations, the way Tim assesses the degree to which his students are practicing and self-regulating their learning on their own is with assessments. "I hold them accountable for the things I assign them. We have a couple of playing quizzes every week." The purpose is to "monitor the musical results, not the practice time."

Meaningful learning can be observed in students when they demonstrate their ability to solve problems. To learn in instrumental music, they must spend their time 
observing skills and then replicating them in practice. Practice helps students master skills, reinforce knowledge, and develop good habits.

\section{Summary of Tim's Case}

Two themes emerged from Tim's case. First, Tim stressed the importance of modeling both music performance skills and personal life skills. Tim saw teaching as more about preparing students for adult life rather than just music. Second, Tim believed that practice was the most important aspect of music learning. According to him, students simply can't master skills without practice. I described Tim as "The Sage," because his answers revealed a wisdom and insightfulness that has come through years of practice as a music educator. They were not the answers of a neophyte. Now I discuss Tim's case as they relate to the main research questions of this study.

Research Question One: Instructional Strategies. Tim uses a variety of instructional strategies to promote self-regulation. First, he uses modeling. He prefers expository teaching. He also models performance skills on a variety of instruments in band and sight-reading. Second, he uses task analysis by giving students benchmarks and dividing tasks into small steps so they don't get overwhelmed. Third, he fosters motivation by first complimenting students and then offering critique to help them improve. He also uses extrinsic motivation through formative performance assessments. Fourth, he teaches home practice preparation strategies so his students will practice where they won't disturb anyone or be disturbed. He also teaches them to establish goals before they practice and to monitor their learning and goal achievement as they practice. Fifth, he teaches self-judgment by having his students to record themselves and listen back. 
Research Question Two: Assessment of Self-Regulated Learning. Regarding

the second research question, Tim reported that to assess his students' levels of selfregulatory development with respect to their performance skills, in addition to performance assessments for a grade, he observes them in the classroom. Tim stated that, "usually the kid that comes in and is all set up and ready to go and they've got their book open and their ready, they're enthusiastically ready to play and they don't wait for me to tell them where to start. They know where they want to start. They know what they want to play for you. They teach me" (Interview 1).

Research Question Three: Most Significant Self-Regulation Strategy. Tim reported that the most significant self-regulation strategy his students could use is the "seek information" strategy. He believes that information is the key to learning and states that in lessons he asks his students, "if they know a certain player, and when was the last time you checked them out on You-tube? Have you ever heard of serial technique? All of a sudden, we were listening to the third act of Vocheck. When I was growing up, I would have to go to the library. Now we have the internet" (Interview 2).

\section{Ivan: The Facilitator}

Ivan got interested in music performance in the fifth grade and then teaching music when he was in high school. In fact, he credits his high school band directors with steering him toward a career in music education. His wife shares his love of music and teaching and chose the same career path. According to Ivan, "we both had an intrinsic love for music. It's just a passion, you know?" (Interview 1). Their college educations were completed at a moderately large university in the Midwest. 
Since fifth grade his principal instrument has been the trumpet, but as an educator he must be able to play every instrument he teaches. At the end of six years of teaching in a small school district in a midwestern state, Ivan currently plays, in addition to trumpet, the clarinet, flute, trombone, saxophones, tuba, and percussion. He feels like he is at the seventh or eighth grade level on each of them and tries to learn a new instrument every year.

As a new teacher, he taught grades three through 12 as well as band and choir. At the time of this study, he only taught band and choir from grades six through 12 . His wife had taken over teaching grades three through 5. "We have the music program on lock-down. We control every aspect, which is great" (Interview 1). Ivan and his wife are able to decide what their students learn and control the process. This allows them to more fully understand what their students know and what they can teach next. They teach their students new skills and concepts that are based on prior knowledge.

Ivan also emphasized a belief that for individuals to realize their full potential, they have to persevere through difficult circumstances such as learning to discriminate pitches. For his students to become everything they are capable of being, Ivan was emphatic that they work their hardest to achieve their goals. To facilitate, he provides them with the necessary praise and critique they should have during their learning trials. Analysis of Ivan's data revealed three themes: Remember the past if you want to understand the future, imitation in practice is half the battle, and personal efforts affect music learning. 


\section{Theme I: Remember the Past if You Want to Understand the Future}

Ivan argues that much of the learning that happens for his students is based on their observations of his demonstrations. "I love modeling" he says, and as they observe it, they relate the new skill he is teaching to the skills they already know, and then master it in home practice. As a result, Ivan's students learn through personal reflections and social observations. He also relies on pedagogical principles that reinforce knowledge and skill building, and creates relationships with his students and their families to help support home their practice.

First, his students learn to play their instruments "by listening to good instruction and by somebody modeling" (Interview 1). The example he used to illustrate this point was that "we all started on recorders. So, when instruments like flute, clarinet, or saxophones get passed out, the students already know how to hold them" (Interview 1). The idea being that, "as long as you know it's been modeled the correct way" (Interview 1), they should be able to anticipate reading notes, learning a fingering scheme, blowing air to make a sound, and playing as a group. These are the elements of music literacy and help musicians communicate musically.

Ivan also works from the understanding that some younger students look up to their peers and are excited about participating in music like them. Older students can influence younger ones in positive ways. The beginners see that "the kids before them are doing it and their having fun doing it" (Interview 1). He also noted that "seeing other people their age who are competing and creating really helped them to do what they do now and love it" (Interview 1). Plus, "I'm a fun teacher and my wife has them first so they love band by the time they start it" (Interview 1). Ivan also suggested that seeing 
other people do it helps the kids think, "hey, you know what? If I try, if I practice, I'm gonna get there" (Interview 1). Ivan has older students perform for younger ones as a form of social learning. Social learning is important in the music room because much a student's education comes from vicariously through models such as a teacher or peer.

Nevertheless, even motivated beginners face learning challenges. For one, their small physical size may preclude their ability to reach all of the notes on an instrument. As Ivan noted, "Their hands are so small they can't reach around all the palm keys" (Interview 1). Other challenges even motivated students might face can be as simple as getting braces. However, Ivan noted that even the trouble braces can cause in a student learning to play flute can be overcome if they remain motivated and are willing to learn ways around their problems. "She struggled, struggled, struggle, never gave up...she's one of the best flute players I have now" (Interview 1). This is an example of a student who has used learning strategies in a problem-solving process to become a successful musician.

Second, instrumental music teachers' adherence to pedagogical principles influence teaching methods, expectations, and relationships. As such, Ivan stated that music instruction should "start small" (Interview 1). Band teachers, according to Ivan, should break vital information into small pieces and only "focus on what they really need to know and then reiterate it" (Interview 1). As he stated, "you get more out of them if you give them easily attained bits" (Interview 1). Teachers should also stop their students and correct their mistakes as soon as they finish playing the passage of music they are working on. Continuing to play the wrong notes during practice periods makes it harder to correct them. 
Ivan also maintains that "it is important to make learning fun for the students" (Interview 1). Instrumental music learning is hard work but if it is not fun students won't persist. Making the work fun is part of the reward for everyone involved including the teachers, students, and their audiences. He also like to build on foundations and "start small" (interview 1) when it comes to learning new concepts.

From the beginning Ivan also establishes his expectations with his students and asserts the fact that "we have a job to do" (Interview 2). He also emphasizes student goal-setting and planning. This is common practice in marching band. "That's out number one thing, achievable goals" (Interview 2). He stresses however that both teachers and students must be patient in their desire to achieve them. Music learning takes time.

Third, he also builds relationships between himself and his students. Ivan suggests that relationship building improves student behavior and promotes opportunities to have fun while learning. Nevertheless, "each student is different" and "as far as discipline in the classroom and building relationships, the book 'Love and Logic' (Fay \& Funk, 1995), is fantastic." Based on that, he uses a strategy he refers to as "the bank account." This is where he will first praise a student's performance (the deposit) and then offer a critique or criticism (the withdrawal) that teaches a better performance. "I love the bank account strategy." In that respect Ivan emphatically stated, "you just cannot let up."

Music teaching starts from what students already know. From there, new skills can be taught. They remain receptive to new instruction so long as they sense a degree of 
respect from their teacher. All knowledge and skills can be consolidated through reinforcement during private practice periods and performances.

\section{Theme II: Imitation in Practice Is Half the Battle}

For students to achieve in instrumental music, they must value the musical skills and models they are observing (McPherson \& Zimmerman, 2011). From that, they are more likely to organize their learning and rehearse the skills on their own in private practice. Even so, some students still experience difficulty replicating a performance skill on their instruments and to address those issues Ivan teaches his students to imitate the skill in question, and understand that they are accountable for their own learning.

First, Ivan explained his idea of imitation. "One of my former band directors told me, "play like you've got it and when you get it, you'll have it"' (Interview 1). By that he means "as long as it has been modeled the correct way," his students should be persistent and try to imitate his performance skills as much as possible, for as long as possible, even if they can't actually execute them correctly.

He emphasizes this for students who give up if they don't get things right on their first trial, or perceive a challenge as too difficult. For a student he "can't push there at that moment" (Interview 1), he gives them the opportunity to get the confidence they need by showing them how to imitate the skill without actually doing it. Ivan noted that self-confidence, and ultimately musical success, can be nurtured through imitation and “it's something you project as an expectation" (Interview 1). Learning can be challenging at times in instrumental music study and as a result, Ivan expects his students to exert a degree of effort in their practice. 
Ivan instructs his students to employ imitation as a home practice strategy. He also recommends include making self-recordings, repeating short passages of music, and to "listen, listen, listen." Repeated moments of listening, as Ivan suggests, helps the learner to more accurately interpret a musical example.

Second, students should learn the skills that have been modeled for them in home practice (Hallam, Rinta, Varvarigou, Creech, Papageorgi, Gomes, \& Lanipekun, 2012). When it comes to students practicing, Ivan recommends 100 minutes in a five-day work week. "That means 20 minutes of you blowing air through that horn." He noted that he takes the time in class to teach his students not only what music to practice at home and how to do it, but also how to solve problems related to practicing as they show up. He has them establish an appropriate place to practice at home before they start to play. They are to avoid televisions, and must be sitting in a chair with their books out and open on their stands and playing "for 20 minutes" (Interview 2). I say, "I need you to go home and do this..." as opposed to saying, "hey, you're not getting that. Go home and practice it" (Interview 2). He also defines practice goals for them. One particularly fun example is having his students learn a pop song. "I said guys, we're going to do a song from memory. What you have to do is listen to a song on the radio. My $6^{\text {th }}$ graders go home and learn it and they love it." Ivan sometimes sets goals that align with "what the student's focus is" (Interview 2). As a teacher, Ivan believes that his students should imitate the skills he is demonstrating in their practice. This strategy helps them to understand key concepts as well as acquire the necessary technical proficiencies he expects them to achieve. 
Third, Ivan believes his students must be held accountable for their learning. The way to do that is to "be diligent" (Interview 2). When you are, it is easy to see who is actually working and who is not. If they are not working at home, they begin to struggle in class. Students who have family members who value music at home tend to do better according to Ivan. He noted that with one particular student who excelled at practicing that "her whole family is a very musical family." Testing also holds students accountable, according to Ivan. He gives them goals to achieve and then tests them on it. Another way to determine is students are being accountable for their own learning is to simply observe how many times they take their instruments home each week.

Nevertheless, some students won't readily take his advice or follow his instructions without resistance. "They will slack off" (Interview 2). Ivan believes that for those who won't monitor their own learning well, or take responsibility for it, that "there's something else there" (Interview 2). Nevertheless, music students can use their mental abilities to learn more effectively (Pape, Zimmerman, \& Pajares, 2002) and although initial attempts to master certain performance skills may be unsuccessful, the efforts are still of value in the learning process and teachers should monitor the selfperceptions students have of their progress in order to maintain their motivation.

\section{Theme III: Personal Efforts Affect Music Learning}

Some people use terms like toil, labor, or drudgery when they reflect on their school music experiences. Ivan is aware of the reality that learning music can be challenging for many of his students, so in his practice he tries to provide them with the proper perspective. "I want them to have fun. I want them to learn that being successful takes a lot of hard work" (Interview 2). Having fun while working hard is something he 
models for his students too. "When it came to that and getting them to be better, I love modeling" (Interview 2). To help his students maximize their learning efforts, Ivan focuses on efforts to remove their barriers, guiding them in the use of learning strategies, and providing funds and resources to inspire them.

First, Ivan understands that some students endure personal and social barriers that can inhibit their opportunities for musical development. He noted that some of his students do not get enough regular sleep at home each night. Others are so busy with other activities that they are not able to effectively practice enough. Still other students struggle to cope with the conduct of classmates, or are simply intimidated by bullies or certain social groups. He noted that musical experiences can be shaped by individual personalities, ideas, and abilities. Nevertheless, student efforts have a payoff so long as they maintain a commitment to participate. Ivan noted that sometimes he can navigate social issues in band by switching instruments. Sometimes problems come and go based on which group of students are working together. One way to solve social problems, as noted by Ivan, is to simply move a student to a new group. Nevertheless, Ivan likes to remind his students that "it's not about you, it's about the music." So above all else, they need to learn to work together. Even with people they may not necessarily get along with.

Second, Ivan also suggested that some learning strategies used by music students are more important than others. In fact, he stated that goal-setting is "day one of band camp" (Interview 2). To do this he sets goals for his students, especially his beginners that are "easily attained bits" (Interview 2). He tells them "we have a job to do, we've got a goal" (Interview 2). Are they going to achieve them or try to achieve them? 
"Maybe, maybe not" (Interview 2). Some students will try to get out of working very hard. "You give them an inch, they take a mile" (Interview 2). In conversations with students who are behaving like this he tells them, “I don't want you to think I'm being mean or unfair, but if you're not willing to take my advice and direction (Interview 2), you're going to have a hard time staying in band.

Third, inspiring his students to try new ideas, instruments, or techniques comes in a variety of ways. One simple way is to "provide funds and literature" for instruments and methods books. Then students see that their teacher and school are willing to invest in them, they can become more trusting and open to trying new things. Ivan told the story of sparking a student's interest in playing the xylophone this way. As a trumpet player by trade, Ivan was proud of the fact that the process was a success. First, he got him interested in it. "I started showing him videos of what he could do if he just tried" (Interview 2). Then he got the school to purchase one. Then, "not to toot my own horn or anything, but I taught him how to play four mallets" (Interview 2). The learning process for the xylophone student included watching videos to observe proficient models in action. Music students will respond to their teacher's attitude and enthusiasm for performing instrumental music. Providing them with new instruments, materials, and objectives will encourage adequate personal effort on the part of the students. Their enthusiasm can be maintained through a balanced variety of learning and performance activities.

\section{Summary of Ivan's Case}

Three themes emerged from Ivan's case. First, Ivan stressed the importance of remembering past learning to help master new learning. He sees learning musical 
instruments as a step-by-step process where new skills are built on top of old ones.

Second, he believes that imitation of proficient models on the part of the students helps them acquire skills. Models, according to Ivan, whether provided in the music room, electronic media, or in other live performances, provide the best examples of performance skills and behaviors for students to learn. Third, students must put in personal effort if they are to master their instruments and band performances. According to him, skill building takes a long time and a lot of effort on the part of the students so they must be willing to work for their success. I described Ivan as "The Facilitator" because his instructional strategies he uses with his students makes their learning process easy and efficient. Next, I discuss Ivan's case as it relates to the main research questions of this study.

Research Question One: Instructional Strategies. Ivan emphasized the importance of modeling musical instrument performance skills. Ivan believed that his students' learning is based on their observations of his demonstrations. They can imitate his performance skills for as long as possible until they can play as well as he can. Imitation, according to Ivan, is a behavior found in students who are trying to learn. Second, Ivan used task analysis to help students learn effectively. According to him, he gives his students task bench marks to help them develop their performance skills. He also gives them goal-setting and planning ideas to help them complete their assignments. Setting goals is a fundamental skill that students are expected to master in his band camp. Additionally, in his instruction he breaks down vital information into small pieces, so that they can start small as they learn new material. 
Third, Ivan believed that motivation is important to student success. To help motivate aspiring learners, Ivan has his bands perform for young students who are just reaching the age where they can consider playing instruments in band. This lets them see that if they try and if they practice, they can be musicians too. Ivan also stated that by keeping his band practices fun, and by building relationships between himself and his students, more individuals stay motivated to continue in his program. Lastly, Ivan that weekly testing keeps his students motivated to learn and grow as well.

Fourth, Ivan stated that preparation for home practice is an important strategy he teaches his students to use. He recommends they establish a place to practice where they won't be disturbed or won't disturb others and practice for five days per week. Ivan also stated that when they practice, they are to avoid television, and must be sitting in a chair with their books out and open on their stands and playing for 20 minutes. Lastly, he suggests to his students that during practice they should make self-recordings, repeat short passages to learn them better, and to listen to themselves while they play and listen to themselves on their recordings.

\section{Research Question Two: Assessment of Self-Regulated Learning. Ivan}

reported that he uses formative assessments to evaluate his students' levels of selfregulatory development with respect to their performance skills. He stated that he tells his students, "alright guys, we're having a test on this tomorrow. You have to go home tonight and you have to have one measure, or whatever it is...you're going to have to show me... whatever" (Interview 1).

Ivan also said: 
They come back the next day, and everybody passes their test. Everybody gets it, and it's because you've now put that goal in front of them. They come back the next day, everything's fine. If it doesn't go well, it's more than likely because the kid was too busy. 'I had softball last night.' 'I didn't get to practice because the baby was sleeping' (Interview 1).

\section{Research Question Three: Most Significant Self-Regulation Strategy. Ivan}

reported that the most significant self-regulation strategy his students could use is the "goal-setting and planning" strategy. He stated that, “...I'm thinking like marching band. Marching band. Goal-setting and planning, that's our number one thing. We set out from the beginning; this is how it's going to be so I need to this, this, and this. I give my kids goals. Are they going to do it? Maybe, maybe not" (Interview 2).

\section{Gertrude: Teaches Her Children}

Gertrude has been involved with music her whole life. She started playing violin when she was four years old and never stopped playing. She has always enjoyed it, found personal fulfillment through playing music, and became a teacher because she wanted to continue to share those experiences with others. She considers herself proficient on all stringed orchestra instruments including violin, viola, cello, and bass. She got her undergraduate degree from a small midwestern state university and is presently pursuing a Master's degree at a large midwestern university in music education.

She has been a music teacher for the past eight years and currently teaches middle school and high school students (grades 6 through 12) in a public-school district. The position requires her to travel between two different school buildings during the day. 
Prior to working in her present district, she had the opportunity to work in China teaching as a music intern. This gave her the opportunity to get a new perspective on cultural diversity. She noted that the position was for only four months long but that she would have been happy to stay for a year. Nevertheless, after her internship she returned to the United States and began working as a music teacher full time.

Overall, Gertrude uses different social support strategies in her music room to foster musical autonomy in her students. Sometimes she provides them with opportunities to learn in sectionals and sometimes she provides them with opportunities to learn alone with their friends. She also establishes and maintains high expectations with her students and is meticulous about delivering her instruction. She was adamant about maintaining high expectations for her students and advises other music teachers to do the same. She tells them to "establish your expectations immediately" (Interview 1), to "be consistent in every aspect of your teaching," and "keep your expectations high" (Interview 1). Analysis of Gertrude's data revealed three themes: instrumental music teaching occurs in a prescribed order, meeting social standards encourages students to self-regulate their learning, and teachers do not have all the answers.

\section{Theme I: Instrumental Music Teaching Happens in a Prescribed Order}

Gertrude believes that musical instrument learning happens as a result of a predetermined “step-by-step” (Interview 1) teaching process. Consequently, her instruction includes an expository teaching method, direct instruction, and scaffolding strategies that are combined with peer to peer teaching and learning opportunities. She also relies on learning standards such as create, perform, respond, and connect to lead her students through the learning processes meant to help them attain musical independence. 
First, Gertrude uses an expository method to educate her students. This method provides them with a logically sequenced delivery of information, ideas, and terms that relate to the musical concepts she wants them to understand. When teaching concepts such as instrument technique, sight-reading, harmony, rhythm, or melody, she states that "there are building blocks and you build that foundation" (Interview 1). In this way her students create an understanding of how different abstractions are related to each other. She can also teach listening skills with the expository method. Among other things, listening skills help students develop the ability to monitor their own performances as well as better play in concert together. Her expository teaching is also used to "break things down" (Interview 1) for her students. This is especially true when musical passages become overly complicated.

Her instruction, which deals primarily with the basic literacy and performance skills students need to play on their instruments, emphasizes a drill and practice approach to learning. In beginning orchestra lessons for example, she first starts her students out by teaching them how to pluck the strings on their instruments. After that skill is mastered, she teaches them a bowing technique. Next, she teaches them how to read music notation and how to play the notes on the necks of their instruments. At this point, "it gets meticulous" (Interview 2). Good technique, hand position, posture, music terminology, tempos, and beats, all come in to play. Music teachers must be clear in their instruction on all of these elements for students to be able to perform effectively. Gertrude indicated that her instruction often relies on the temporary use of "training wheels" (Interview 1). The idea is to give her students the necessary scaffolding they 
need to learn difficult concepts and performance skills. When the basics of the skills are mastered, she removes the wheels.

One scaffolding strategy she successfully uses is to apply "finger tape" to specific points on the instrument necks when the students are first learning to play notes. The tape helps them handle the initial learning curve of identifying the physical location of the notes along each string without having first developed a sense of intonation. Over time they the get an idea of where notes are located and what they sound like when correctly tuned. Then she removes the tape and the students take the final learning step on their own as they practice fine tuning their exact finger placements. Because this last step requires some trial and error effort on the part of the students, she tells them "if it's not perfect, that's ok." She expects them to fall over a few times at this point.

Although "students don't need to be social all the time," Gertrude lets them "practice in small groups" (Interview 2) during class time. This gives them the opportunity to synthesize knowledge between themselves. As Gertrude stated, group learning has the added benefit of keeping the learning fun. Before she sends them off in groups, she models the skills she wants them to acquire. Modeling, as a form of social learning, gives students the opportunity to observe what their teacher is doing and then imitate it. "The modeling of it helps" (Interview 2) she states. Students learn from each other's behaviors in social settings.

When she splits them up into groups, they can learn to critique each other, they can teach each other, and they can "learn to work together and cooperate" (Interview 2). She also likes to give different students a chance to lead each day. The idea being that each student learns how to lead and to follow. Either way, she wants her students to 
know that "we're all valuable to the group and you're here to be a member of that group" (Interview 2).

As an example of the effectiveness of modeling and social learning, Gertrude told a story about the time she took a one week leave to go on her honeymoon. She instructed her students to learn a performance piece and that they were to teach it to themselves based on their observations of her instructional model. She anticipated them playing the piece in their concert and expected them to "play what you've prepared when I come back." Before she left, she gave them the assignment. "I gave them jobs. I gave them responsibility" (Interview 2). When she returned a week later, the students had "basically played a perfect piece of music." They were able to learn and perform the music on their own "based on what they watched me do for two years" (Interview 2). Based on her teaching model, the students were able to regulate their behavior and their learning both as individuals and as musicians, whether they were alone or in groups, in order to achieve the performance goal.

Instrumental music teachers need to make sure they teach in a sequential manner, building new knowledge on top of old (Ericsson, Krampe, \& Tesch-Romer, 1993). Even though each student is unique and different in certain ways, they will all still imitate their teacher when they learn, practice, and perform. As a consequence, teachers should keep in mind that learning can be social in nature (Schunk, 2012).

Theme II: Meeting Social Standards Encourages Students to Self-regulate Their Learning

Maintaining a position in an orchestra in a school music program requires individual students to self-regulate their learning. According to Gertrude, the basis for 
self-regulation is motivation. Intrinsically, "the motivation has to be there." She believes that "it has to do with enthusiasm." For an instrumentalist in a school orchestra, the motivation to learn can also come from extrinsic sources such as playing tests and live performances. "People realize that they have to show that they've practiced." "I do a playing test. A short excerpt or something." Gertrude, leaning on her pedagogical expectations in this respect, usually tells her students, "you're auditioning for me every day." Although she admits that "high school kids are practicing for different reasons," this form of motivation encourages home practice on their part because "they have to practice on their own in order to be prepared."

Gertrude raises the question of home practice with her students. "I'll show them how to practice in rehearsal" and "I give them goals" (Interview 1). She also indicated that she has them "make goals for themselves and I teach them how and tell them what that looks like" (Interview 1). But as a matter of policy, she does not do practice logs because "they're just big old lies" (Interview 1). Instead, she gives them different ways to practice so when they go home, "they don't feel helpless." She starts off by teaching them how to use a metronome and how to practice playing music at slow tempos. She also admonishes them about the virtues of repetition in instrumental music learning and tells them that when they are learning a new skill during home practice periods to "do it five times in a row" (Interview 2). Goals promote actual music learning and support motivation in students.

Gertrude also advises her students that during home practice they should find a good place to practice, get in the right mind set and get rid of distractions. "You have to figure out how to get rid of distractions, no tv, no phone" (Interview 2). The reason is 
"because the whole process of practicing is a life style change," and isn't always fun. So, she tells them to make it a game; go play for a pet, sibling, friend or parents. This helps them feel successful and consolidate their learning according to Gertrude, and "if they feel successful, they will practice" (Interview 2). Other practice strategies revolve around social settings where they can learn with their friends. Often times, as Gertrude notes, students will practice together. It's makes it fun and sometimes "kids will turn in recordings and their friends will be in the background giving them support" (Interview 2). For beginning students, she tells them to practice about an hour a week. For $7^{\text {th }}$ grade students, she tells them to practice about an hour and a half per week. For $8^{\text {th }}$ grade students, she tells them to practice about two hours per week. At the lower level in high school, her students should be practicing at least two hours per week. At the top level, high school students "should be practicing three to four hours a week" (Interview 2).

Gertrude argues that music students must be able to exercise self-discipline in order to practice effectively on their own. "I'm not going to hold their hands. I have to force myself not to hold their hands through some of it because they have to learn to do it on their own. They have to. The only way for them to learn to do it on their own, is to make them do it on their own" (Interview 2). She doesn't believe in spoon-feeding their learning nor doing their work for them. This hands-off approach helps students learn to fix problems on their own and to self-critique their progress.

Gertrude also indicates that in addition to motivation, personal responsibility is a big part of self-regulated learning. "I'm very big on personal responsibility." This is especially true as orchestra students are tasked with personally caring for expensive 
musical instruments. "There's an instrument, something tangible and expensive that they have to be responsible for."

Self-discipline and taking personal responsibility for learning shows Gertrude that her students are self-regulating. Gertrude noted that by the time they're at the high school level they're able to do it on their own. In social settings, students who are regulating their own learning are often times "confident enough to make mistakes" (Interview 2) in front of others.

Music students who are learning to practice on their own are also likely to spend time thinking about their own thinking (McCormick \& McPherson, 2003). This metacognitive aspect of self-regulation in music learning reflects on the fact that students are inherently trying to do things right. According to Gertrude, "at the high school level, they should know what works for them" (Interview 2). Students who are thinking metacognitively "are always asking questions" or "they come in one day and tell me that they figured something out." "They're excited about it. They come in and they tell you. They're proud of themselves" (Interview 2). Social situations can influence the degree to which self-regulate their learning. In response to a situation where students wish to participate, they will often engage in self-instruction, seek help from more knowledgeable others, and self-monitor their own performance. In response to a desired performance in a social situation, students are also likely to give themselves rewards for their efforts.

\section{Theme III: Teachers do not Have all the Answers}

Many of the learning challenges instrumental music students face are unique to school learning and not easily overcome by the student alone (Miksza, 2012). Personal 
relationships between teacher and student can interfere with learning, as can circumstances within a student's home life. Other factors such as a student's physical development or emotional maturation can also act as barriers to learning.

To combat personal problems between herself and her musicians, Gertrude tries “to have individual relationships with the students so when we're in big groups it still feels like I'm just talking to them" (Interview 1). Nevertheless, "it's difficult to diagnose individual problems" (Interview 1) without spending precious time on a one-to-one basis with each student and trying to determine "what their learning style is and figure out how to fix their problems" (Interview 1).

Student's home lives may impede instrumental music learning. Gertrude suggests that she can tell that students are having trouble at home with practicing because they get "very defensive" about it. "I have students who don't practice because their parents won't let them." Nevertheless, as Gertrude stated, "it's the whole village thing." All the stakeholders are responsible for making sure students have the time and place to practice their instruments. Sometimes, by the very size of their instruments, some students may have trouble getting them home to practice on without securing better transportation arrangements. Sometimes they may have trouble practicing at home due to circumstances that preclude them from making any noise. For her part, she can "open the classroom up for them to practice before school" (Interview 2) as an effort to accommodate their needs. At least some students can get in the practice time they need.

Gertrude argues that, in addition to what she teaches them in class, the attitude parents project about music learning affects student success. "It's the biggest thing other than what I teach them" (Interview 2). To facilitate learning at home Gertrude talks to 
the parents when she can "to make sure that they understand what is required" (Interview 2). She states that for student success to occur, "parent involvement and communication has to happen" (Interview 2).

Other challenges to learning at home can arise because of responsibilities the student is accountable for or because "the parents don't have the resources or the time. Maybe they have to take care of a younger sibling. Maybe they can't practice because someone is working the night shift" (Interview 1). Clearly, in this regard the parents play the biggest role and she encourages them to help find the time for their child to practice at home and to listen to them.

Students struggling with learning challenges at home tend to run into motivation problems before long. In cases like that, she tries to be honest with them. She says, "look, practicing is not going to be fun. I'm not going to cherry coat it" (Interview 2). Aside from that, "there's only so much I can do" (Interview 2) when it comes to helping music students solve their own problems.

Learning barriers such as size or age may also play a part in challenging young learners. "You're teaching them to do this at a young age and it's difficult for them." They are just learning how to learn and all of a sudden "they have to change their routines" in order to keep up. For some students this can be difficult. For students in the $6^{\text {th }}$ and $7^{\text {th }}$ grades, "I'll have to talk slow."

Teachers, as Gertrude suggests, can only do so much to get their students to learn. For learning to occur, students must take responsibility for their own academic success and attend to the information being presented to them. Additionally, in instrumental 
music programs, students must be willing to invest significant amounts of time isolated from others in practice periods that are often times less than pleasurable.

\section{Summary of Gertrude's Case}

Three themes emerged from Gertrude's case. First, music teaching happens in a prescribed order. Gertrude sees learning instrumental music as a step-by-step process where students continuously build new knowledge on previously learned precepts. Second, social learning encourages self-regulation in students. Gertrude uses group and sectional learning periods during class time to for learning and rehearsing new material. She feels the students take more responsibility for their behavior when they are faced with the responsibility of being responsible to their peers. Third, Gertrude does not believe that that has every answer to every student's problem. Given the complexity of the environment she works in, it seems impossible for her to understand, much less help some of her student's learning needs. I described Gertrude as one who attempts to help her students learn to teach themselves, even if they have to sometimes learn the hard way. Now I discuss Gertrude's case as it relates to the main research questions of this study.

Research Question One: Instructional Strategies. Gertrude uses five instructional strategies to promote self-regulation in her students. First, she uses task analysis as it is based on her belief that musical instrument learning happens as a result of a predetermined "step-by-step" teaching process. This strategy provides her students with a logically sequenced delivery of information, ideas, and terms that relate to the musical concepts she wants them to understand. An example is of a scaffolding strategy she uses to apply "finger tape" to specific points on violin necks when her students are 
first learning to play notes. Once they have learned where the notes are, she removes the tape.

Second, she uses a listening and self-observation strategy. Listening skills help her students develop the ability to monitor their own performance as well as perform better in concert as an orchestra.

Third, Gertrude uses motivation as a strategy to help her students become better self-regulated learners. When learning in groups, students will often engage in selfinstruction, seek help from their peers, and remain cognizant about self-monitoring their own performances. Gertrude also uses goal-setting with her students to promote motivation. She shows them how to practice and she gives them goals. She also shows them how to make goals for themselves. Lastly, Gertrude using performance assessments to help motivate her students. This form of motivation is deemed to be extrinsic in nature in that the students are working for a grade rather than for personal satisfaction.

Fourth, Gertrude uses self-control and self-instruction as in instructional strategy to teach her students to become self-regulating learners. Based on the teaching model her students observe on a daily basis, they were able to regulate their behavior and their learning both as individuals and as musicians, when they were alone or in groups in order to achieve certain performance goals in Gertrude's absence. Social situations in music rooms can also influence the degree to which students self-regulate their learning. In response to a situation where they wish to participate, they will often engage in selfinstruction, seek help from more knowledgeable others, and self-monitor their own performances. 
Fifth, Gertrude teaches home practice preparation as an instructional strategy to promote self-regulation in her students. She gives teaches different ways to practice so when they go home, they don't feel helpless. She also advises them to practice about an hour and a half per week and that that during home practice they should find a good place to practice, get in the right mind set, and get rid of distractions.

\section{Research Question Two: Assessment of Self-Regulated Learning. Gertrude} reported that she uses playing tests to determine her students' levels of self-regulatory development with respect to their performance skills. She stated that, "I do a playing test - a short excerpt or something in addition to their big playing test. I feel like it is more successful. People realize that they have to show that they practiced it. The big playing tests we go over in class and we perfect it. But the small ones, the practice tests, it is up to them to prepare for. We learned how to do something and they need to go home and prepare to play it for a test. Signing a piece of paper means nothing. I feel like it's been more successful" (Interview 1).

\section{Research Question Three: Most significant Self-Regulation Strategy.}

According to Gertrude, the most significant self-regulation strategy her students could use is the "self-evaluation" strategy because "it can be so instantaneous. It can happen right away. If we are playing a piece of music, I will stop them and say, 'what did you do wrong? Why did I stop you? What do we need to fix?' It's instantaneous. It's the first thing that can be done to change, to improve, to fix something, so I use that constantly. I feel like it's the most important because it's the first step" (Interview 1). 


\section{Evan: Learn Through Experience}

Evan has been a middle school and high school band director for fourteen years.

Overall, he relies heavily on formative assessments to observe and measure his student's learning progress. He also values the opportunity to provide instruction through a variety of learning experiences and routinely takes his students on trips where they have opportunities to perform, compete, and watch other musicians. His purpose for this is to enrich their lives and learning experiences, and help them discover the meaning of instrumental music for themselves. Analysis of Evan's data revealed three themes: knowledge is gained by watching others, assessments helps students take personal responsibility for their own education, learning comes from a variety of personal experiences.

\section{Theme I: Knowledge is Gained by Watching Others}

Instrumental music learning in a school music program is generally a social experience where students are likely to spend a significant amount of time watching their teacher perform skills and then attempt to emulate them in practice on their own (Austin \& Haefner-Berg, 2006). The goal is to perform the music they learn in public as a group. To help students learn to play music and work together, Evan focuses on: instruction in the music room, social learning opportunities, and personal relationships.

First, Evan focuses on his instruction in the music room. Teaching music begins with "basic building blocks." Instruction begins based on what a student already knows. From there, new knowledge is sequentially constructed on top of it. You have to "build off of basic building blocks" and give them "the foundational materials they need to grow 
musically." It is like "opening a window" so students can see for themselves how things go.

Learning from Evan begins with an explanation where he states his belief that "all problems can be resolved" (Interview 1). He also takes the time to outline his "clear expectations" because "I want them to be successful" (Interview 1). To do that, you have to "find the right instrument for the kid" (Interview 1). After that, his music room instruction is deliberately concise in nature because "you learn in short sections" in a "step-by-step process" (Interview 1). As a consequence, he gives his students "a lot of bits and pieces to build up their knowledge" (Interview 1) over time. Nevertheless, sometimes he is not always sure about what strategy to use so he will actually "throw as many pieces at them as I can, and see what sticks" (Interview 1).

In the music room, Evan relies on "modeling" (Interview 1) for a large part of his instruction in skill building. "Those kids need a good example" (Interview 1) which he provides every day for them in the music room. Outside of the music room he encourages "private lessons" (Interview 1) from teachers in town, or watching videos on line. "We have Youtube" (Interview 1). There they can observe lots of modeling, especially of "licks for jazz" (Interview 1). The best outside opportunities to learn come from "seeing other groups march." Evan feels that, for better or worse, when students observe their peers, they gain a better sense of where they stand in their music education.

In his music room he also likes to take the time to "talk about notes and rhythms" and "do a lot of clapping" (Interview 1). To diagnose problems students are having, he will "try to mimic what they are doing" (Interview 1). He will even "play things wrong to figure out what the students are doing wrong" (Interview 1). He will also take the time 
to "talk about the problems we need to fix and the long-term goals of performing on stage in form of an audience," (Interview 1) how "sound works, to recognize patterns," and to "guide them to listen" (Interview 1). Another important skill to have is to teach them "what to listen for." Evan mentioned that he spends a lot of time teaching them to "listen for patterns" (Interview 1). Opportunities like that help his students with "terminology" (Interview 1) and keeps lessons interesting and entertaining. The stages of instrumental music learning are logically sequenced. In the music room, drill and practice exercises led by a proficient model helps students learn key concepts relating to the elements of music. Both visual and auditory representations of a performance skill aid in student understanding.

Second, Evan provides his students with a variety of social activities. For one, he likes to put his older students "with younger students to share their knowledge" (Interview 2). The consequence of that is that the school can build a culture that is not about entitlement. Evan states that, "we've actually built a culture in the high school that they're building a legacy" (Interview 2). He also likes to do "instrument rental night" (Interview 2). This gives him an opportunity to prep the incoming students for what they can expect to experience and match them up to the right instruments beforehand. Matching the students to the right instrument reduces and eliminates "mistakes ahead of time" (Interview 2).

take his bands to competitions. "It's not like we do marching competitions for donuts and trophies. If they stay at home, they don't see other bands and how good they are" (Interview 2). 
Personal motivation plays an important role in instrumental music learning. Giving students the opportunity to experience the different aspects of a school music program, vicarious or otherwise, helps them value the activity and identify goals they might like to achieve as a participant. As a result, students begin to self-regulate their music learning.

Third, Evan focuses on personal relationships between himself and his students in his music room. To him, relationships are important. "Building a positive and professional relationship with your kids is essential" (Interview 2). One reason for that is because, as a teacher, you need to "understand your student" to help him learn. "I can do that one on one relationship building to make sure they know that I care about them and that I'm there for them."

Good working relationships among peers are essential in the music room. A lot of learning can happen "by that peer assistance" (Interview 2). The relationships can also affect the "culture of a section" (Interview 2) and as Evan notes, students will be influenced by their friends to do things they might otherwise never have done.

A teacher cannot help their students learn if they do not understand them. To understand them, one must be in a positive professional relationship with them. Sharing an understanding of their experiences through a relationship makes opportunities for the teacher to provide timely instruction for students who need help understanding a learning objective. 


\section{Theme II: Assessments Helps Students Take Personal Responsibility for Their Own}

\section{Education}

As a strategy to get students motivated to excel, assessment activities can help. They can both encourage students to tackle personal learning challenges as well as help them become more responsible in their conduct and to feel more accountable for the direction their educational initiatives are taking. To that end, Evan focuses on: formative assessments, and personal learning challenges in his music room.

First, Evan addresses the issue of assessments with his students. He doesn't do "practice logs" because he may end up getting "a lie from some kid who forged his parent's signature." It is possible to have his students write "a reflection sheet or turn in a recording of their practicing," but Evan prefers to do "lots of formative assessment." To determine how well they're learning, he likes to "see them perform in the classroom."

Instrumental music assessments generally have a variety of criteria. Students can expect to be judged according to their tone and intonation, and technical facility and articulation. They may also be required to demonstrate their ability to perform rhythms and a variety of other musical issues such as various dynamics and articulations.

Second, Evan addresses the personal learning challenges his students are likely to encounter as they work their way through his music program. For one, students may not really enjoy playing a certain instrument or participating in a band. They may not like sitting through rehearsals. "It's just not their thing" (Interview 2). Other students may endure downtime in a program but not actually put much work into learning and as a result, "the slackers will kind of catch a ride on the other kid's coat tails" (Interview 2). 
Evan mentioned that "you have to look at their background" (Interview 2). If they are not interested in getting good, they are probably not interested in competing. "You have to look at their family history" he suggests, and poses the question "are their parents encouraging them to play music?" (Interview 2).

To that end, when students are struggling, Evan says “I'm willing to try things I haven't done before" (Interview 1) to help them with their barriers because the student's learning is still in part "a collective responsibility" between the teacher and student. $\mathrm{He}$ also requires the students to "give explanations" about why they may not be learning well. His last line of defense is to have the section leaders teach the students. "If the saxophone section is not holding their own, the section leader will get on them because they want it to sound good."

Formative assessments as well as peer assessments can help both teacher and student understand the student's personal perceptions of the program they are in as well as provide feedback about their sense of motivation. They can also help diagnose certain difficulties students may be having as well as underscore their strengths.

\section{Theme III: Learning Comes From Experiences}

Evan takes an empirical view of learning in that he believes that experiences are the source of most knowledge. To that end he argues, that students will naturally evaluate themselves in reflective moments after participating in musical performances. They make a self-judgment of their performance by comparing it to a goal they had for themselves. As a result, their future efforts will be affected by how they react to their self-judgment. It helps them set and meet new goals. This is a part of the self-regulation process. To support and develop student self-regulation process, Evan focuses on: 
student's self-efficacy, motivation, home practice strategies, personal behavior, and metacognitive skills.

First, Evan focuses on his student's sense of self-efficacy. Self-efficacy is the personal belief one has about their ability to learn or perform a skill (Schunk, 2012). Personal doubts about adequately performing instrumental music abound among music students, especially if they are not receiving the appropriate modeling of skills by their teacher. Evan addresses this issue by providing his students with a lot of small, confidence boosting successes before they have to step in to large arenas and perform. He states, “big successes don't happen very often, and they won't happen without the little successes to build off of" (Interview 2).

The idea being that, that when faced with big challenges, his students can look back on the little triumphs to fortify their self-confidence. "It's like eating our vegetables" (interview 2). A student's personal sense of efficacy can influence their choice of activities to participate in as well as the types of tasks they will undertake. Observing and imitating a model helps instrumental music students develop a realistic sense of self-efficacy.

Second, Evan focuses on the personal motivations of his students. Motivation is a process of initiating and sustaining goal-directed learning activities (Schunk, 2012). He noted that motivation is, in a sense, a moving target and he works with each student based on their motivation. Some students show up to his music room motivated because of their personal goals. For example, one student he had "was motivated to practice because he wanted to be successful" (Interview 2). Other students are motivated by "the success of their section" (Interview 2). Still other students are "motivated by their peers" 
(Interview 2). For others, just to hold an instrument is enough motivation to participate because "shiny instruments look cool." so you are saying that students are motivated by personal and social reasons.

Other students appear to lack motivation from time to time. To deal effectively with this, Evan looks for ways to get them excited about something they might find of interest. Music after all, is about "success and the continual pursuit of betterment" (Interview 2). However, he considers the possibility that students may lack motivation because "they aren't having a good time in class" (Interview 2). They realize that they have to engage in a lot of mental and physical work with little down time during the period. As a consequence, "the ones who are in it for a social experience will not do much" (Interview 2). He usually starts to see "a lot of drop in motivation around $8^{\text {th }}$ grade" (Interview 2). Other students lose their motivation when "they aren't seeing the success they want to see" (Interview 2). Sometimes what helps in cases like these is to engage in "competitive or team building activities" (Interview 2). Evan notes that other ways to help students with their motivation is to find them "a mentor", such as another teacher, or to see if there is some "family motivation" that can help.

Students who are attracted to music performance in school programs tend to show up prepared and eager to learn. Beyond what is set by their teacher, they also set their own learning goals and believe they can achieve them. Teachers who create learning environments that promote motivation creates conditions that promote a desire in students to continue learning.

Third, he focuses on their home practice strategies. Home practice involves selfdirected learning on the part of the student through experiences and repetitive exercises 
that are oriented towards technical and performance goals that normally align with repertoire. Practice helps students with their motor skills and increases their accuracy, fluency, velocity, consistency, automaticity, and flexibility. It reinforces their knowledge, and can help them relate different musical concepts to each other.

Evan encourages a variety of activities students can engage in to keep practicing both fun and productive. "We'll talk about the problems you might find in practice" (Interview 2). One can be boredom or a sense of isolation. In that case he suggests "practicing in front of a mirror" (Interview 2). Or, they can "go over to a friend's house" (Interview 2) and practice with them. Either way, it is important that they "hear the wrong notes" (Interview 2) and identify and "emulate the best musicians out there" (Interview 2) in order to improve.

Instrumental music practice gives students the opportunity to learn fingering and technical skills, as well as the opportunity to hear familiar patterns such as scales and arpeggios (Chaffin \& Logan, 2006). Music students can also focus on accurately performing interpretive cues such as dynamics or tempo changes, or they can rehearse expressive emotional cues. Nevertheless, instrumental music practice is generally time consuming and effortful. It requires students to consciously monitor their own learning and focus on the strategies that will most likely help them master skills and achieve their goals as efficiently as possible.

Fourth, Evan focuses on teaching problem-solving strategies to support his student's learning. As he noted, "nothing really beats having someone there who can figure out problems" (Interview 1) but the fact is, students must spend a lot of time alone in practice, and without someone there to help, they risk failure. Strategies help mitigate 
failure. "The strongest learning happens when we recognize it, and we strategize on how to fix it" (Interview 1). The best strategy Evan advises his students to use is to "learn from your mistakes" (Interview 1).

Strategy use while practicing instrumental music can help improve performance and overcome learning problems. Some strategies used to improve musicianship include counting out loud or using a metronome. Students are encouraged to reflect on their effectiveness of the strategies they use.

\section{Summary of Evan's Case}

Three themes emerged from Evan's case. First, he emphasized that knowledge in instrumental music is gained by watching others. Evan views music room learning as a social experience. Second, Evan valued the effectiveness of formative assessments in motivating his students to learn and practice. Assessments are performed in class in front of the other students. Third, Evan believes that learning also happens through experiences. When students experience different situations, they have new opportunities to learn. I described Evan as the teacher who likes his students to "learn through experience" because providing his students with new experiences is what he is all about as a teacher. He is constantly taking his school bands of trips to experience musical performances and competitions. Now I discuss Evan's case as it relates to the main research questions of this study.

Research Question One: Instructional Strategies. Evan uses six instructional strategies to promote self-regulation in his students. First, he uses task analysis. He does this through a sequencing process as teaching music begins with basic building blocks. Instruction starts with what a student already knows. From there, new knowledge is 
sequentially constructed on top of it. He also uses task analysis because students learn in short sections in a step-by-step process.

Second, Evan uses modeling to promote self-regulation. He models technical and performance skills in classroom demonstrations and uses videos or other electronic media as well. He also encourages his students to take private lessons from other teachers in town. According to Evan, the best outside opportunities to learn come from seeing different groups march. He also uses older students as peer models for younger students as a way to get them excited about joining band. Peer assistance can be a forceful learning tool according to Evan.

Third, he uses motivation as an instructional strategy to encourage his students to become self-regulating learners. He motivates his students through formative assessments that also help him determine how well they are learning. Indirectly, he motivates his students by focusing on self-efficacy. He gives his students a lot of small, confidence boosting successes before they step in to large arenas and perform. His motivation strategy also incorporates competition, team activities, and mentors for his bands.

Fourth, Evan uses listening and self-observation as an instructional strategy. He teaches his students what to listen for in the music and in themselves as they play their instruments.

Fifth, Evan uses self-judgement as an instructional strategy. He teaches them to make a self-judgment of their own performance by comparing it to a goal they have for themselves. As a result, their future efforts will be affected by how they react to their self-judgment. 
Sixth, Evan uses home practice as a strategy to teach his students to become selfregulated learners. He teaches them to practice in front of a mirror. Or they can go over to a friend's house and practice with them. Either way, it is important that they hear the wrong notes and identify and emulate the best musicians out there in order to improve.

\section{Research Question Two: Assessment of Self-Regulated Learning. Evan}

reported that he uses formative assessments to assess his students' levels of selfregulatory development with respect to their performance skills. He stated that he gives "lots of formative assessments. Not a lot of summative assessments." "There's a certain point of saturation where I have to choose to rehearse the group or take a day to test everyone. More formative assessments along the way or more summative? So, I think we use a lot of these in various forms during the year" (Interview 1).

\section{Research Question Three: Most significant Self-Regulation Strategy. Evan} explained that the most significant self-regulation strategy his students could use is the "self-evaluation" strategy. He stated that, "I don't think they do it enough within their own practice. I could see a reflection sheet or turning in a recording and then having them being graded on their comments after their recording. These are things that I probably should do" (Interview 2).

\section{Richard: Enrichment Through Music}

Richard comes from a musical family and has a music performance background that has helped him sustain a participatory role in music for his entire life. His mother encouraged him as a child and he had "a great band director" who "took him under his wing" (Interview 1) and helped him develop the performance and teaching skills he would need to become a successful band director and educator himself. "The experiences 
that brought are second to none" (Interview 1). Richard stated emphatically that his career path was established early on in his life and that he knew that's what he wanted to do for a living.

Overall, Richard underscored the immense value of the experiences students will reflect on after their participation in school music programs has come to a close. $\mathrm{He}$ believes that they augment their well-being - to the point of life-long satisfaction - and help provide a deeper understanding of their society. "We tell kids all the time, 'it's such a rich experience"' (interview 1). Analysis of Richard's data revealed three themes: Structure music programs to build on fundamental precepts, be mindful of student learning needs, instruction should begin based on what the student already knows.

\section{Theme I: Structure Music Programs to Build on Fundamental Precepts}

School music programs help students learn to communicate ideas and beliefs effectively and encourages them to develop and apply problem-solving skills on their own (Miksza \& Gault, 2014). To help students learn, solve their own problems, and be accountable for their own educations, Richard focuses on: curriculum, classroom instructional strategies, and his pedagogical principles.

First, Richard starts with "a good curriculum" (Interview 1) that is built on the foundation of a "sound elementary music program" (Interview 1) from which middle school and high school students have emerged. He insists that schools must have a good curriculum in place if students are to fully participate in musical experiences. "You have to have good fundamental music education going on" (Interview 1) throughout the course of a student's primary and secondary grade education. 
Instrumental music curriculum focuses on musical elements such as rhythm, harmony, and melody. Music literacy helps students communicate and collaborate effective with others. Beyond that, some of those skills can transfer to life experiences outside the classroom. Literacy help students continue to actively participate in creative musical opportunities for the rest of their lives (Lowe \& Belcher, 2012).

Second, Richard uses a variety of classroom instructional strategies to help his students learn. "You're there to facilitate the learning, to coach, to model" (Interview 1). According to Richard, "good teachers always model” (Interview 1). In fact, as Richard states, "modeling is huge in the music classroom" (Interview 1). Additionally, since literacy in instrumental music is essential, "developing sight-reading skills" (Interview 1) becomes a necessity. Consequently, much of the purpose of his music room instruction is to "get those kids to sight-read" (Interview 1). To do that, he "teaches them one note at a time" (Interview 1) and continually provides "useful feedback" (Interview 1).

In his instruction, Richard relies on a "good method" (Interview 1) where he first "clearly defines outcomes and learning goals" (Interview 1). These in essence become a useful map for the students that helps them understand the objectives of their learning. "Always communicate clear, concise learning outcomes to your students" (Interview 1). He tells his students, "this is what we want to accomplish, this is the outcome we want to see" (Interview 1).

He also provides scaffolding during lessons. The idea is to help with skill building and "achievement" (Interview 1). Richard also emphasizes the importance of listening to musical examples with his students and demonstrates what to listen for in an effort to "teach them how to do it right" (Interview 1). 
Instruction in instrumental music helps students gain an appreciation for learning artistic processes and building specialized skills. Students can also learn to pursue quality in their performances and appreciate the benefits of pursuing quality in their lives when they understand that these things are objectives in their learning.

Third, Richard applies pedagogical principles to his instruction. Chiefly to help his students get "cultural experiences" (Interview 2) and has even gone so far as to take his students "to a ropes course to work on team building and relationships in the band" (Interview 2). The idea is to reinforce in his students that music performance requires teamwork and that "you're a piece of this section" (Interview 2).

Students, according to Richard, also need to know that "they are in a safe environment" (Interview 1) and "can make mistakes, because that's how you learn" (Interview 1). "They have to know they can make mistakes" (Interview 1). Richard gives his students the freedom to make mistakes as they study. They are not going to learn "if they are going to have a fear of being wrong" because "they learn by doing" so there needs to a "freedom and a safety in the music room" (Interview 1). He may say to his clarinet players, “clarinets, you've got to rip that! Don't be afraid to screw it up fifty times" (Interview 1). To learn a musical instrument, students must be comfortable in their environment. Much of the learning comes in the form of trial and error where the student constantly compares their performance with that of a desired goal until they reach the goal (McPherson \& Zimmerman, 2011).

\section{Theme II: Be Mindful of Student Learning Needs}

Students enter school music programs to learn to play musical instruments, gain an understanding of the role and history of music in their worlds, and to enjoy 
communicating and performing in musically artistic ways cite. To help students realize their endeavors, Richard helps them overcome learning barriers and accept responsibility for their own education by focusing on: their personal needs, assessments, and their home and family lives.

First, Richard focuses on their personal needs. He likes to diagnose "what purpose students have for being in a band" (Interview 2) and then help them with "what's lacking" (Interview 2). Kids, he says, "have to buy into the program" (Interview 2). It has to "have some meaning for them." (Interview 2). To give them meaning, he "makes them see the excitement of success and celebrate the little things along the way" (Interview 2).

To address their needs, he also makes sure that he is "teaching the fundamentals and "keeping them motivated" (Interview 2). According to Richard, motivation is fostered with "goals" (interview 2) that align with individual abilities. Some students can achieve higher goals and outperform others in that respect but nevertheless, at his school "there's really a place for everybody" (Interview 2). Students need their teachers help in developing certain skills. As a result, music educators have the opportunity to not only teach students performance skills on their instruments, but also how to appreciate the rewards that come along with it. The rewards help students remain persistent in the face of learning challenges (McPherson \& Zimmerman, 2011).

Second, Richard focuses on assessments in his music room. "You have to give them playing tests. That's how you know" (Interview 2) they are learning and practicing as they should. He also used to require his students to "keep practice logs" and makes the logs "a part of their grade" (interview 2). Assessments in instrumental music are 
designed to determine the status of a student's learning progress. Formative assessments, such as weekly performance tests, give an educator regular updates about in process learning. Summative assessments, such as performance tests, are used to determine if students have learned what was expected of them over the course of a whole semester.

Third, Richard focuses on his student's home and family life. The reason is because of the discouragement that sometimes finds its way into the lives of his students. "What kind of support are they getting at home?" (Interview 2). There may be financial hardships. "Are they a kid whose main concern is getting breakfast?" (Interview 2). Not only that, but "can they practice?" (Interview 2). Parents need to be able to provide their students with the physical space and time they need to learn. Furthermore, "parents think cheap instruments are going to work" (Interview 2). Or even worse, the parents "can't afford to buy an instrument," (Interview 2) or even get the one they have repaired. Richard takes the time in class to address these issues with his students and teaches them "what a successful practice session looks like and "how to block out a practice time" (Interview 2). He also teaches them "what to practice and how to practice" (Interview 2). "Practicing is vital and the band director who slacks off on that gets beat down' (Interview 2). Otherwise, "the kid goes off and says, 'what am I supposed to do? I'm going in there and I don't know what to do" (Interview 2). So first, "show them how to practice, and then what to practice. Do this, do this, do this." (Interview 2).

Students also need to "learn how to correct themselves. He likes to "give them ideas to try" and suggests "goal-setting" as a practice strategy as well as to keep track of their learning. They should also "put time in to listening to good musicians and take 
private lessons if they can afford them," (Interview 2) or record themselves because "recording yourself is an awesome home practice strategy" (Interview 2).

Nevertheless, helping students to learn on their own in practice is "not easy because you're not there with them" (Interview 2). With the parents on board in that respect, you can help them understand what it is they need to do. "You can even switch them to different instruments" (Interview 2) if needed.

Home and family life can either help or hinder a student's success in music. For Richard, his family was helpful and had a part in setting him up for a career as a band director and as a life-long music performer. "It didn't take long for me to just know what I was going to do" (Interview 1). Unfortunately, the reality is that not all students have the same opportunities or access to the same resources and underscores the need for music teachers to be sensitive to the experiences their students are having at home. Understanding a student's home life can help a teacher better help his student.

\section{Theme III: Instruction Should Begin Based on What the Student Already Knows}

New instruction can begin after a teacher observes what a student currently knows. Once that has been established, teachers can create learning goals that align with course objectives and introduce new skills sets and knowledge to underpin a healthy work ethic and the creation of problem-solving skills that may transfer to circumstances beyond the world of music. To support those aspects, Richard focuses on: personal behavior, self-efficacy, and his students' listening skills.

First, Richard focuses on his students' personal behaviors. There are bound to be issues relating to music room conduct, attention spans, and motivations because "you're dealing with kids." Nevertheless, "most kids want to please their teacher." He points out 
that some students are just not going to behave the way they should in order to make adequate progress. Richard argues that "they could just be lazy. what does he do about that? Self-regulating students who are participating in school music programs generally make efficient use of their time, strive to develop and maintain their performance skills, and anticipate new instruction. They use a variety of strategies when practicing on their own, are usually able to solve their own problems, and work well in groups.

Second, Richard focuses on his student's sense of self-efficacy. He believes that some students “don't have any self-confidence” (Interview 2). By that he means they don't believe they can do the things necessary to learn and perform at the level he establishes as an expectation. If the problem doesn't get addressed, “they don't want to practice because they sound like crap" (Interview 1). It could just be that "sometimes they're on the wrong instrument." Nevertheless, he tells them "there's a player in everybody" and that "it's like learning a language" (Interview 1). Self-efficacy is an essential element for students in school music programs. Student's with a high sense of self-efficacy are more inclined to try as hard as they can when confronted with difficult tasks while students with lower self-efficacy are inclined to quit when the going gets tough.

Third, Richard focuses on his student's listening skills. Most importantly, as “a musician student's have to listen" (Interview 2). Helping them develop their listening skills helps "get them to do what I want them to do" (Interview 2). If they can't control their own thoughts while learning, they don't exert any effort to try and learn. As a result, Richard asks, “who’s working harder, the student or the teacher?” (Interview 2). To that end Richard offers, "you've just got to fight through it" (Interview 2). The 
deliberate, conscious control of one's thoughts and learning activities are fundamental to musical instrument practice. Without the capacity to think through a learning period on a musical instrument, students are not likely to develop performance skills.

\section{Summary of Richard's Case.}

Three themes emerged from Richard's case. First, Richard stressed the importance of structuring music programs to build on fundamental precepts. Music programs should begin in the primary grades and continue through the secondary grades. Second, he emphasized that music teachers should be mindful of student learning needs. Students are individuals who have different backgrounds, personalities, and educational requirements and therefore teachers should remain cognizant of what they will need to learn effectively. Third, he stated that instruction should begin based on what the student already knows. Given that music learning is sequential in nature, it would be detrimental to teach new concepts without teaching the foundational material to those concepts. I described Richard as a teacher who believes that personal enrichment comes through music. Richard stated that the experiences related to musical performances are substantial and long-lasting and offer much in the way of personal rewards for the student. Now I discuss Richard's case as it relates to the main research questions of this study.

Research Question One: Instructional Strategies. Richard uses six instructional strategies to teach his students to become self-regulated learners. First, he uses task-analysis as a strategy in the form of sight-reading exercises. This is done because literacy in music is essential to an effective performance and therefore sightreading skills as an element of literacy become a necessity. The task-analysis strategy is 
also used in the form of step-by-step instruction where he teaches one note at a time while providing useful feedback. Finally, the task-analysis strategy is used with goalsetting. Richard defines outcomes and learning goals which in essence become a roadmap of learning for the students.

Second, Richard uses motivation as an instructional strategy to teach is students to become self-regulating learners. One way is by allowing his students to make mistakes while they practice their repertoire because in fact that is how they learn. According to Richard, feeling safe enough to make mistakes in front of others minimizes discouragement among the students and keeps them motivated to learn. The next way Richard uses motivation is to diagnose the student's purpose for being in his band. By understanding that, he can help them find more meaning for participating. The next way Richard uses motivation as an instructional strategy is with testing. For him, playing tests indicate whether or not his students are practicing as they should and encourage the students to practice in order to earn a better grade. Richard also uses practice logs to motivate his students because they are a part of their grades.

Third, Richard uses listening skills as an instructional strategy to help his students become self-regulating learners. He does this in two ways. First, by teaching his students to listen to musical examples and demonstrate what to listen for. This helps with skill building and achievement on the part of the students and thus keeps them motivated to learn. Second, by teaching his students to listen and watch for his instruction during performance. The idea is that they will better control their own thoughts and remain motivated to work harder while he is teaching. 
Fourth, Richard uses modeling as an instructional strategy to teach his students to become self-regulated learners. According to Richard, instrumental music teachers always model for their students.

Fifth, Richard uses self-observation via goal-setting as an instructional strategy to teach his students to become self-regulated learners. The idea being that when they use goals in their practice, they will keep better track of their learning and have a more accurate perception of their learning progress.

Sixth, Richard uses home practice preparation as an instructional strategy to help his students become self-regulating learners. Richard takes the time in class to address home practice issues with his students and teaches them what to practice and how to practice so they understand what a successful practice session looks like.

Research Question Two: Assessment of Self-Regulated Learning. Richard uses formative assessments to determine his students' levels of self-regulatory development with respect to their performance skills. He stated that, "I think you have to have playing tests. That's how you know. Soli and sectional playing. Right off the bat I want everybody to know their scales. My director has a chart and he's assessing them but it takes time. It takes time out of rehearsal but this goes right back to 'are you trying to go from concert to concert, or are you trying to teach music?'” (Interview 2).

Research Question Three: Most significant Self-Regulation Strategy. Richard indicated that the most significant self-regulation strategy his students could use is the "goal-setting and planning" strategy. He stated that, "definitely for me - goal-setting. When you're able to clearly define your outcomes and your learning goals, it starts there 
whether it's in rehearsal or in English class, when they come in, 'this is what we want to accomplish, this is the outcome we want to see" (Interview 1).

\section{Samuel: The Student Already Knows How It Goes}

"Electric guitar and rock and roll" (Interview 1) are what got Samuel interested in music as a child. But since then he has learned to play the violin and the piano, compose, conduct, and teach classical music. "Violin is the instrument which I most shape music with," (Interview 1) but "the piano is the instrument I most understand. It's vertical, linear, structural. As a composer and conductor, I use piano a lot just to find out what's in the music. It's a practical instrument for me" (Interview 1).

Academically, Samuel earned a bachelor's degree in music composition from a large midwestern university, a master's degree in composition from a large southwestern university, and a doctor of musical arts degree in composition from a large southern university. He also traveled to Europe and earned another graduate degree in music composition from a conservatory. "That was one of the most important degrees I've gotten." (Interview 1). Then he came back to the U.S. and got a master's degree in conducting at a large midwestern university.

Samuel got his start in education as an orchestra conductor because, as he says, "it is up to me teach the orchestra how it goes, how it works, and the musical ideas, in order to accomplish the goals I have." He has been teaching and conducting both middle school and high school students, as well as adults in orchestras for over a quarter century.

Overall, Samuel's teaching strategies address the practical needs of his student's and himself. With some students "a single word can solve a massive amount of issues" (Interview 1). With others, "you have to stimulate their interests" (Interview 1). 
Analysis of Samuel's data revealed three themes: Teaching and learning happens through relationships, mastery of music starts and ends with honesty, and knowledge is a kinetic hypothesis.

\section{Theme I: Teaching and Learning Happen Through Relationships}

According to Samuel, teaching and learning opportunities in instrumental music happen through a unique relationship between interrelated factors including: the delivery of his instruction, the student's responses to his instruction, and the personal connection his students have with their instruments.

First, Samuel focuses on his instruction in the music room. His intent is to help his students understand that music is a form of communication, they are a part of the artistry in the communication, and to explain to them how music can be personally satisfying for the composer, the performer, and the listener.

He begins by "stimulating their interest" (Interview 1) in the music. Then to simply "teach how the music goes" (Interview 1). For that, he has to figure out how he is actually going to "physically communicate to a player, 'it's time to play that note."” (Interview 1). He also stresses the importance of helping students get to the point where they can interpret music for themselves; especially in an artistic sense on their instruments. "Don't ever let anyone tell you a quarter note is exactly so long, because it's not" (Interview 1). For Samuel, artistry in instrumental music instruction begins with an understanding of how he is going to convey the meaning of the music to the musicians and how they are going to interpret what is written before them. He also takes the time to convey to his students a belief in themselves that they have the capacity to influence the music's character by modifying expressive elements with their interpretations. 
Second, Samuel helps his students learn by considering their responses to his instruction. To do that, he makes an initial effort to "earn the student's trust" (Interview 1). Then, he engages in a strategy called "points of praise for points of critique" (Interview 1). Samuel argues that it is imperative that his student's response to his critique in a positive way. For him, this strategy helps his students "to be more receptive" to his instruction and criticisms. "You have to praise a student when they do something well" and "you have to mean it. "You can't say it gratuitously" so "when you deliver the critique, the student will be more receptive." (Interview 1). Dignity in the music room can help foster learning. Educators who are mindful of that precept first provide their students with praise for doing something well, then offer a critique to improve their performance.

Third, Samuel advises his students to get to know their instruments because as musicians, they "must pursue knowledge in relationships" (Interview 1) and one of the most important relationships they can have is "that relationship with the instrument" (Interview 1). He tells them that "you have to see it as a living object with which you can have a dialog. If you do, it will speak back to you" (Interview 1). As musicians, their relationships with their instruments "are rhetorical" (Interview 1). By that he means the relationship between the musician and their instrument are linguistic in nature. $\mathrm{He}$ suggests that "the dialog you have with your instrument is no different than the dialog you have with people" (interview 1) and considers how "I can't imagine working hard on something that you weren't interested in having a dialog with" (Interview 1).

Samuel also points out the importance of the teacher/student relationship. He tells his students, "I'm no different than you" (Interview 2). By that he means that he faces 
the same problems and challenges as them and that he shares the same experiences and emotions as them. Nevertheless, "if you don't understand me, I won't understand you." As a consequence, he takes pains to teach as directly as possible. For example, when explaining how music functions as a language art he states "you have to communicate to the kid that this is the most primary thing there is" (Interview 2). Instrumental musicians should consider how their instruments work in relation to how they think and feel, and how music functions as an art form. Students who know their instruments can realize better self-satisfaction, improve musical performances, and reduce anxiety. Teachers should have a working idea of their student's level of knowledge in order to be certain new information in being conveyed in terms they can understand. this sounds like good teaching.

\section{Theme II: Mastery of Music Starts and Ends With Honesty}

Most students eagerly enter music programs with preconceived ideas about how they will perform on a musical instrument and should have the chance to affirm them through a process that lets them reap the rewards as well as experience the labor they will need to exert to attain them (McPherson \& Zimmerman, 2011). To help his students take responsibility for their own educational goals and rise to the challenge's they are likely to face, Samuel focuses on: their personal interests, their home and family life, and their metacognitive skills.

First, Samuel focuses on the student's personal interests. He posits that "you have to make them interested in discovering their talent" (Interview 2). "They have to want to find out" (Interview 2). Although "some students are more serious than others" (Interview 2), he informs music teachers to "make sure everyone is given the opportunity 
to realize that they want to do it" (Interview 2). To fortify that point with his students, he argues that their performance is their voice. "This is what you are about. You have something to say here" (Interview 2). Nevertheless, not all students remain interested in music throughout their entire academic lives. "Let's face it, no matter the strategy, theory, or philosophy, you're not going to have 100\% success" (Interview 2). Some students lose interest or "only do it as a diversion" (Interview 2).

Students enter and leave music programs for a variety of reasons (McPherson \& Zimmerman, 2011). Some join because their friends are involved, others join because they enjoy learning. Still other participate because they want to experience the thrill of performing for audiences. To the contrary, students also leave because they have difficulty solving the ancillary problems associated with musical instrument study.

Second, as do the other participants, Samuel focuses on his student's home and family life. He notes that support from home can come by "helping the student's approach music the way they do other things" (Interview 2). He suggests that if you "ask a 14-year-old student what she is interested in, you can stimulate her interest in music by relating it to that interest" (Interview 2). Parents also need to reinforce the idea to their children that when it comes to instrumental music, "it's ok to learn about this. Let them see that what they're doing is connected to everything" (Interview 2). Homes where music study is valued, and parents are actively participating in supporting their child's learning, create an environment that helps them create their own values and establish personal educational and achievement goals for themselves (McPherson \& Zimmerman, 2011). 
Third, Samuel focuses on his student's metacognitive skills. He reported that how students' think about their learning can be tied to their motivation. In order for them to learn effectively, "they must absolutely want to deal with the material" because if they don't have that deep hunger, it's just not going to work" (Interview 2). When it comes to their own thinking in terms of solving music related problems, he propounds that many of their problems will take care of themselves once they start to work. He tells them, "just start doing it. Just trust me. Just start the job" (Interview 2). Knowing one's own learning habits helps students identify strategies that will efficiently and effectively help them learn. After considering their own personal thinking processes, students can better assess learning tasks, learning strategies, and learning preferences before they begin to work on the task at hand.

\section{Summary of Samuel's Case.}

Two themes emerged from Samuel's case. First, teaching and learning happen through relationships. According to Samuel, relationships not only exist between the teacher and student but also between the musician and his instrument. It is this relationship that concerns Samuel the most. Second, Samuel believes that the mastery of music starts and ends with honesty. The student must be honest with himself and with his teacher if he is going to become a skilled expert. I described Samuel as an educator who believes that "the student already knows how it goes." This describes his approach to musical performances in that he believes that musical expressions, even when they are described in minute detail by the compose on manuscript, are inherently personal in nature and ultimately an artistically interpretive product of the musician. Now I discuss Samuel's case as it relates to the main research questions of this study. 


\section{Research Question One: Instructional Strategies. Samuel uses two}

instructional strategies to promote self-regulation in his students. First, he uses selfreflection in order to show his students that they can realize better self-satisfaction, improve their musical performances, and reduce anxiety if they reflect on the relationship they have between themselves and their instruments. Second, he uses motivation to promote self-regulation in his students. He argued that motivation is integral to learning. The student must want to deal with the music and have the desire to learn. Otherwise, they won't make much of an effort. Motivation, according to Samuel, stimulates interest within the student and helps them maintain an interest in discovering their own talent.

\section{Research Question Two: Assessment of Self-Regulated Learning. Samuel} reported that in addition to using formative assessments to assess his students' levels of self-regulatory development with respect to their performance skills, he also engages in conversations with them to get a working idea of how well they are learning on their own. He stated that he tells them, "this is what you are about. You have something to say here. You must be interested in that. You have to see it as a living object with which you have a dialog. I can't imagine working hard on something that you weren't interested in having a dialog with" (Interview 1).

\section{Research Question Three: Most significant Self-Regulation Strategy.}

According to Samuel, the most significant self-regulation strategy his students could use is the "seek information" strategy. This strategy focuses on non-human sources students can turn to for learning. Samuel stated that, "if a student is not seeking information on their own and is depending only on the teacher to teach them, the limits are severe" (Interview 1). 


\section{Summary of Chapter Four}

The McPherson and Zimmerman (2011) self-regulation of music learning theory informs the data analysis of the topical discussions by the participants on theoretical elements such as the role of the individual, their personal behavior, and the environments in which they learn. The data also tell of the importance the participants gave to the concepts of modeling, student self-efficacy, their motivations, the importance of their metacognitive actions while learning, and the influence of social factors such as parental support. Other data informed the theory by suggesting students allocate and manage practice time either with the help of others on their own.

Overall, these teachers enacted different strategies and approaches for supporting self-regulated learning. The participants reported that modeling was the most important strategy they have to teach their students, regardless of the topic. They reported that they model performance skills on their instruments as well as certain personal behaviors for their students to emulate. The participants were also unanimous in their response in that they use formative assessments, performances, and competitions to observe and measure their student's learning progress.

Finally, participants identified related, but different strategies as most significant for their students to adopt. The most frequent strategies identified by the participants were self-evaluation, goal-setting and planning, seeking information, and seeking social assistance. Self-evaluation, according to the participants, helps their students keep a good perspective on their learning progress. Some of the participants believed that goalsetting and planning are useful when it comes to motivational issues. Samuel actually felt that students should be learning so fast that goals shouldn't matter to them. The 
participants believed that seeking social assistance from other teachers or peers provide additional opportunities to observe other models and gain additional perspective on approaches to music performance. A cross-case analysis of the findings as they relate to the research questions is discussed in Chapter 5. 


\section{CHAPTER FIVE: CONCLUSIONS, LIMITATIONS, FUTURE \\ RESEARCH RECOMMENDATIONS, AND IMPLICATIONS \\ Introduction}

This chapter is organized around the literature review, a with-in case analysis, a cross-case analysis, the McPherson and Zimmerman (2011) theoretical framework, the results as they relate to the research questions, the limitations, future research recommendations, and implications for teachers.

\section{Statement of the Problem}

The ability to self-regulate learning becomes especially important as children and adolescents who, upon entering a school music program, are frequently required to spend large amounts of time in solitary practice periods learning a musical instrument where there is an absence of immediate instructional feedback from a teacher. Consequently, students who enter school music programs, but lack the knowledge, skills, and strategies necessary to solve their own learning problems, can fall behind, fail, or ultimately drop out (Boyle, De Carbo, \& Jordan, 1995; McPherson \& Zimmerman, 2011; Miksza, 2012; Sandene, 1994).

\section{Research Questions}

Three research questions guided this research:

1. What instructional strategies do instrumental music teachers report using to help their students become self-regulated learners on their musical instruments?

2. How do instrumental music teachers assess their students' levels of selfregulatory development with respect to their instrumental music performance skills? 
3. What self-regulation strategies do instrumental music teachers perceive as most significant for students learning to play musical instruments?

\section{Within-Case Findings}

The purpose of this within-case analysis was to illuminate unique experiences for each participant, provide a deeper understanding of each case, and offer descriptions that allow readers to determine transferability of the case for themselves (Stake, 1995). This transferability, like generalization, focuses on the commonalities and differences between participants' perceptions, their experiences, and the ways they make sense of their teaching practices (Lincoln \& Guba, 1985). The quantity and direction of the themes that emerged from the with-in case analysis varied with each participant.

Although they are varied in scope, each participant nevertheless identified beliefs and instructional practices they feel they need to be mindful of as they teach their students to play musical instruments. Table 5 om page 65 displays the themes that emerged from each participant's data. Although the themes were different for each participant, they each nevertheless illustrated certain imperatives for readers to consider. Among them were their emphatic comments about the effectiveness of modeling performance skills as an instructional strategy and how well students observe their demonstrations in the music room. To them, the acquisition of knowledge and skill for students is gained through the experience of watching others and then emulating their actions during practice trials.

The participants also emphasized the importance of home practice, the personal efforts their students put in to learning, and the question of honesty in learning. Home 
practice can be a challenge for many young learners as it requires a fundamental change in behavior on the part of the student, an adaptation of their environment, and a tolerance by others who have to endure the inconvenience of noisy musical instruments. They also suggested that, from the student's perspective, honesty with one's self helps to identify strengths and weaknesses in musicianship.

Finally, the themes suggest the importance the participants place on the use of formative assessment to determine how well their students are learning, and by extension, how well they are self-regulating their behavior in the classroom and during home practice. The themes also suggest that instrumental music learning requires a structured curriculum in which students are taught the technical and performance aspects of instrumental music in a step-by-step process.

\section{Addressing the Research Questions: Cross-Case Analysis}

To facilitate a comparison of the commonalities and differences among the six participants, a cross-case analysis of the within-case themes was completed. Each of the research questions was considered when framing the cross-case analysis (Stake, 2006).

\section{Research Question 1: Instructional Strategies Used to Foster Self-Regulated}

\section{Learning}

The authors of the McPherson and Zimmerman (2011) music learning theory address the fact that instrumental music learning requires a high degree of self-regulation on the part of the student. To succeed, they must be "metacognitively, motivationally, and behaviorally active participants in their own learning" (Zimmerman, 1989). All six participants addressed the behavioral self-regulation issue of self-observation but held 
conflicting beliefs as to its relevance in their teaching practices. Additionally, all six participants agreed that environmental self-regulation (shaping and monitoring one's learning space) is important and that finding the proper practice space is important to learning.

According to McPherson and Zimmerman's (2011) music learning theory, students move through four developmental levels of self-regulation: observational, emulative, self-controlled, and self-regulated. At the first level, learners simply attend to learning by observing a model perform a skill. They move to the emulative level as they attempt to learn it on their own and rely on social feedback and social guidance for further refinement. When they acquire the skill in full, they rely more on their own internal standards and turn to solitary practice to consolidate it (self-controlled). Once the skill has become automatized, the student uses self-regulatory processes such as selfreflection and self-efficacy to address their personal motivational issues.

There were several similarities across the cases. Overall, teachers reported that they use ten separate strategies to promote self-regulation for their students. These instructional strategies include modeling, discussing task-analysis, motivation, home practice preparation, listening skills, self-evaluation, self-reflection, self-control/selfinstruction, self-judgment, and self-observation with setting goals. Four general insights can be drawn from the data. First, all of the participants held the view that modeling as an instructional strategy was the best way to teach instrumental music. Second, they also believed that home practice was essential for skill building and suggested similar practice strategies such as finding an appropriate workspace. Third, they all believed that relationships between them and their students facilitated communication, provide for 
emotional security, and ensured mutual respect. Fourth, they all agreed that the inclusion of students' families in the learning process facilitated learning.

More specifically, two aspects of the data stand out: the use of instructional strategies related to fostering self-regulation across McPherson and Zimmerman's phases and different ways teachers prepared students to be independent learners in their home practice.

Instructional strategies for self-regulated learning. The authors of the McPherson and Zimmerman's (2011) self-regulation of music learning theory incorporate a reciprocal three-phase problem-solving process to music learning when students face challenging work. They cycle through forethought, performance, and selfreflection in successive order to achieve their goals. In the forethought phase, they reflect on their progress and engage in personal thoughts where they consider task analysis activities such as goal-setting and strategic planning, and contemplate self-motivating beliefs such as self-efficacy, their intrinsic motivations, and their goals. In the performance phase, students exert volitional self-control as they focus their attention, employ learning strategies, and use self-instruction to learn while metacognitively monitoring their learning progress relative to their goals. In the self-reflection phase, students exercise self-judgment through self-evaluation, attribute reasons for failure or success in their efforts, and then react with either self-satisfaction or adaptive behaviors.

Table 6 illustrates the general strategies that the participants reported that they used. These strategies are categorized by which phase of the McPherson and Zimmerman (2011) model the strategy supports. 
Table 6. Instructional Strategies for Self-Regulated Learning

\begin{tabular}{|c|c|c|c|}
\hline & Forethought & Performance & Self-Reflection \\
\hline Tim & $\begin{array}{l}\text { Modeling: expository teaching, } \\
\text { sight-reading } \\
\text { Task-analysis: benchmarks, small } \\
\text { steps } \\
\text { Fosters motivation: compliment } \\
\text { \& critique }\end{array}$ & $\begin{array}{l}\text { Strategies for home } \\
\text { preparation: monitor } \\
\text { environment, goal- } \\
\text { setting }\end{array}$ & $\begin{array}{l}\text { Self-judgment: self- } \\
\text { recording and } \\
\text { listening }\end{array}$ \\
\hline Ivan & $\begin{array}{l}\text { Modeling: demonstration and } \\
\text { imitation } \\
\text { Task-analysis: bench marks, goal- } \\
\text { setting and planning, small steps } \\
\text { Fosters motivation: makes it fun, } \\
\text { peer mentoring }\end{array}$ & $\begin{array}{l}\text { Strategies for home } \\
\text { preparation: } \\
\text { monitor environment, } \\
\text { self-recording }\end{array}$ & \\
\hline Gertrude & $\begin{array}{l}\text { Task-analysis: } \\
\text { small steps, logical sequence, } \\
\text { scaffolding } \\
\text { Fosters motivation: assessments, } \\
\text { goal-setting peer mentoring }\end{array}$ & $\begin{array}{l}\text { Listening and self- } \\
\text { observation strategy: } \\
\text { monitor performance } \\
\text { Self-control/self- } \\
\text { instruction: } \\
\text { self-regulate learning } \\
\text { behaviors, seek help } \\
\text { from others } \\
\text { Strategies for home } \\
\text { preparation: practice } \\
\text { techniques, monitor } \\
\text { time }\end{array}$ & \\
\hline Evan & $\begin{array}{l}\text { Task-analysis: } \\
\text { small steps, logical sequence } \\
\text { Modeling: demonstration and } \\
\text { imitation } \\
\text { Fosters motivation: } \\
\text { assessments, goal-setting, peer } \\
\text { mentoring }\end{array}$ & $\begin{array}{l}\text { Listening and self- } \\
\text { observation strategy: } \\
\text { monitor performance }\end{array}$ & $\begin{array}{l}\text { Self-judgment: } \\
\text { comparing one's } \\
\text { performance against } \\
\text { established goals }\end{array}$ \\
\hline
\end{tabular}




\begin{tabular}{|c|c|c|c|}
\hline Richard & $\begin{array}{l}\text { Task-analysis: } \\
\text { sight-reading, elements of literacy } \\
\text { small steps } \\
\text { Fosters motivation: } \\
\text { fosters a sense of safety for risk- } \\
\text { taking, uses tests, practice logs } \\
\text { Listening skills: } \\
\text { students listen to examples, listen } \\
\text { to modeling } \\
\text { Modeling: demonstrations }\end{array}$ & $\begin{array}{l}\text { Self-observation via } \\
\text { goal-setting: } \\
\text { track learning } \\
\text { progress based on } \\
\text { goals } \\
\text { Strategies for home } \\
\text { preparation: } \\
\text { practice techniques } \\
\text { and monitor } \\
\text { environment }\end{array}$ & \\
\hline Samuel & $\begin{array}{l}\text { Fosters motivation: } \\
\text { fosters intrinsic motivation } \\
\text { between the musician and } \\
\text { instrument }\end{array}$ & & $\begin{array}{l}\text { Self-reflection: } \\
\text { musician's personal } \\
\text { dialogue with } \\
\text { instrument }\end{array}$ \\
\hline
\end{tabular}

Table 6 shows the instructional strategies the participants attest to use to teach instrumental music to their students and the relationship of those strategies to the threephase problem solving process used in self-regulation as viewed from the student's perspective. Most of the instructional strategies the participants reported that they use appear in the forethought phase. They include modeling, task analysis, and fostering motivation. Only Richard discussed a listening skills strategy as part of the forethought phase.

Instructional strategies that relate to the performance phase include home preparation and self-judgment. The home preparation strategy further breaks down instruction to specific practice techniques for students to employ including practicing in front of a mirror, practicing with friends, and environmental monitoring. Other strategies included goal-setting and self-recording. With the self-judgment strategy, Tim suggested that students should record and listen to their practice performances.

The performance phase also included a self-observation strategy that Gertrude, Evan, and Richard reported to have suggested and a self-control/self-instruction strategy 
Gertrude said she suggested. The self-observation strategy requires students to monitor their performances and track their progress based on learning goals. The selfcontrol/self-instruction strategy requires students to take deliberate measures to talk themselves through a learning sequence and employ technical practice strategies as aids.

Only two participants indicated that they utilized instructional strategies that prepared students for the self-reflection phase. As a self-reflection strategy, Evan claimed to have suggested using self-judgement to compare one's performance against established goals. This is in contrast to Tim who said he suggested that students use selfjudgement while listening to the playback of personal recordings made during the performance phase. The other instructional strategy was self-reflection, which Samuel shared that he suggested. He believed that students should think about the relationship they have with their instruments and reflect on the importance it has in their lives.

As illustrated in Table 6, teachers reported that they employed instructional strategies that assisted students in the forethought phase through modeling, task analysis, and goal setting. Few teachers said that they addressed strategies that helped students become reflective or self-evaluative.

Preparing Students for Home Practice. As shown in Table 6, most participants in the study reported that they attempted to give their students home practice strategies to help them to be more effective in their home practice. Table 7 lists the most frequently used strategies. 
Table 7. Strategies for Home Practice

\begin{tabular}{|c|c|c|}
\hline $\begin{array}{l}\text { Strategy and Participant(s) } \\
\text { Who Used It }\end{array}$ & Example(s) & Phase \\
\hline $\begin{array}{l}\text { Establish appropriate place to } \\
\text { practice: } \\
\text { Ivan, Tim, Gertrude }\end{array}$ & $\begin{array}{l}\text { No distractions, be seated in a } \\
\text { chair, use a music stand }\end{array}$ & $\begin{array}{l}\text { Performance } \\
\text { Self-control }\end{array}$ \\
\hline $\begin{array}{l}\text { Teaching practice technique: } \\
\text { Gertrude, Richard, Tim }\end{array}$ & $\begin{array}{l}\text { Use a metronome, play in } \\
\text { front of a mirror, repeat short } \\
\text { phrases, perform for others, } \\
\text { repetition of short passages }\end{array}$ & $\begin{array}{l}\text { Performance } \\
\text { Self-control }\end{array}$ \\
\hline $\begin{array}{l}\text { Setting up time management: } \\
\text { Gertrude, Richard, Ivan }\end{array}$ & $\begin{array}{l}\text { Schedule consistent practice } \\
\text { times, practicing for a set } \\
\text { amount of time }\end{array}$ & $\begin{array}{l}\text { Performance } \\
\text { Self-control }\end{array}$ \\
\hline $\begin{array}{l}\text { Practicing listening skills: } \\
\text { Evan, Ivan }\end{array}$ & $\begin{array}{l}\text { Listening to recorded music } \\
\text { so learn how to play it }\end{array}$ & Performance: self-observation \\
\hline $\begin{array}{l}\text { Practice with peers } \\
\text { Evan }\end{array}$ & Practice with a friend & Performance: self-observation \\
\hline $\begin{array}{l}\text { Setting goals to monitor } \\
\text { progress during practice: } \\
\text { Tim }\end{array}$ & Practicing scales & Performance: self-control \\
\hline $\begin{array}{l}\text { Self-record: } \\
\text { Tim }\end{array}$ & $\begin{array}{l}\text { Recording a musical passage } \\
\text { that the student plays and } \\
\text { compare to notes }\end{array}$ & Self-reflection: self-judgment \\
\hline
\end{tabular}

As Table 7 illustrates, most of the strategies that participants assert that they teach focus on self-control. Gertrude, Richard, and Ivan, for example, said they teach their students to exercise self-control when they ask them to hone their time managements skills by scheduling their own home practice periods. Tim also claimed that he teaches self-control by using goals as a way to help his students track their learning progress while they practice.

Only two strategies address self-observation. These include practicing listening skills and practicing with peers. Evan and Ivan reported that they use these strategies to foster self-observation in their students as they said they suggest to their students that 
they listen to recorded music as a way to learn to play it. Evan also suggested that his students practice with their friends.

Finally, only Tim specifically shared that he teaches a strategy for self-judgment. He said he teaches his students to record their practice performances and judge the quality of their performances. This helps them to more accurately assess their learning progress.

Samuel does not have a response included in the table, because the approach to home practice he described did not incorporate specific practice strategies like the other participants did. Samuel's approach to home practice centered more on a personal dialogue between the instrument and the student. As Samuel sees it, the dialog forges a relationship, which consequently gives the student a more intrinsic sense about home practice and thus transcends traditional home practice strategy issues.

The McPherson and Zimmerman (2011) self-regulation of music learning theory incorporates a reciprocal three-phase problem-solving process to music learning as well where students cycle through forethought, performance, and self-reflection in successive order to achieve their goals. In the forethought phase, they engage in personal thoughts where they consider task analysis activities such as goal-setting and strategic planning, and contemplate self-motivating beliefs such as self-efficacy, their intrinsic motivations, and their goal-orientations. In the performance phase, students exert volitional selfcontrol as they focus their attention, employ learning strategies, and use self-instruction to learn while using metacognition to monitor their learning progress relative to their goals. In the self-reflection phase, students exercise self-judgment through selfevaluation, attribute reasons for failure or success in their efforts, and then react with 
either self-satisfaction or adaptive behaviors. Both Table 6 and Table 7 show that teachers do not prepare students for the self-reflection stage. Most of the forethought strategies include modeling, task analysis, and fostering motivation. The home preparation strategies focus mostly on self-control.

\section{Research Question 2: How Teachers Assess for Self-Regulation}

Assessment is a "formal attempt to determine students' status with respect to educational variables of interest" (Schunk, 2012, p.14). Similarly, the role of assessment in instrumental music is to help the practitioner determine student achievement as it relates to technical and performance skills on their instruments. These same assessments can also help determine a students' level of self-regulatory ability.

To pass an assessment, students must be able to plan (forethought), execute (performance), and evaluate (self-reflection) their own learning (McPherson \& Zimmerman, 2011). As seen in the forethought phase, students must complete an analysis of the learning with which they are tasked, define learning goals, and plan how they will achieve them. They also consider their personal self-motivating beliefs and what they expect regarding outcomes. As seen in the performance phase, they will have to exercise self-control and use metacognition to monitor their thoughts and environment while they learn. They will also have to evaluate their progress relative to the goals and adopt new learning strategies if they are not achieving them.

Without going through this self-regulation problem solving process, students would not be able to adequately prepare for the assessment. Thus, self-regulation on the part of the student is observable and measurable. As McPherson Zimmerman's (2011) music learning theory states, there are four levels of self-regulation: observational, 
emulative, self-controlled, and self-regulated. To a certain extent, if they are able to perform on their instruments in the assessment, they are able to realize these levels in their learning.

In this study, participants indicated that they mostly used performance tests, both formative and summative, to assess their students' levels of self-regulatory development with respect to their instrumental music performance skills. The assessments had three main functions: monitoring student learning, holding them accountable, and fostering their self-satisfaction.

First, the participants revealed that they used assessments to monitor their student's learning. For example, Evan stated that he uses "lots of formative assessments. Not a lot of summative assessments" (Interview 2). He indicated that these assessments helped him monitor learning. Likewise, Ivan stated that he uses assessment to monitor learning. He stated that he likes to "establish achievable goals, have periodic assessments - playing tests, and have them establish a place to practice at home" (Interview 1).

Second, participants disclosed that they used assessments to hold their students accountable for their own practice behaviors. Gertrude stated, "People realize that they have to show that they practiced it...signing a piece of paper means nothing" (Interview 2). Ivan discussed accountability as well.

They come back the next day and everybody passes their test. Everybody gets it, and it's because you've now put that goal in front of them... if it doesn't go well, it's more than likely because the kid was too busy: 'I had softball last night,' 'I didn't get to practice because the baby was sleeping. 
Third, two participants claimed to use assessments for either determining motivation or to foster self-satisfaction in their students. When determining his student's motivation, Tim stated,

Usually the kid that comes in and is all set up and ready to go and they've got their book open and their ready, they're enthusiastically ready to play and they don't wait for me to tell them where to start. They know where they want to start. They know what they want to play for you. They teach me.

Samuel shared that he uses assessments to foster a sense of self-satisfaction in his students. He stated that “I can't imagine working hard on something that you weren’t interested in having a dialog with." Tim's alleged approach to assessment focuses on extrinsic motivation while the approach Samuel approach discussed focuses on intrinsic self-satisfaction.

These teachers report that they use assessment to determine how well their students are progressing. They also allegedly use them to hold students accountable for their learning. For the participants in this study, assessments seemed to be tied to the performance phase of the self-regulation music learning model: Students must metacognitively monitor their own learning, control their thoughts, and employ learning strategies. Based on actual strategies used by the teachers, which are illustrated in tables six and seven, participants did not really support student's self-evaluation in their teaching or as part of assessments. How can students fully self-regulate without selfevaluation?

Participants view of their assessments do not seem to foster self-regulation in their students. This matters to the field of music education because how the students feel 
about themselves and their ability to learn is at the heart of their interest and motivation in instrumental music performance.

\section{Research Question 3: Perceptions about Most Important Self-Regulation Learning Strategies}

As part of the interview process, participants were presented with a list of the most common self-regulation learning strategies and were asked to determine which strategy they believed was most important. (See Appendix B for the full list of strategies

provided.) The three learning strategies valued most by the participants were: selfevaluation, goal-setting and planning, and seeking social assistance. Next, I discuss how participants described these strategies.

Self-evaluation. Although only three participants reported using strategies that support self-evaluation or self-reflection, all participants valued self-evaluation. As a way for students to keep track of their progress. Gertrude for example, stated that selfevaluation is "the first thing that can be done to change, to improve, to fix something. I feel like it's the most important because it's the first step" (Interview 2). Tim noted that self-evaluation is useful so "They don't get the wrong idea about themselves" (Interview 2). Richard suggested, "Self-evaluation is huge. They need to know how to correct themselves, and to do that consciously" (Interview 2). Evan stated that he should probably require his students to evaluate themselves more often because "I don't think they do it enough within their own practice" (Interview 2). Samuel reported that he uses self-evaluation to learn and to reflect on as a conductor, "I videotape myself. I have to study and reflect on the gestalt of conducting" (Interview 2). Ivan revealed that he uses 
self-evaluation as a reflecting tool that helps his students improve their performances. "I might have to ask them for a self-evaluation" (Interview 2) when they are not doing well. McPherson and Zimmerman (2011) define self-evaluation as a way for students to respond to feedback, monitor their progress, and evaluate their learning. It is a process that occurs in the third phase of the McPherson and Zimmerman's (2011) self-regulation of music learning theory. It involves self-judgment and response on the part of the learner as they compare their current level of performance to a learning goal. As a consequence, students may feel a sense of satisfaction or resort to adaptive behaviors after they evaluate themselves (Schunk, 2012). All of the participants reported that they saw self-evaluation as beneficial to learning.

Although teachers in this study indicated that they valued self-evaluation as an important self-regulation skill, evidence in Tables 6 and 7 illustrates that three participants implemented instructional strategies that foster student's self-evaluation or self-reflection. Most participants asserted that they used instructional strategies that focused on goal setting and planning and only a few said they addressed self-evaluation and seeking social assistance in their teaching.

Goal-setting and planning. All participants except Samuel saw goal setting as a way to motivate their students. To the contrary, Samuel allegedly used students' personal interest in their dialog with their instruments to get them to practice.

Goal setting and planning is a process that occurs in the forethought phase of McPherson and Zimmerman's (2011) self-regulation of music learning theory. In this phase, students identify goals and devise goal-directed actions to achieve them. Goals based on motivational orientations, such as those provided by a teacher's grades, an 
audience's praise, or from experiencing personal pleasure in music practice, may impact the quality and quantity of learning (Schunk, 2012). Furthermore, goal-oriented students who are intent on mastery and are adaptive in their behaviors, "enjoy putting effort into achieving their goals" (McPherson \& Zimmerman, 2011, p. 153). They are also more focused and determined and show sustained engagement in higher levels of practice.

Teachers reported several reasons why goal setting and planning were important. Tim noted that it helps guide his students "towards healthy types of performances" (Interview 1). Ivan stated that goal setting and planning is "our number one thing" (Interview 1) for marching band because of the program requirements. He said that he puts the goal "in front of them" (Interview 2) along with his expectations, and then shares them with parents so everyone is aware of the requirements. Gertrude disclosed that she has her students make goals for themselves to help them through practice periods. She said she teaches them "how and what that looks like" (Interview 1). Evan stated that he used goal setting and planning for the same reason: to get his students to solve problems and to practice. For Richard, goal setting allegedly guides his students in a direction that takes them to higher levels of knowledge. Samuel suggested that goal setting and planning are important because "goal-setting follows a commitment to the present" (Interview 2).

Seeking social assistance. McPherson and Zimmerman's (2011) self-regulation of music learning theory states that when students are faced with overwhelming learning obstacles, they will inherently seek out more knowledgeable others to help them overcome them, which they labeled seeking social assistance. Learners may turn to their peers, their parents, or other teachers who can model skills for them. All of the 
participants valued their students' efforts in seeking social assistance as a way to fortify their learning.

All the participants viewed seeking social assistance similarly in that they believed it provided their students with other models to observe and emulate. Gertrude stated, "Students have the opportunity to take private lessons," (Interview 2) which can be a big help in their learning. Tim viewed seeking social assistance in light of good relationships between musicians; he suggested that maintaining "good relationships" (Interview 2) could help students learn from each other better. Richard viewed seeking social assistance as it relates to finding other models to observe, "It goes back to modeling... you can't play a solo until you've heard the good ones, you know?” (Interview 2). Evan viewed seeking social assistance in terms of peer teaching, "it's about teaching behaviors and team cooperation" (Interview 2). Samuel believed that seeking social assistance was important because "the student must pursue knowledge in relationships" (Interview 2). Ivan also viewed the seeking social assistance strategy as happening "mainly with their peers" (Interview 2).

\section{Summary}

Data from the cross-case analysis reveal several key points about the participant's perceptions. First, most instructional strategies that participants reportedly used fell into the forethought phase of the theory. This might be the case primarily because they want their students to think about what they must accomplish. The McPherson and Zimmerman (2001) music learning theory suggests that instructional goal-setting and planning is an important first step in learning and problem-solving using self-regulation. 
The theory states that they align with the scientific question that answers why and addresses the psychological question of motivation. The scientific questions inform knowledge and the psychological dimensions affect well-being. Instructional strategies that participants claimed to use also fell into the performance phase of the theory. These mostly addressed student home practice issues in which self-control, strategy use, and self-monitoring of learning were primary concerns. McPherson and Zimmerman's (2001) music learning theory suggests that participants are focused on the scientific question of what, the psychological question of behavior as well as the self-regulation process where performance is self-monitored and evaluated as they plan their learning activities.

Second, most participants shared that they used assessments to monitor student learning and hold them accountable for practicing. Only two participants claimed to use assessments to promote self-satisfaction. Overall, this suggests that the participants are not as concerned with their student's personal sense of accomplishment as they are with coaxing them to practice at home to meet learning objectives. McPherson and Zimmerman's (2001) music learning theory suggests that the participant's thoughts align with the scientific question of how, the psychological dimension of method, and a socialization process as the student task strategies are modeled or guided socially by the teachers. Here, the participants are not teaching the students to self-regulate their learning.

Third, participants believed that the most important strategies from the list were self-evaluation, goal-setting and planning, and social-seeking assistance. This suggests that the participants almost unanimously believed that their students must have a good 
understanding of themselves as individuals and as instrumentalists, be able to identify and work at achieving learning objectives, and make an effort to seek out help from more knowledgeable others when needed. McPherson and Zimmerman's (2001) music learning theory suggests that the participants are focused on the scientific questions of what, why, and with whom, the psychological questions of behavior, motive, social as well as the self-regulation processes of self-monitoring their own learning performances, have a developed sense of self-efficacy, and take their own initiative to personally seek out help from other sources when needed.

\section{Limitations}

This collective case study was limited to six participants who were each interviewed twice. On average, each interview lasted about ninety minutes. There were no classroom observations, nor were students interviewed. Also, there were very few related research articles that addressed prior research into instrumental music teachers' perceptions of students' self-regulation. Furthermore, future research studies might ask additional questions in the interview protocols similar to questions one, two, and three used in this research study. Changes to the interview protocols may have better prompted the participants to more accurately describe how, when, and why they teach the way they do relative to the three phases of McPherson and Zimmerman's (2011) music learning theory. One final limitation is no pilot study was conducted to refine the research questions, and the interview protocol questions. 


\section{Future Research}

Future research that relates to McPherson and Zimmerman's (2011) selfregulation of music learning theory could focus on the differences between beginning instrumentalist's and professional musician's self-regulatory processes and learning strategy use. As McPherson and Zimmerman (2011) stated, "this could lead to systematic efforts to train students to focus on their self-regulatory processes" (p. 165). Studies such as this could also help educators integrate instruction in self-regulation into their music room practice.

As McPherson and Renwick (2001) noted, most students enter school music programs with a desire to learn but may lack self-regulation strategies required to ensure success. Therefore, it is not enough to teach students "how to practice" and "ways to practice and techniques," as Gertrude noted (Interview 2). Future research could also focus on incorporating instruction that shows students how to use problem-solving processes, develop the capacities to cognitively monitor and regulate their own learning, select and implement strategies, set goals, and self-reflect on their progress. The practical benefits from research such as this could educate students at-risk of failing or who otherwise "do not pick up these skills informally" (McPherson \& Renwick, 2001, p. 184). Future research might also look at the connections between music teachers' beliefs and practices in regard to teaching self-regulated music learning behaviors. 


\section{Implications}

The instrumental music teachers in this study reported the use of different strategies to address students' self-regulation issues relating to solitary practice: selfevaluation, time management, environmental structuring, goal-setting and planning, and seeking social assistance. Nevertheless, practitioners need more support in learning how to help their students utilize the benefits of understanding the actual problem-solving process of self-regulation in instrumental music learning. This study suggests implications for music teachers and music teacher education programs.

Implications for teachers. Teachers could benefit by learning about the selfregulation music learning theory for themselves and then take the time to teach it to their students. They can, as Steffens (2006) suggested, provide instruction in self-regulation either with or without modeling in their music rooms and only need to take into account their student's age, grade level, and their learning objectives (Ramdass \& Zimmerman, 2011).

The main components of the self-regulation in music learning theory are the three-phase problem-solving process, the self-regulation learning strategies, the six psychological dimensions of self-regulation, the four developmental levels of regulatory skill, and the learning strategies. (See figure 1 on page 41 for a diagram of the McPherson \& Zimmerman model). The problem-solving process illustrates the three phases of forethought, performance, and self-reflection. The six psychological dimensions relate to the six scientific questions individuals inherently ask themselves as they undertake a problem-solving task. The four developmental levels of regulatory skill explain how students migrate from social reinforcement and feedback provided by a teacher or model 
to a student's own internal, self-regulatory processes and self-efficacy beliefs. The learning strategies, as Zimmerman (1989) suggests, are necessary for self-regulation; without the use of a strategy at some point in the process, students are not self-regulating. In classroom lectures, practitioners could teach the theory to their students by discussing and modeling examples of self-regulating behaviors. Practitioners could also observe a student while he/she practices by themselves in a practice room and then offer strategies to overcome their practice problems. The three phases problem-solving process would be the model for the discussion. Along with the model, the teacher could also introduce self-regulation strategies to use with the phases.

For example, within the forethought phase, the subprocesses of task analysis and self-motivation beliefs occur. Practitioners could provide examples of what task-analysis and self-motivating beliefs might entail when students are confronted with new learning objectives and introduce strategies to help them explore those subprocesses more fully.

During the performance phase, in which the subprocesses of self-control and selfobservation are found, they could identify and model relevant learning strategies for students to use. A discussion of a strategy that helps students metacognitively monitor their learning more thoughtfully or stay on task might be beneficial. Tim, for example, had his students self-record and listen back to their performances during practice. A practitioner could introduce a strategy to teach their students about environmental shaping to help them create a viable practice space.

Within the self-reflection phase are the subprocesses of self-judgment and selfreaction. Practitioners could identify strategies that help students attribute causes to their 
success or failure or suggest a strategy to help students more accurately evaluate their learning progress.

A discussion on the psychological dimensions of self-regulation could also be held by the teacher in the classroom. The six dimensions are: motive, method, time, behavior, physical environment, and social. These align with why, how, when, what, where, and with whom respectively. Each dimension can be viewed in terms of a socialization process or a self-regulation process. It is in a comparison of these two processes as they relate to the six dimensions that teachers can help their students learn about.

The socialization process suggests that students need opportunities to learn from more knowledgeable others. Students need support in mastering a particular psychological dimension; perhaps as they ask themselves how or when to practice. The self-regulation process suggests independence on the student's part as they are capable of answering on their own how or when to practice. As students become better at selfregulating their learning, they are able to self-set their learning goals, employ their own learning strategies, manage their time effectively, self-monitor their learning, create their own learning environments, and seek help on their own if they feel inclined.

The four developmental levels of regulatory skill, which include observational, emulative, self-controlled, and self-regulated, outline the social origins of self-regulation. Practitioners could use these four levels of regulatory skill to teach their students about their learning both in the classroom and at home as they practice. Each level describes the degree to which a student is self-regulating. The observational level shows the need for a proficient model. The emulative level shows the need for students to imitate a skill 
while relying on social feedback, the self-controlled level shows how students can display skills under structured conditions, and the self-regulated level shows how students are able to independently display their skills and maintain a sense of efficacy across changing conditions.

Implications for music teacher education programs. According to Papae, Zimmermann, and Pajares (2002), few teachers deliberately help students improve their self-regulatory processes because they don't know how. This may be due to the gap in the literature that addresses the issue of teaching teachers to teach self-regulation to their students; especially in instrumental music. Music education courses that provide instruction in self-regulation in music learning for preservice college students might improve the effectiveness of music teacher instruction across all grade levels and act as an intervention for students at-risk of dropping out of school instrumental music programs.

First, educating preservice teachers on issues that are unique to learning instrumental music, and the degree to which students at different age and ability/skill levels are able to address them, may foster more success for both teacher and the student (Kiewra, 2002). Students who are trying to learn go through specific problem-solving steps. Understanding those steps and explaining them to students could help them address their immediate issues as well as help them with their overall achievements (Huh \& Reigeluth, 2017).

Second, preservice teachers should be given opportunities to learn how to implement self-regulation into their curriculum and then have opportunities to practice teaching it to their music students. Personally, they could also use self-evaluation 
strategies and report upon them or they could keep a learning log where they list their accomplishments. They could also list what gave them a sense of frustration of selfsatisfaction and discuss their concerns with others.

\section{Conclusions}

This study was undertaken to understand instrumental music teacher perceptions regarding their student's abilities to self-regulate their musical instrument learning. None of the participants had ever heard the term "self-regulation" prior to the interviews and none had ever heard of the McPherson and Zimmerman's (2011) self-regulation music learning theory or how it functions as a problem-solving framework for musicians. Nevertheless, participants identified how they help their students overcome learning challenges in their own way and consequently addressed the problem-solving phases identified in the theory without even knowing it.

To a large extent, participants identified aspects of the forethought phase, in which they help their students with goal-setting, personal motivation, and self-efficacy. These elements, as the participants suggested, can be challenging for beginning musicians. Ivan noted that achieving goals are a part of the expectations he gives to his students on the first day of band camp.

However, participants hardly mentioned how they help their students solve learning problems that occur in the performance phase. In this phase, in which learning and skill building are accomplished, students are required to maintain self-control, engage in self-instruction, employ learning strategies, and monitor their progress while 
they practice. Gertrude stated that she suggests to her students they use can candy to track how many times they played through a musical passage.

In the self-reflection phase, participants valued self-evaluation as an important learning strategy. They explained how self-evaluations can help their students assess the degree to which they are learning and give them personal feedback that they can react to. Nevertheless, none of the participants had a formal process in place to teach students to master skills in self-evaluation.

Participants indirectly alluded to the developmental levels of self-regulatory skills identified in the music learning theory. They all stated that their students observe and emulate their classroom modeling and instruction and rely on their feedback as they learn to play their instruments. To facilitate this process, some rely on an instructional strategy in which they first provide their students with praise and then offer a critique to improve their performance. Gertrude, Samuel, and Ivan mentioned that the older their students, the more likely they were to display independent learning abilities and rely more on themselves for self-reinforcement and internal standards.

Although self-regulation has been shown to be highly predictive of academic achievement, few instrumental music teachers systematically help their students improve their self-regulatory processes (Pape, Zimmerman, \& Pajares, 2002). Instrumental music educators can teach their students to focus more on the self-regulatory processes that help them take better control of their own learning. This can be especially helpful when there is an absence of immediate instructional feedback from a teacher, like during a home practice period, and thus help students to thrive in school music programs. Implementing pedagogy based on the tenets of McPherson and Zimmerman's (2011) can be a helpful 
first step in that process. Instruction in self-regulation can act as an intervention for struggling instrumental music learners, help children and adolescents who lack selfconfidence reflect more thoughtfully on their abilities when learning a musical instrument, and help other young instrumentalists to independently identify and use more effective learning strategies. 


\section{References}

Araujo, M.V. (2016). Measuring self-regulated practice behaviors in highly skilled musicians. Psychology of Music, 44(2) 278-292. doi:

10.1177/0305735614567554. Retrieved from http://pom.sagepub.com.

Asmus, E. P., \& Harrison, C. (1990). Characteristics of motivation for music and musical aptitude of undergraduate non-music majors. Journal of Research in Music Education, 38, 258-268.

Atkinson, R.C., \& Shiffrin, R.M. (1968). Human memory: A proposed system and its control processes. Retrieved from https://pdfs.semanticscholar.org.

Austin, J.R., \& Haefner Berg, M. (2006). Exploring music practice among sixth-grade band and orchestra students. Psychology of Music, 34(4): pp. 535-558. Retrieved from http://pom.sagepub.com.

Austin J. R., \& Vispoel, V. P. (1998). How American adolescents interpret success and failure in classroom music: Relationships among attributional beliefs, selfconcepts and achievement. Psychology of Music, 26, 26-45.

Bandura, A. (1971). Social learning theory. New York, NY: General Learning Press.

Bandura, A. (1986). Social foundations of thought and action: A social cognitive theory. Englewood Cliffs, NJ: Prentice-Hall.

Bandura, A. (1989). Social cognitive theory. In R. Vasta (Ed.), Annals of child development. vol. 6. Six theories of child development (pp. 1-60). Greenwich, CT: JAI Press. 
Bandura, A. (2006). Adolescent development from an agentic perspective. In F. Pajares \& T. Urdan (Eds.), Self-efficacy beliefs of adolescents (pp. 1-45). Charlotte, NC: Information Age Publishing.

Bandura, A., Barbaranelli, C., Caprara, G., \& Pastorelli, C. (1996). Multifaceted impact of self- efficacy beliefs on academic functioning. Child Development, 67(3), 1206-1222. doi:10.2307/1131888.

Bandura, A., \& Schunk, D. H. (1981). Cultivating competence, self-efficacy, and intrinsic interest through proximal self-motivation. Journal of Personality and Social Psychology, vol. 41, pp. 586-598.

Barry, N.H. (1990) The effects of different practice techniques upon technical accuracy and musicality in student music instrumental practice. Research Perspectives in Music Education, 1(4-8). Retrieved from http://journals.sagepub.com.

Barry, N. H. (1992). The effects of practice strategies, individual differences in cognitive style, and gender upon technical accuracy and musicality of student instrumental performance. Psychology of Music, 20(2), 112-123.

https://doi.org/10.1177/0305735692202002.

Barry, N. H., \& McArthur, V. (1994). Teaching practice strategies in the music studio: A survey of applied music teachers. Psychology of Music, 22(1), 44-55. https://doi.org/10.1177/0305735694221004.

Barry, N.H., \& Hallam S. (2002). Practice. In R. Parncutt \& G.E. McPherson (Eds.), The science and psychology of music performance-creative strategies for teaching and learning. pp. 151-165). New York: Oxford University Press. 
Bartolome, S. (2009). Naturally emerging self-regulated practice behaviors among highly successful beginning recorder students. Research Studies in Music Education, 31(1), pp. 37-51. doi 10.1177/1321103X09103629.

Bembenutty, H. (2011). Meaningful and maladaptive homework practices: The role of self-efficacy and self-regulation. Journal of Advanced Academics. Vol. 22, No. 3., pp. 448-473. Retrieved from http://journals.sagepub.com.

Bergin, D. (1996). Adolescents' out-of-school learning strategies. The Journal of Experimental Education, 64(4), pp. 309-323. Retrieved from http://www.jstor.org/stable/20152496.

Betts, S. L., \& Cassidy, J. W. (2000). Development of harmonization and sight-reading skills among university class piano students. Journal of Research in Music Education, 48(2), 151-161.

Boekaerts, M., Pintrich, P., \& Zeidner, M. (1999). Handbook of Self-Regulation. Academic Press Books. doi.org/10.1016/B978-0-12-109890-2.X5027-6

Bond, A. (2003). Learning music online: An accessible learning program for isolated students. Research Report. Retrieved from https://www.ncver.edu.au/researchand-statistics/publications.

Borst, J., \& Anderson, J. (2013). Using model-based functional MRI to locate working memory updates and declarative memory retrievals in the fronto-parietal network. Proceedings of the National Academy of Sciences of the United States of America, 110(5), pp. 1628-1633. Retrieved from http://www.jstor.org/stable/4199209.

Boyle, J. D., De Carbo, N. J., \& Jordan, D. J. (1995). Middle/junior high school band directors' views regarding reasons for student dropouts in instrumental music. 
Retrieved from University of South Florida, Music Department, website: http://arts.usf.edu/music/rpme/boyledec.htm.

Brooks, R.W. (1995). Mental practice and the musician: A practical approach to practice. Update: Applications of Research in Music Education13(2): 4-8.

Cahn, D. (2008). The effects of varying ratios of physical and mental practice, and task difficulty on performance of a tonal pattern. Psychology of Music, 36(2), pp. 179191. doi: $10.1177 / 0305735607085011$.

Carver, C. S., \& Scheier, M. F. (1998). On the Self-regulation of Behavior. New York, NY: Cambridge University Press.

Cash, C., Allen, S., Simmons, A., \& Duke, R. (2014). Effects of Model Performances on Music Skill Acquisition and Overnight Memory Consolidation. Journal of Research in Music Education, 62(1), 89-99. Retrieved from http://www.jstor.org/stable/43900234.

Chaffin, R., \& Imreh, G. (1997). Pulling teeth and torture: Musical memory and problem solving. Thinking and Reasoning, 3, pp. 315+336.

Chaffin, R. \& Imreh, G. (2001). A comparison of practice and self-report as sources of information about the goals of expert practice. Psychology of Music, 29(1), pp. 39-69. doi. 10.1177/0305735601291004.

Chaffin, R., \& Imreh, G. (2002). Practicing perfection: piano performance and expert memory. Psychological Science, 13(4). doi/abs/10.1111/j.0956-7976.2002. 00462.x. 
Chaffin, R. Lisboa, T., Logan, T. \& Begosh, K. (2009). Preparing for memorized cello performance: the role of performance cues. Psychology of Music. Vol 3, (30). Doi $10.1177 / 0305735608100377$.

Chaffin, R., \& Logan, T. (2006). Practicing perfection: How concert soloists prepare for performance. Advances in cognitive psychology, 2(2-3), 113-130. Retrieved from http://researchgate.net.

Cheung, C. S.S., \& Pomerantz, E. M. (2011). Parents' involvement in children's learning in the United States and China: Implications for children's academic and emotional adjustment. Child Development, 82(3), pp. 932-950.

http://doi.org/10.1111/j.1467-8624.2011.01582.

Chong, W.H. (2007). The role of personal agency beliefs in academic self-regulation. School Psychology International, vol. 28, 1: pp. 63-76. Retrieved from http://journals.sagepub.com.

Clark, T., \& Williamon, A. (2011). Imagining the music: Methods for assessing musical imagery ability. Psychology of Music 40(4) 471-493. DOI:

10.1177/0305735611401126.

Committee of College and University Examiners. (1956). Taxonomy of Educational Objectives: Handbook I: Cognitive Domain, B.S. Bloom (Ed.). New York: David McKay Co.

Conti-Ramsden, G., Ullman, M. T., \& Lum, J. A. G. (2015). The relation between receptive grammar and procedural, declarative, and working memory in specific language impairment. Frontiers in Psychology, 6, 1090.

http://doi.org/10.3389/fpsyg.2015.01090. 
Costa-Giomi, E., Flowers, P.J., \& Sasaki, W. (2005). Piano lessons of beginning students who persist or drop out: Teacher behavior, student behavior, and lesson progress. Journal of Research in Music Education. Vol. 53, No. 3. Pp. 234-247. Retrieved from www.jstor.org.

Craik, F, \& Lockhart, R. (1972). Levels of processing: A framework for memory research. Journal of Verbal Learning and Verbal Behavior. Vol. 11., pp. 671-684. Retrieved from wixtedlab.ucsd.edu/publications/Psych\%20218.

Cremaschi, A. (2012). The effect of a practice checklist on practice strategies, practice self-regulation and achievement of collegiate music majors enrolled in a beginning class piano course. Research Studies in Music Education 34(2) 223 233 doi: $10.1177 / 1321103 X 12464743$.

Creswell, J. (2007). Qualitative inquiry \& research design: choosing among five approaches. ( $2^{\text {nd }}$ ed.). Thousand Oaks, CA: Sage Publications, Inc.

Creswell, J., \& Poth, C. (2018). Qualitative inquiry \& research design: choosing among five approaches. Thousand Oaks, CA: Sage Publications, Inc.

Crotty, M. (2015). The foundations of social research. Meaning and perspective in the research process. Thousand Oaks, CA: Sage Publications, Inc.

Dave, R.H. (1970). Psychomotor levels in developing and writing behavioral objectives. R.J. Armstrong, ed. Tucson, Arizona: Educational Innovators Press.

Davidson, J. Sloboda, J. \& Howe, M. (1995). The role of parents and teachers in the success and failure of instrumental learners. Bulletin of the Council for Research in Music Education. 127, 40-44. 
Davidson, J., Howe, M, \& Sloboda, J. (1997). Environmental factors in the development of musical performance skill over the life span. In D.J. Hargreaves \& A.C. North (Eds.), The social psychology of music (pp. 188-206). Oxford: Oxford University Press.

Davidson, J., Moore, D., Sloboda, J., \& Howe, M. (1998). Characteristics of music teachers and the progress of young instrumentalists. Journal of Research in Music Education, 46(1), 141-160. Retrieved from http://www.jstor.org/stable/3345766

Dembo, M., \& Eaton, M. (2000). Self-Regulation of Academic Learning in Middle-Level Schools. The Elementary School Journal, 100(5), pp. 473-490. Retrieved from http://www.jstor.org/stable/1002280.

Denzin, N., \& Lincoln, Y. (Eds). (2008). The Sage handbook of qualitative research. (2nd ed.). Thousand Oaks, CA: Sage Publications, Inc.

Després, J.P., Burnard, P., Dubé, F., \& Stévance, S. (2017). Expert western classical music improvisers' strategies. Journal of Research in Music Education, 65(2), 139-162. https://doi.org/10.1177/0022429417710777.

Duke, R.A., Cash, C.D., Allen, S.E. (2011). Focus of attention affects performance of motor skills in music. Journal of Research in Music Education. 59(1) pp. 44 -55. doi: $10.1177 / 0022429410396093$.

Duke, R. A., Flowers, P. J., \& Wolfe, D. E. (1997). Children who study piano with excellent teachers. Bulletin of the Council for Research in Music Education, 132, $51-84$

Duke, R.A., \& Simmons, A.L. (2006). The nature of expertise: Narrative descriptions of 19 common elements observed in the lessons of three renowned artist-teachers. 
Bulletin of the Council for Research in Music Education. No. 170. Retrieved from https://cml.music.utexas.edu/assets/pdf/DukeSimmons2006.pdf.

Duke, R.A., Simmons, A., \& Cash, C.D. (2009). It's not how much; it's how:

Characteristics of practice behavior and retention of performance skills. Journal of Research in Music Education, 56(4), pp. 310-321. Retrieved from http://www.jstor.org/stable/40204936.

Edossa, K.A., Schroeders, U., Weinert, S., \& Artelt, C. (2018). The development of emotional and behavioral self-regulation and their effects on academic achievement in childhood. International Journal of Behavioral Development, Vol. 42(2) 192-202. DOI: $10.1177 / 0165025416687412$.

Ericsson, A. (2008). Deliberate practice and acquisition of expert performance: a general overview. Academic Emergency Medicine. 2008. (11):988-94. doi: $10.1111 / \mathrm{j} .1553-2712.2008 .00227 \mathrm{x}$.

Ericsson, A., Krampe, R., \& Tesch-Romer, C. (1993). The role of deliberate practice in the acquisition of expert performance. Psychological Review, 100(3). Retrieved from http://projects.ict.usc.edu.

Ericsson, K. A., \& Smith, J. (1991 b). Prospects and limits of the empirical study of expertise: An introduction. In K. A. Ericsson \& J. Smith (Eds.), Toward a general theory of expertise: Prospects and limits (pp. 1-39). Cambridge, England: Cambridge University Press.

Ericsson, K. A., Tesch-Romer, C, \& Krampe, R. (1990). The role of practice and motivation in the acquisition of expert-level performance in real life: An empirical evaluation of a theoretical framework. In M. J. A. Howe (Ed.), 
Encouraging the development of exceptional skills and talents (pp. 109-130).

Leicester, England: The British Psychological Society.

Ericsson, K.A., \& Ward, P. (2007). Capturing the naturally occurring superior performance of experts in the laboratory: Toward a science of expert and exceptional performance. Current Directions in Psychological Science, 16(6), pp. 346 - 350 https://doi.org/10.1111/j.1467-8721.2007.00533.x.

Ersozlu, Z. N., \& Miksza, P. (2015). A Turkish adaptation of a self-regulated practice behavior scale for collegiate music students. Psychology of Music, 43(6), pp. 855869. doi:10.1177/0305735614543283.

Fay, J., \& Funk, D. (1995). Teaching with Love \& Logic: Taking Control of the Classroom. Golden, CO: Love and Logic Press.

Fine, A., Baglivio, M.T., Cauffman, E., Wolff, K.T., Piquero, A.R. (2017). Does the effect of self-regulation on adolescent recidivism vary by youths' attitudes? Criminal Justice and Behavior. Vol 45, Issue 2, pp. $214-233$. doi:10.1177/0093854817739046.

Fine, P., Goldemberg, R., Wise, K., \& Bravo, A. (2015). Performing musicians' understanding of the terms "mental practice" and "score analysis". Psychomusicology: Music, Mind, and Brain, 25(1), 69-82.

Fortney, P. (1992). The effect of modeling and silent analysis on the performance effectiveness of advanced elementary instrumentalists. Research Perspectives in Music Education. No. 3, 18-21. Retrieved from http://files.eric.ed.gov/fulltext/ED375034.pdf. 
Fortney, P. M., David Boyle, J., \& De Carbo, N. J. (1993). A Study of Middle School Band Students' Instrument Choices. Journal of Research in Music Education, 41(1), 28-39. doi.org/10.2307/3345477.

Furneaux, S., \& Land, M. (1999). The Effects of Skill on the Eye-Hand Span during Musical Sight-Reading. Proceedings: Biological Sciences, 266(1436), 2435-2440. Retrieved from http://www.jstor.org/stable/51700.

Gardner, J. (1987). Excellence: Can we be equal and excellent too? New York, NY: W.W. Norton \& Company.

Geertz, C. (1973). Thick Description: Toward an Interpretive Theory of Culture. In the Interpretation of Cultures: Selected Essays. New York: Basic Books.

Geldhof, J., Little, T.D., \& Hawley, P.H. (2012). Two measures of self-regulation for young adults and late adolescents in the academic and social domains. International Journal of Behavioral Development. Vol 36, Issue 6, pp. 476 - 488. doi.org/10.1177/0165025412462153.

Grape, C., Sandgren, M., Hansson, L., Ericson M., \& Theorell, T. (2003). Does singing promote well-being?: An empirical study of professional and amateur singers during a singing lesson. Integrative Psychology \& Behavioral Science. Vol. 38, No. 1. Pp. 65-74.

Gromko, J.E. (2009). Predictors of music sight-reading ability in high school wind players. Journal of Research in Music Education. Vol. 52, No. 1. pp. 6-15. Retrieved from http://journals.sagepub.com.

Hallam, S. (1997b). What do we know about practicing? Towards a model synthesizing the research literature. In H. Jørgensen \& A. Lehman (Eds.), Does practice make 
perfect? Current theory and research on instrumental music practice (pp. 179231). Oslo, Norway: Norges Musikkhogskole.

Hallam, S. (1998). The predictors of achievement and dropout in instrumental tuition. Psychology of Music, 26(2), 116-132. doi.org/10.1177/0305735698262002.

Hallam, S. (2002). Musical motivation: Towards a model of synthesizing the research. Music Education Research, 4(2), 225-244.

Hallam, S., Rinta, T., Varvarigou, M., Creech, A., Papageorgi, I, Gomes, T., \& Lanipekun J. (2012). The development of practicing strategies in young people. Psychology of Music. 40(5) DOI: 10.1177/0305735612443868.

Hammersley, M., \& Atkinson, P. (2007). Ethnography: Principles in practice. ( $3^{\text {rd }}$ ed.). New York, NY: Routledge, Inc.

Harnischmacher, C. (1997). Does practice make perfect? Current theory and research on instrumental music practice. H. Jørgensen \& A.C. Lehman (Eds.). Norges Musikkhogskole. Retrieved from https://www.yumpu.com.

Harrow, A. J. (1972). A taxonomy of the psychomotor domain: A guide for developing behavioral objectives. New York. David McKay Company.

Hartley, L. A. (1991b). The relationship of student attitude, enrollment, and retention in instrumental music to beginning instructional grade and grade level organization (Doctoral dissertation, Kent State University, Kent, OH). Dissertation Abstracts International.

Hartley, L. A. (1996). Influence of Starting Grade and School Organization on Enrollment and 
Retention in Beginning Instrumental Music. Journal of Research in Music Education, 44(4), 304-318. Retrieved from http://www.jstor.org/stable/3345443.

Hatfield, J.L., Halvari, H., Lemyre, P. (2017). Instrumental practice in the contemporary music academy: A three-phase cycle of self-regulated learning in music students. Musicae Scientiae Vol 21, Issue 3, pp. 316 - 337. doi.org/10.1177/1029864916658342.

Hayward, C.M., \& Gromko, J.E. (2009). Relationships among music sight-reading and technical proficiency, spatial visualization, and aural discrimination. Journal of Research in Music Education. Volume 57 Number 1 26-36. doi: 10.1177/0022429409332677.

Henry, M. (2011). The effect of pitch and rhythm difficulty on vocal sight-reading performance. Journal of Research in Music Education 59(1) 72 -84 DOI: 10.1177/0022429410397199.

Hewitt, M.P. (2001). The Effects of Modeling, Self-Evaluation, and Self-Listening on Junior High Instrumentalists' Music Performance and practice Attitude. Journal of Research in Music Education. Vol. 49 no. 4, pp. 307-322. Doi: $10.2307 / 3345614$.

Hudziak J.J., Albaugh, M.D., et al. (2014). Cortical thickness maturation and duration of music training: Health-promoting activities shape brain development. Retrieved from http://blog.uvm.edu/drettew/2014/12/02/musical-training-linked-toenhanced-brain-maturation/JAACAP. 2014; 11:1153-1161.

Huh, Y., \& Reigeluth, C.M. (2017). Online K-12 teachers' perceptions and practices of supporting self-regulated learning. Journal of Educational Computing Research 
Vol 55, Issue 8, pp. 1129 - 1153. doi.org/10.1177/0735633117699231.

Hyllegard, R., \& Bories, T.L. (2009). Deliberate practice theory: perceived relevance, effort, and inherent enjoyment of music practice: study II. Perceptual and Motor Skills. 109, 431-440. Retrieved from http://journals.sagepub.com.

Jørgensen, H., \& Lehmann, A. C. (1997). Does practice make perfect? Current theory and research on instrumental music practice. Oslo: The Norwegian State Academy of Music. Retrieved from http://scholar.google.com.

Keetch, M., \& Lee, D.T. (2007). The effect of self-regulated and experimenter-imposed practice schedules on motor learning for tasks of varying difficulty. Research Quarterly for Exercise and Sport. Vol. 78, No. 5, pp. 476-486. Retrieved from http://www.science.mcmaster.ca.

Kemp, A. E. (1996). The musical temperament: Psychology and personality of musicians. Oxford: Oxford University Press.

Kiewra, K. (2002). How Classroom Teachers Can Help Students Learn and Teach Them How to Learn. Theory Into Practice, 41(2), 71-80. Retrieved from http://www.jstor.org/stable/1477458.

Kitsantas, A., \& Zimmerman, B. (2009). College students' homework and academic achievement: The mediating role of self-regulatory beliefs. Metacognition and Learning, 4, 97-110.

Kostka, M. J. (2000). The effects of error-detection practice on keyboard sight-reading achievement of undergraduate music majors. Journal of Research in Music Education. Vol. 48, No. 2, pp. 114-122. Retrieved from http://journals.sagepub.com. 
Kostka, M. (2002). Practice Expectations and Attitudes: A Survey of College-Level Music Teachers and Students. Journal of Research in Music Education, 50(2), 145-154. Retrieved from http://www.jstor.org/stable/3345818.

Krampe, R. Th., \& Ericsson, K. A. (1995). Deliberate practice and elite musical performance. In J. Rink (Ed.), The practice of performance: Studies in musical interpretation (pp.84 \pm 102$)$. Cambridge: Cambridge University Press.

Krathwohl, D., Bloom, B.S., \& Masia, B. (1964). Taxonomy of educational objectives: Handbook II: Affective domain. New York: David McKay Co.

Kreutz, G., Ginsborg, J., Williamon, A. (2009). Health-promoting behaviors in conservatory students. Society for Education, Music and Psychology Research. vol 37(1): 47-60 Retrieved from http://pom.sagepub.com.

Kruth, E. C. (1964). Student drop-out in instrumental music in the secondary schools of Oakland, California (Doctoral dissertation, Stanford University, Stanford, CA). Dissertation Abstracts International, 25, 5633A.

Kuppuraj, S., Rap, P., \& Bishop, D. (2016). Declarative capacity does not trade-off with procedural capacity in children with specific language impairment. Autism \& Developmental Language Impairments. https://doi.org/10.1177/2396941516674416

Lehmann, A. C. (2002). Effort and enjoyment in deliberate practice: a research note. In I. M. Hanken \& S. G. Nielsen (Eds.), Research in and for higher music education. Oslo, Norway: Norwegian Academy of Music. Pp. 55-68. 
Lehmann, A. C., \& Ericsson, K. A. (1996). Performance without preparation: Structure and acquisition of expert sight-reading and accompanying performance. Psychomusicology. Vol. 15, pp- 1-29. Doi: 10.1037/h0094082.

Lehmann, A. C., \& Ericsson, K. A. (1997). Research on expert performance and deliberate practice: Implications for the education of amateur musicians and music students. Psychomusicology: A Journal of Research in Music Cognition, 16(1-2), p. 40. Retrieved from http://scholar.google.com.

Lincoln, Y.S., \& Guba, E.G. (1985). Naturalistic inquiry. Newbury Park, CA: Sage Publication, Inc.

Lowe, G., \& Belcher, S. (2012). Direct instruction and music literacy: One approach to augmenting the diminishing? Australian Journal of Music Education, (1), 3-13. Retrieved from http://webproxy.potsdam.edu:2048.

Ludovico, L., \& Mangione, G. (2014). Self-regulation competence in music education. Retrieved from http://files.eric.ed.gov/fulltext/ED557283.pdf.

Mantalvo, G.P., Mansfield, E.A., \& Miller, R.B. (2007). Liking or disliking the teacher: Student motivation, engagement, and achievement. Evaluation and Research in Education, 20(3), 144-158.

Martinez-Pons, M. (1996). Test of a model of parental inducement of academic selfregulation. The Journal of Experimental Education, 64(3), 213-227. Retrieved from http://www.jstor.org/stable/20152487.

Martinez-Pons, M. (2002). Parental influences on children's academic self-regulatory development. Theory Into Practice, 41(2), 126-131. Retrieved from http://www.jstor.org/stable/1477464. 
Macnamara, B.N., Hambrick, D.Z., \& Oswald, F.L. (2014). Deliberate practice and performance in music, games, sports, education and professions: A meta-analysis. Psychological Science. Vol. 25(8). Pp. 1608 -1618. doi: 10.1177/0956797614535810.

McCombs, B. L. (2001). Self-regulated learning and academic achievement: A phenomenological view. In B. J. Zimmerman, \& D. H. Schunk (Eds.), Selfregulated learning and academic achievement (pp. 67-123). Lawrence Erlbaum Associates.

McCormick, J., \& McPherson, G. E. (2003). The role of self-efficacy in a musical performance examination: An exploratory structural equation analysis. Psychology of Music, 31(1), 37-51.

McCormick, J. \& McPherson, G.E. (2007). Expectancy-value motivation in the context of a musical performance examination. Musicae Scientiae, Special Issue, 37-52. McPherson, G. (2005). From child to musician: Skill development during the beginning stages of learning an instrument. Psychology of Music. 33(1), pp. 5 35. doi 10.1177/0305735605048012.

McPherson, G. (2009). The role of parents in children's musical development. Psychology of Music. Vol. 37(1). Pp 91-110. Retrieved from http://journals.sagepub.com.

McPherson, G.E., \& Davidson, J.W. (2002). Musical practice: Mother and child interactions during the first year of learning an instrument. Music Education Research, 4(1), 141-156. 
McPherson G.E, \& McCormick, J. (1999). Motivational and self-regulated learning components of musical practice. Bulletin of the Council for Research in Music Education. No. 141. Retrieved from https://www.researchgate.net.

McPherson, G. E., \& McCormick, J. (2000). The contribution of motivational factors to instrumental performance in a performance examination. Research Studies in Music Education, 15, 31-39.

McPherson, G., \& McCormick, J. (2006). Self-efficacy and music performance. Psychology of Music. Vol. 34(3): pp. 325-339. Retrieved from https://www.researchgate.net.

McPherson, G., \& O’Neill, S.A. (2010). Students' motivation to study music as compared to other school subjects: A comparison of eight countries. Vol 32, Issue 2, pp. 101 - 137. doi.org/10.1177/1321103X10384202.

McPherson, G., \& Renwick, J. M. (2001). A longitudinal study of self-regulation in children's musical practice. Music Education Research, 3(2), 169-186. Retrieved from http://scholar.google.com.

McPherson, G., \& Zimmerman, B. (2002). Self-regulation of musical learning: A social cognitive perspective. In R. Colwell \& C. Richardson (Eds.), The new handbook of research on music teaching and learning (pp. 327-347). New York: Oxford University Press.

McPherson, G., \& Zimmerman, B. (2011). Self-regulation of music learning: A social cognitive perspective on developing performance skills. In R. Colwell, \& P. R. Webster (Eds.), MENC Handbook of Research on Music Learning. Volume 2. Applications. (Pp. 130-175). New York, NY: Oxford University Press, Inc. 
Meinz, E., \& Hambrick, D. (2010). Deliberate practice is necessary but not sufficient to explain individual differences in piano sight-reading skill: The role of working memory capacity. Psychological Science, 21(7), 914-919. Retrieved from http://www.jstor.org/stable/41062445.

Merriam, S. (1988). Case study research in education: A qualitative approach. San Francisco, CA: Jossey-Bass.

Merriam, S, \& Tisdell, E. (2016). Qualitative research: A guide to design and implementation ( $4^{\text {th }}$ ed.). San Francisco, CA: Jossey-Bass.

Mieder, K. \& Bugos, J.A. (2017). Enhancing self-regulated practice behavior in high school instrumentalists. International Journal of Music Education. Vol 35, Issue 4, pp. 578 - 587. https://doi.org/10.1177/0255761417689921.

Mielke, S. \& Comeau, G. (2017). Developing a literature-based glossary and taxonomy for the study of mental practice in music performance. Musicae Scientiae $1-16$. DOI: $10.1177 / 1029864917715062$.

Miksza, P. (2006). An exploratory investigation of self-regulatory and motivational variables in the music practice of junior high band students. Contributions to Music Education, 33(2), 9-26. Retrieved from http://www.jstor.org/stable/24127206.

Miksza, P. (2011). Relationships among achievement goal motivation, impulsivity, and the music practice of collegiate brass and woodwind players. Psychology of Music. Vol. 39(1), pp. 50-67. Doi 0.1177/0305735610361996. 
Miksza, P. (2011). The development of a measure of self-regulated practice behavior for beginning and intermediate instrumental music students. Journal of Research in Music Education. XX(X) 1-18. DOI: 10.1177/0022429411414717.

Miksza, P. (2012). The development of a measure of self-regulated practice behavior for beginning and intermediate instrumental music students. Journal of Research in Music Education. 59(4) 321 -338. DOI: 10.1177/0022429411414717.

Miksza, P., Prichard, S., \& Sorbo, D. (2012). An observational study of intermediate band students' self-regulated practice behaviors. Journal of Research in Music Education, 60(3), 254-266. Retrieved from http://www.jstor.org/stable/41653836.

Miksza, P. (2013). The effect of self-regulation instruction on the performance achievement, musical self-efficacy, and practicing of advanced wind players. Psychology of Music. 0(0) 1-25. doi: 10.1177/0305735613500832.

Miksza P., \& Gault. B.M. (2014). Classroom experiences of U.S. elementary school children. Journal of Research in Music Education. Vol. 62, No. 1, pp 4-17. $10.1177 / 0022429413519822$.

Miksza, P. \& Tan, L. (2015). Predicting collegiate wind players' practice efficiency, Flow, and self-regulation: A exploratory study of relationships between teachers' instruction and students' practicing. Journal of Research in Music Education. Vol. 63(2) pp. 162-179. DOI: 10.1177/0022429415583474.

Miles, M.B., \& Huberman, A.M. (1994). Qualitative Data Analysis (2 ${ }^{\text {nd }}$ ed.). Thousand Oaks, CA: Sage Publications.

Mishra, J. (2014). Improving sight-reading accuracy: a meta-analysis. Psychology of Music. Vol. 42(2) pp 131-156. DOI: 10.1177/0305735612463770. 
Missouri State High School Activities Association. (2018). Retrieved from https://www.mshsaa.org/Activities/Info/MusicActivities.aspx.

National Center for Education Statistics (2018). Arts education in public elementary and secondary schools: 1999-2000 and 2009-2010. Retrieved from https://nces.ed.gov/pubsearch/pubsinfo.asp?pubid=2012014rev.

Nicol, D.J., \& Dick, D., (2006). Formative assessment and self-regulated learning: A model and seven principles of good feedback practice. Studies in Higher Education, 31(2), pp. 199-218. doi: 10.1080/03075070600572090. Retrieved from http://www.tandfonline.com/doi/pdf.

Nielsen, S. G. (1999). Learning strategies in instrumental music practice. British Journal of Music Education, 16(3), 275-291.

Nielsen, S.G. (2011). Epistemic beliefs and self-regulated learning in music students. Psychology of Music. Vol 40, Issue 3, pp. 324 - 338. doi.10.1177/0305735610385509.

Oare, S. (2012). Decisions made in the practice room: a qualitative study of middle school students' thought processes while practicing. Update 30, 63-70. doi: $10.1177 / 8755123312437051$.

O’Neill, S. A. \& McPherson, G. E. (2002). Motivation. In R. Parncutt, \& G. E. McPherson (Eds.), The science and psychology of music performance: Creative strategies for teaching and learning (pp. 31-46). New York: Oxford University Press. 
Orange, C. (1999). Using Peer Modeling to Teach Self-Regulation. The Journal of Experimental Education, 68(1), 21-39. Retrieved from http://www.jstor.org/stable/20152613.

Ormrod, J.E. (2011). Human Learning. (6 ${ }^{\text {th }}$ ed.). Upper Saddle River, NJ: Pearson.

Pape, S., Zimmerman, B., \& Pajares, F. (2002). Becoming a self-regulated learner. Theory Into Practice, 41(2), 63-63. Retrieved from http://www.jstor.org/stable/1477456.

Palmer, C. (2005). Sequence Memory in Music Performance. Current Directions in Psychological Science, 14(5), 247-250. Retrieved from http://www.jstor.org/stable/20183037.

Papageorgi, I., Hallam, S., \& Welch, G.F. (2007). A conceptual framework for understanding musical performance anxiety. Research Studies in Music Education. Vol 28, Issue 1, pp. $83-107$. doi.org/10.1177/1321103X070280010207.

Partti, H. (2014). Cosmopolitan musicianship under construction. Digital musicians illuminating emerging values in music education." International Journal of Music Education 32 (1): 3-18. doi:10.1177/0255761411433727.

Partti, H., \& Karlsen, S. (2010). Reconceptualizing musical learning: New media, identity, and community in music education. Music Education Research 12 (4): 369-382. doi:10. 1080/14613808.2010.519381.

Penttinen, M. \& Huovinen, E. (2011). The early development of sight-reading skills in adulthood: A study of eye movements. Journal of Research in Music Education. 59 (2) 196 -220 DOI: 10.1177/0022429411405339 http://jrme.sagepub.com. 
Pike, P.D. (2017). Self-regulation of teenaged pianists during at-home practice. Psychology of Music. DOI: 10.1177/0305735617690245.

Pintrich, P., Smith, D., Garcia, T., \& Mckeachie, W. (1993). Reliability and predictive validity of the motivated strategies for learning questionnaire. Educational and Psychological Measurement. 53(3). Pp. 801-813. Retrieved doi.org/10.1177/0013164493053003024.

Pintrich, P.R. (2004). A conceptual framework for assessing motivation and selfregulated learning in college students. Educational Psychology Review, Vol. 16, No. 4. Retrieved from https://pdfs.semanticscholar.org.

Pitts, S., Davidson, A., \& McPherson, G. (2000). Developing effective practice strategies: Case studies of three young instrumentalists. Music Education Research, 2(1), 45-56. https://doi.org/10.1080/14613800050004422.

Platz, F., Kopiez, R., Lehmann, A.C., \& Wolf, A. (2014). The influence of deliberate practice on musical achievement: a meta-analysis. Frontiers in Psychology. Vol. 5, No. 646. Doi: 103389/fpsyg.2014.00646.

Pressley, M., \& McCormick, C. (1995). Cognition, Teaching, and Assessment. New York, NY: Harper Collins.

Pressley, M. \& McCormick, C. (1997). Advanced Educational Psychology for Educators, Researchers, and Policymakers. Boston, MA: Allyn \& Bacon.

Prichard, S. (2017). Music practice instruction in middle school instrumental ensembles: An exploratory analysis. Bulletin of the Council for Research in Music Education, (213), 73-86. Retrieved from http://www.jstor.org/stable/10.5406/bulcouresmusedu.213.0073 
Purves, R. 2012. "Technology and the Educator.” In The Oxford Handbook of Music Education, edited by G. E. McPherson and G. F. Welch, 457-475. Oxford: Oxford University Press.

Ramdass, D., \& Zimmerman, B.J. (2011). Developing self-regulation skills: the important role of homework. Journal of Advanced Academics. Vol 22, Issue 2, pp. 194 - 218. Doi 10.1177/1932202X1102200202.

Rohwer, D. \& Polk, J. (2006). Practice behaviors of eighth-grade instrumental musicians. Journal of Research in Music Education. Vol. 54(4), pp. 350-362. Retrieved from http://journals.sagepub.com/toc/jrma/54/4.

Rojas, J., \& Springer, D. (2014). An exploratory study of musicians' self-efficacy to maintain practice schedules. Bulletin of the Council for Research in Music Education, (199), 39-52. doi:10.5406/bulcouresmusedu.199.0039.

Rolfe, G. (2006). Validity, trustworthiness and rigor: quality and the idea of qualitative research. Methodological Issues in Nursing Research. doi.org/10.1111/j.13652648.2006.03727.

Rosemann, S., Altenmüller, E., \& Fahle, M. (2016). The art of sight-reading: Influence of practice, playing tempo, complexity and cognitive skills on the eye-hand span in pianists. Psychology of Music, 44(4), 658-673.

Rosenthal, T. L., \& Zimmerman, B. J. (1978). Social learning and cognition. New York: Academic Press.

Sandene, B. A. (1994). Fighting attrition: After successful recruiting for their music programs, how do teachers keep students excited about and involved in the programs? Educators Journal, 81(1), 32-61. https://doi.org/10.2307/3398795. 
Schmidt, C. (2005). Relations among motivation, performance achievement, and music experience variables in secondary instrumental music students. Journal of Research in Music Education. Vol. 53(2) pp 134-147. Doi:

$10.1177 / 002242940505300204$.

Schmidt, C.P., Zdzinski, S.F., \& Ballard, D.L. (2006). Motivation orientations, academic achievement, and career goals of undergraduate music education majors. Journal Research in Music Education, vol. 54, 2: pp. 138-153. Retrieved from http://journals.sagepub.com.

Schunk, D.H. (2012). Learning Theories. An Educational Perspective ( $6^{\text {th }}$ ed.). Upper Saddle River, NJ: Pearson.

Schunk, D.H., \& Meece, J.L. (2006). Self-efficacy development in adolescence. In F. Pajares \& T. Urdan (Eds.), Self-efficacy beliefs of adolescents (pp. 71-96). Greenwich, CT: Information Age Publishing.

Schunk, D.H., \& Miller, S.D. (2002) Self-efficacy and adolescents' motivation, in F. Pajares and T. Urdan (eds) Academic Motivation of Adolescents, pp.29-52. Greenwich, CT: Information Age Publishing.

Schunk, D.H., \& Pajares, F. (2001) The development of academic self-efficacy, in A. Wigfield and J.S. Eccles (eds) Development of Achievement Motivation, pp.1531. San Diego, CA: Academic Press.

Schunk, D.H. and Pajares, F. (2002) 'The Development of academic self-efficacy, in A. Wigfield and J.S. Eccles (eds) Development of Achievement Motivation, pp.1531. San Diego, CA: Academic Press. 
Schunk, D. H., Pintrich, P. R., \& Meece, J. L. (2008). Motivation in education: Theory, research, and applications. Upper Saddle River, NJ: Pearson.

Schunk, D.H., \& Zimmerman, B.J. (1994). Self-regulation of learning and performance: Issues and educational applications. Hillsdale, NJ: Lawrence Erlbaum Associates, Publishers.

Schunk, D. H., \& Zimmerman, B. J. (1997). Social origins of self-regulatory competence. Educational Psychologist, 32, 195-208.

Schunk, D.H., \& Zimmerman, B.J. (2003). Self-regulation and learning. In W.M. Reynolds \& G.E. Miller (eds.)., Handbook of psychology: Educational psychology (pp. 59-78). Hoboken, NJ: John Wiley \& Sons.

Shields, G.S., Moons, W.G., \& Slavich, G.M. (2017). Inflammation, self-regulation, and health: An immunologic model of self-regulatory failure. Perspectives on Psychological Science 2017, Vol. 12(4) 588 -612. DOI:

$10.1177 / 1745691616689091$.

Silverman, D. (2005). Interpreting qualitative data. (2nd. Ed.). Thousand Oaks, CA: Sage Publications, Inc.

Simpson, E. (1972). The Classification of Educational Objectives in the Psychomotor Domain. Washington, DC: Gryphon House.

Sloboda, J. A., Davidson, J. W., Howe, M. J., \& Moore, D. G. (1996). The role of practice in the development of performing musicians. British Journal of Psychology, (2), 287. Retrieved from http://eds.a.ebscohost.com. 
Sloboda, J., \& Howe, M. (1992). Transitions in the early musical careers of able young musicians: Choosing instruments and teachers. Journal of Research in Music Education, 40(4), 283-294. Retrieved from http://www.jstor.org/stable/3345836.

Stake, R. (1995). The art of case study research. Thousand oaks, CA: Sage Publications, Inc.

Stake, R. (2006). Multiple case study analysis. New York, NY: The Guilford Press, Inc.

Stambaugh, L.A. (2011). When repetition isn’t the best practice strategy: effects of blocked and random practice schedules. Journal of Research in Music Education. 58(4) 368 -383. DOI: 10.1177/0022429410385945.

Steffens, K. (2006). Self-Regulated Learning in Technology-Enhanced Learning Environments: Lessons of a European Peer Review. European Journal of Education, 41(3/4), 353-379. Retrieved from http://www.jstor.org/stable/4543062

Stoeger, H., \& Ziegler, A. (2008). Evaluation of a classroom based training to improve self-regulation in time management tasks during homework activities with fourth graders. Metacognition and Learning, 3, 207-230.

Steffens, K. (2006). Self-Regulated Learning in Technology-Enhanced Learning Environments: Lessons of a European Peer Review. European Journal of Education, 41(3/4), 353-379. Retrieved from http://www.jstor.org/stable/4543062.

Tan, L. (2016). A Transcultural Theory of Thinking for Instrumental Music Education: Philosophical Insights from Confucius and Dewey. Philosophy of Music Education Review, 24(2), 151-169. doi:10.2979/philmusieducrevi.24.2.03. 
U.S. Department of Education (2018). No child left behind: Elementary and secondary education act (ESEA). Retrieved from https://www2.ed.gov/nclb/landing.jhtml.

Upitis, R., P. C. Abrami, and J. Brook. 2010. “Using ePEARL for Music Teaching: A Case Study." In Proceedings of the International Association for Scientific Knowledge Conference, edited by G. Pérez-Bustamante, K. Physavat, and F. Ferreria, 36-45. Seville: IASK Press.

Uygun, M.A., \& Kilincer, O. (2017). Developing a scale for strategies used during the practice and learning of instrumental music. Educational Research and Reviews. Vol. 12(8), pp. 518-530. Doi: 10.5897/ERR2017.3176.

Vaughan, C. (1980). Identifying Course Goals: Domains and Levels of Learning. Teaching Sociology, 7(3), 265-279. Retrieved from http://www.jstor.org/stable/1317141.

Vygotsky, L. (1962). Thought and language. Cambridge, MA: MIT Press.

Waldron, J. (2013a). YouTube, Fanvids, Forums, Vlogs and Blogs: Informal music learning in a convergent on- and offline music community. International Journal of Music Education. 31 (1): 91-105. doi:10.1177/0255761411434861.

Wertz, F., Charmaz, K., McMullen, M., Josselson, R., Anderson, R., McSpadden, E. (2011). Five ways of doing qualitative analysis. New York, NY: The Guillford Press.

White, M.D., \& Marsh, E.E. (2006). Content analysis: A flexible methodology. Library Trends. 55(1). Pp. 22-45. Retrieved from dlib.org. 
Williamon, A. \& Valentine, E. (2000). Quantity and quality of musical practice as predictors of performance quality. British Journal of Psychology. 91, 353-376. doi/10.1348/000712600161871.

Wood, D., Bruner, J., \& Ross, G. (1976). The role of tutoring in problem solving. Journal of Child Psychology and Child Psychiatry, 17, 89-100.

Yin, R. K. (2003). Case study research: Design and methods ( $\left.3^{\text {rd }} \mathrm{ed}\right)$. Thousand Oaks, CA: Sage Publications, Inc.

Yin, R.K. (2014). Case study research: Design and methods $\left(5^{\text {th }}\right.$ ed.). Thousand Oaks, CA: Sage Publications, Inc.

Zhukov, K. (2016). Experimental (informal/non-informal) practice does not improve sight-reading skills. Musicae Scientiae. Vol 21, Issue 4, pp. 418 - 429. doi.org/10.1177/1029864916684193.

Zhukov, K., Viney, L., Riddle, G., Teniswood-Harvey, A., \& Fujimura, K. (2016). Improving sight-reading skills in advanced pianists: A hybrid approach. Psychology of Music, 44(2), 155-167.

Zimmerman, B. (1985). The development of intrinsic motivation: A social learning analysis. Annals of Child Development, Vol. 2, pp.117-160.

Zimmerman, B. (1986). Development of self-regulated learning: Which are the key subprocesses? Contemporary Educational Psychology, 16, pp. 301-313. Retrieved from https://www.journals.elsevier.com/contemporary-educational-psychology.

Zimmerman, B. (1989). A social cognitive view of self-regulated academic learning. Journal of Educational Psychology. Vol. 81, Issue 3. Retrieved from https://www.apa.org/pubs/journals/edu/index.aspx. 
Zimmerman, B. (1995). Self-efficacy and educational development. In. A. Bandura (ed.), Self-efficacy in changing societies (pp. 202-231). Cambridge: Cambridge University Press.

Zimmerman, B. (2002). Becoming a Self-Regulated Learner: An Overview. Theory into Practice, 41(2), 64-70. Retrieved from http://www.jstor.org/stable/1477457.

Zimmerman, B., Bandura, A., \& Martinez-Pons, M. (1992). Self-motivation for academic attainment: The role of self-efficacy beliefs and personal goal setting. American Educational Research Journal, 29(3), 663-676. Retrieved from http://www.jstor.org/stable/1163261.

Zimmerman, B., \& Bandura, A. (1994). Impact of self-regulatory influences on writing course attainment. American Educational Research Journal, 31(4), 845-862. Retrieved from http://www.jstor.org/stable/1163397.

Zimmerman, B., Bonner, S., \& Kovach, R. (1996). Developing Self-Regulated Learners: beyond Achievement to Self-Efficacy. Washington DC: American Psychological Association.

Zimmerman, B., \& Campillo, M. (2003). Motivating self-regulated problem solvers. The Psychology of Problem Solving. Pp. 233-262. 10.1017/CBO9780511615771.009.

Zimmerman, B., \& Kitsantas, A. (2005). Homework practices and academic achievement: the mediating role of self-efficacy and perceived responsibility beliefs. Contemporary Educational Psychology, 30(4), pp. 397-417. https://doi.org/10.1016/j.cedpsych.2005.05.003. 
Zimmerman, B., \& Martinez-Pons, M. (1986). Development of a structured interview for assessing student use of self-regulated learning strategies. American Educational Research Journal, 23(4), pp. 614 - 628. doi.org/10.3102/00028312023004614.

Zimmerman, B., \& Risemberg, R. (1997). Becoming a self-regulating writer: A social cognitive perspective. Contemporary Educational Psychology. 22(1), pp. 73-101.

Zimmerman, B., \& Schunk, D. (1989). Self-regulated learning and academic achievement: Theory research and practice. New York, NY: Springer-Verlag.

Zimmerman, B. (2000) Attaining self-regulation: A social cognitive perspective, in M. Boekaerts, P. Pintrich, and M. Zeidner (eds.) Handbook of Self-regulation, pp.1339. San Diego, CA: Academic Press.

Zimmerman, B., \& Schunk, D. (2001). Self-Regulated Learning and Academic Achievement: Theoretical Perspectives. Mahwah, NJ: Lawrence Erlbaum Associates, Inc. 


\section{Appendix A}

\section{McPherson and Zimmerman (2011) Music Learning Theoretical Framework}

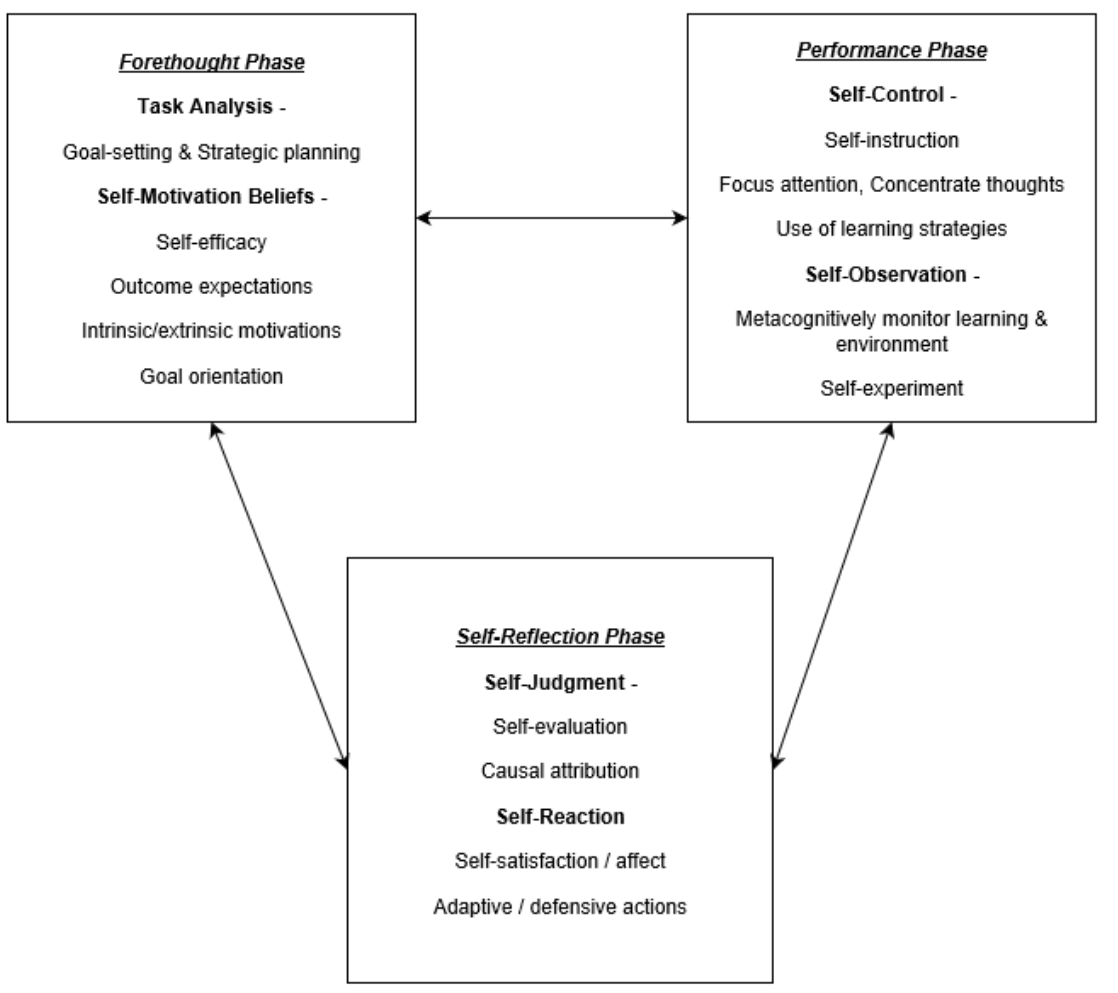




\section{Appendix B}

Learning Strategies Used by Self-Regulating Students (Zimmerman, 1989)

\section{STRATEGY}

Self-evaluation

Organize and transform

Goal-setting and planning

Seek information

Keep records \& monitor learning

Environmental structuring

Self-consequence

Rehearse and memorize

Seek social assistance

Review records

\section{DEFINITION}

Student initiated evaluations of the quality or progress of their work

Overt or covert rearrangement of instructional materials to improve learning

Student sets goals and sub-goals, sequencing tasks, timing

Student initiated efforts to increase task information from non-human sources when engaged in learning assignments

Student initiated efforts to record events and monitor results (notebook)

Student initiated efforts to select and arrange a physical setting to optimize learning

Student initiated arrangements of rewards or punishments for success or failure

Student initiated efforts to memorize material through overt or covert practice

Student initiated efforts to solicit help from peers, teachers, or MKO

Student initiated efforts to read their notes in an effort to learn and be prepared 
Appendix C

\section{$\underline{\text { Participant Consent Form }}$}

Researcher:

Philip Horsley, A.B.D.

University of Missouri

College of Education

211 Townsend Hall

Columbia, MO 65211

(315) 842-0503

pthfn7@mail.missouri.edu

Research topic:

Music teacher perceptions on the importance of teaching self-regulation to their students.

\section{YOU ARE BEING ASKED TO PARTICIPATE IN A RESEARCH STUDY}

Dear Participant,

This form provides you with information about the research study. The person in charge of this research will describe this study and answer all of your questions.

Furthermore, you will receive a copy of this consent before participating in this study.

When you are invited to participate in research, you have the right to be informed about the study procedures so that you can decide whether you want to give your consent to participate. This form may contain words that you do not know. Please ask the researcher to explain any words or information that you do not understand.

You have the right to know what you will be asked to do so that you can decide whether or not to be in the study. Your participation is voluntary. You do not have to be in the study if you do not want to be. You may refuse to be in the study and nothing will happen. If you do not want to continue to be in the study, you may stop at any time without penalty or loss of benefits to which you are otherwise entitled. If you choose to 
stop participation in this study, simply inform the researcher of your desire to stop the study.

The purpose of this study is to understand music teachers' perceptions of the importance of teaching self-regulation strategies to their students. If you agree to be in this study, I will ask you to do the following things:

- Participate in two interviews: each lasting 45 minutes to one hour.

- Spend a total estimated time of two hours as a participant in this study.

Risks and benefits of being in this study:

- Your participation in this study is not expected to cause any risks greater than those encountered in everyday life.

- Participants have an opportunity to reflect upon their views of teaching, prior school experiences, and the roles and purposes of music education.

Compensation:

- There is no compensation for participating in this study.

Confidentiality and Privacy Protection:

- The data resulting from your participation may be made available to other researchers in the future for research purposes not detailed within this consent form. In these cases, the data will contain no identifying information that could associate you with it, or with your participation in the study.

- No identifiable information will be collected during the interview.

- A pseudonym will be used in place of your real name.

- All interviews will be digitally recorded for transcription.

- The digital recordings will be stored in a password-protected computer folder for digital files. 
- All digital recordings will be destroyed after interview recordings have been transcribed.

The records of this study will be stored in a password-protected computer folder for digital files. However, authorized persons from the University of Missouri and members of the Institutional Review Board have the legal right to review such research records and will protect the confidentiality of those records to the extent permitted by law. All publications and presentations will use pseudonyms to protect identities. Throughout the study, this researcher will notify you of new information that may become available and might affect your decision to remain in this study.

The campus Institutional Review Board approved this study. You may contact the Institutional Review board if you have questions about your rights, concerns, complaints, or comments as a research participant.

You can contact the campus Institutional Review Board directly by telephone or e-mail to voice or solicit any concerns, questions, input or complaints about the research study.

Campus Institutional Review Board

483 McReynolds Hall

Columbia, MO 65211

(573) 882-9585

Signatures:

I have read this consent form and my questions have been answered. My signature below means that I want to be in this study. I know that I can remove myself from this study at any time without any problems. 


\section{Appendix D}

\section{$\underline{\text { Interview Protocols }}$}

\section{Interview One Protocol}

Teacher background questions

- What lead you to become an instrumental music teacher?

- What instruments do you play?

- Where did you get your music education certificate/training from?

- How long have you been teaching?

- Have you taught at different grade levels and schools?

Current Teaching Assignment:

- How long have you taught here and what do you teach here (or other responsibilities)?

- What grade levels do you currently teach now?

- How would you describe the demographics of the students you are teaching now?

Views on teaching students to play instrumental music

- In your opinion, how do students learn to play a musical instrument? (RQ3)

- In your opinion, what challenges do students face when learning to play an instrument? (RQ1-3)

- What other factors influence student success in learning to play an instrument? (RQ3)

- Can you tell me a story of when you had a student struggle with learning to play an instrument? How did you help that student? (RQ1)

- What challenges did that student face? (possible probing questions)

- What strategies did you teach that student? (possible probing questions)

$\circ$ What were the outcomes? (possible probing questions)

Instructional strategies for teaching students to become self-regulating learners

- Can you tell me a story about when you discovered an instructional strategy that helped a student, or group of students, learn to become self-regulating learners? (RQ1)

O What happened?

- What was the context?

- For whom did the strategy work for?

- Are there other strategies you also discovered to be effective with students? If so, can you share what those are and how you discovered them? (RQ1)

- Here is a list of various learning strategies that some teachers teach their students. You might have discussed some of these already. Please review the list and mark ones that you use most often (RQ3) [see interview handout \#1 below]. 
○ Please tell me about how you use these strategies when teaching students to play their instruments.

o Which strategy do you think is most important? Why?

- Which one is least important and why?

- Is there anything else you would like to tell me about your views on students' musical instrument learning or your instructional strategies? (RQ1-3)

\section{Interview Two Protocol}

Supporting Independent Learning

- Tell me about how you teach your students to become independent learners on their instruments? (RQ1)

- What does that look like for you?

$\circ$ What do students do that shows you they are becoming independent learners?

- Can you tell me a success story of when you got a student to be independent in her/his instrument playing? (RQ 1-2)

- Tell me about how you support students who struggle with

○ Motivation?

- Work ethic?

$\circ$ Working with peers in band?

$\circ \quad$ working alone in practice?

Supporting Home Practice

- How do you support students in being independent learners at home? (RQ1)

- What is your experience with students practicing their instruments at home? (RQ2)

- In your opinion, what factors contribute to students practicing or not practicing at home?

(RQ2)

- Can you tell me about how you motivate your students to practice at home? (RQ2)

- Describe how you teach your students to practice at home (RQ1)

$\circ$ What reasons do you give them for practicing? (RQ1)

$\circ$ What strategies do you advise them to use? (RQ1)

○ When should they correct their mistakes? (RQ1)

○ How long and how often do you tell them to practice? (RQ1)

- Where do you tell them to practice? (RQ1)

○ How do you teach students to reflect or evaluate on their own practice? (RQ1) 
- How do you assess to what degree your student is an independent learner at home? (RQ2)

- Is there anything else you would like to tell me about how you support independent learning and home practice? (RQ1-3) 


\section{VITA}

Hailing from Massena, New York, Philip Horsley has a two-year certificate from Berklee College of Music, a Bachelor of Science degree from the State University of New York, a Master of Arts in Teaching degree from Missouri State University, and a Graduate Certificate from the University of Missouri. Mr. Horsley is licensed to teach K12 instrumental music in New York and Missouri and has worked with students of all ages in those states.

Professionally, Mr. Horsley would like to continue to teach at both the university level and occasionally at the primary and secondary grade levels. He would also like to continue investigating and reporting on research interests that include self-regulation and the role of self-efficacy in music learning. For as Theodore Roosevelt said, "believe you can and you're half way there." 